\title{
GUÍA DE CAMPOS Y PARÁMETROS OPERATIVOS DE INTERÉS EN EL DIAGNÓSTICO CONVECTIVO
}

\author{
Nota técnica 17 de AEMET
}

Carlos Perea Hitos

Carlos Jiménez Alonso

Jesús Riesco Martín 


\section{datos \\ abiertos}

Aviso Legal: los contenidos de esta publicación podrán ser reutilizados, citando la fuente y la fecha, en su caso, de la última actualización.

\section{Edita:}

(C) Ministerio de Agricultura, Alimentación y Medio Ambiente Agencia Estatal de Meteorología Madrid, 2015

Catálogo de Publicaciones de la Administración General del Estado: https://cpage.mpr.gob.es

NIPO: $281-15-023-0$

https://doi.org/10.31978/281-15-023-0

Agencia Estatal de Meteorología (AEMET)

C/ Leonardo Prieto Castro, 8

28040 Madrid

http://www.aemet.es/

\section{@Aemet_Esp}

https://www.facebook.com/AgenciaEstataldeMeteorologia 


\section{ÍNDICE}

1.- Introducción

2.- Campos y parámetros: definición, uso e inconvenientes

2.1.- Convección

2.2.- Forzamiento dinámico

2.3.- Campos termodinámicos

2.4.- Cizalladura y organización

2.5.- Granizo y rayos

2.6.- Supercélulas y tornados

2.7.- Vientos convectivos no tornádicos

2.8.- Precipitaciones intensas

3.- Casos de estudio

4.- Referencias principales 


\section{1.- Introducción}

Se ha desarrollado una aplicación interna en AEMET que trata de recopilar un conjunto de campos y parámetros que han demostrado su utilidad real o potencial, en el pronóstico de la convección y de fenómenos adversos asociados.

Todos estos campos y parámetros están disponibles en la intranet http://kumori.aemet.es/bucles conveccion

Las salidas se obtienen a partir de las dos pasadas de los modelos deterministas del ECMWF (ECMS/ECMC: 00 y 12 UTC) y HIRLAM (ONR3/CNN1: 00 y 12 UTC) en las áreas geográficas de Península Ibérica-Islas Baleares, e Islas Canarias. El alcance de la predicción es hasta $\mathrm{H}+72$ para el ECMWF y hasta $\mathrm{H}+48$ para el HIRLAM (sólo hasta $\mathrm{H}+36$ para Canarias).

Los productos generados se han agrupado en ocho grupos principales en función de su propia naturaleza o a partir de los fenómenos generados en superficie.

El aspecto de la aplicación web se presenta en la figura 1.1. En la parte superior aparecen los alcances de predicción y a la izquierda los ocho grupos principales con los distintos campos y parámetros, así como acceso a otros productos relacionados con fenomenología adversa en general (PEFMA: "Predicción de Entornos Favorables para Meteorología Adversa"), en la que los campos generados se refieren a la cuantificación empírica de la predisposición del entorno atmosférico para que se puedan producir distintas adversidades meteorológicas (en una gran parte relacionadas con la convección). El resto del área se reserva para la visualización de campos, y puede estar dividida en uno o varios paneles.

El nombre de los campos/parámetros está codificado en tres colores en virtud de su posible uso operativo:

- verde

el índice es totalmente operativo

- magenta

el índice es experimental y debe usarse con precaución

- azu

el índice forma parte de PEFMA

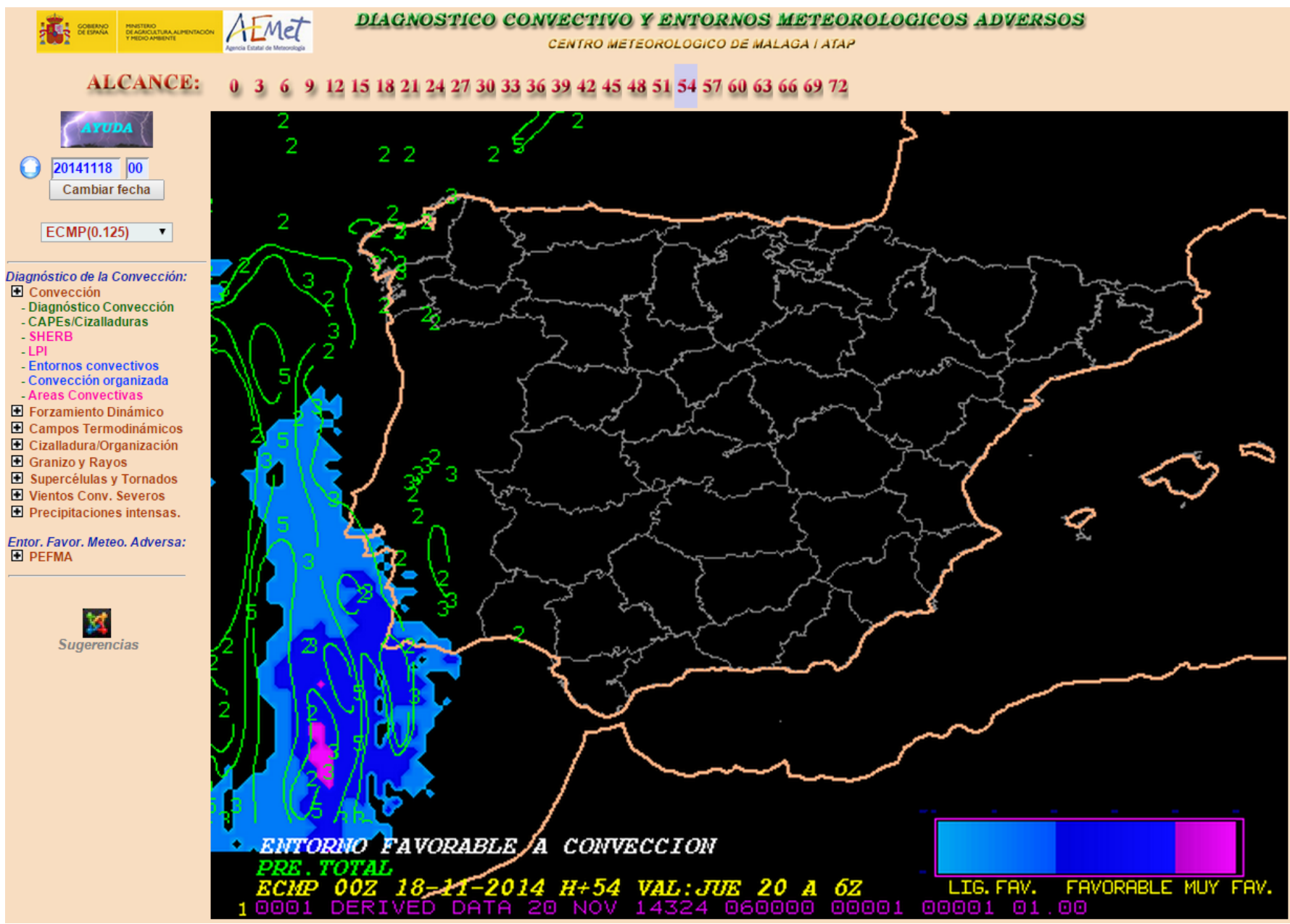

Figura 1.1. Vista general de la apariencia de la aplicación web. 
Esta aplicación de diagnóstico convectivo "avanzado" viene a complementar la herramienta de diagnóstico convectivo del ATAP que se realizó hace ya bastante tiempo y sigue estando disponible en la intranet de AEMET: http://www0.inm.es/wwj/pgatap/conveccion.html polivalencia.

Hay que hacer constar que el mismo parámetro o índice puede formar parte de varios grupos debido a su

Los grupos que se han definido finalmente son los siguientes:

- Convección (general).

- Forzamiento dinámico.

- Campos e índices termodinámicos.

- Cizalladura / Organización.

- Granizo y Rayos.

- Supercélulas y Tornados.

- Vientos convectivos no tornádicos.

- Precipitaciones Intensas.

\section{Convección}

Se incluyen en este apartado, tres tipos de productos: campos básicos combinados para el diagnóstico convectivo general, índices y parámetros experimentales (LPI, SHERB), y otros que tratan de delimitar áreas que presentan entornos favorables a que pueda desarrollarse convección y el tipo de organización potencialmente esperada.

- Diagnóstico Convección (Diagnos. Conv. I, II, y III: 3 productos presentados en paneles combinados).

- CAPEs / Cizalladuras (producto resumen combinado).

- SHERB.

- LPI.

- Entornos Convectivos (PEFMA).

- Entornos de Convección Organizada (PEFMA).

- Áreas Convectivas.

\section{Forzamiento Dinámico}

Se presentan campos sinópticos básicos y relacionados con la teoría cuasigeostrófica.

- Geopotencial, temperatura y viento en $500 \mathrm{hPa}$.

- Geopotencial y viento en $300 \mathrm{hPa}$.

- Viento y convergencia del viento en superficie.

- Velocidad vertical (W) y geopotencial en $925,850,700$ y $500 \mathrm{hPa}$.

- Parámetro frontal térmico y geopotencial en $925,850,700$ y $500 \mathrm{hPa}$.

\section{Campos e Índices Termodinámicos}

Aquí se recogen índices y parámetros relacionados con la estructura térmica vertical de la atmósfera.

- Lifted Index calculado en 700 (LI7) y 500 (LI5) hPa, índice TT e índice K.

- Lifted Index en 700 (LI7) y 500 (LI5) con evolución desde condiciones medias de capa mezclada de los 100 primeros mb y con evolución desde las condiciones de superficie (SBLI500 y SBLI700).

- CAPE / MUCAPE / SBCAPE / CAPE3 [J/Kg].

- CAPE / CIN / SBCAPE / SBCIN.

- Z/T500.

- $\quad$ Z/T 850.

- Humedad relativa y geopotencial en $925,850,700$ y $500 \mathrm{hPa}$.

- Índice de estabilidad estática húmeda (ESTW) calculada en 925,850 y $700 \mathrm{hPa}$ y gradiente vertical de temperatura calculado en el estrato $700-500 \mathrm{hPa}$.

- Temperatura potencial equivalente y su advección en distintos niveles $(925,850,700$ y $500 \mathrm{hPa})$.

- NCA / NCC / NCL / NE [m].

- NE en unidades de temperatura $\left[{ }^{\circ} \mathrm{C}\right]$.

- NCL - NCA / NCA [m].

- NCC $[\mathrm{m}]$ y temperatura de disparo $\left[{ }^{\circ} \mathrm{C}\right]$.

- Flotabilidad en la columna. 
Se muestran en este apartado, índices y parámetros relacionados con la cizalladura vertical del viento.

- Cizalladura vertical del viento a 1, 3 y $6 \mathrm{~km}$ (CIZ1 / CIZ3 / ClZ6).

- Viento y geopotencial en SFC, 925, 850 y $700 \mathrm{hPa}$.

- Helicidad relativa a la tormenta clásica calculada en los estratos inferiores de 1 y $3 \mathrm{~km}$ (SRH1 y SRH3).

- Helicidad relativa a la tormenta de las células divididas calculada por el método de Bunkers a 1 y $3 \mathrm{Km}$. (SRH1 y SRH3 para las células convectivas que se mueven a derecha e izquierda del viento medio).

- Helicidad relativa a la tormenta de las células divididas calculada por el método de Bunkers en la capa efectiva junto con la base y el espesor de la capa efectiva en $m$.

- Índice de helicidad-energía (EHI) / Bulk Richardson Number (BRN).

\section{Granizo y Rayos}

Se destacan al respecto, campos y parámetros influyentes en la generación de granizo y rayos.

- CAPE / CIN / SBCAPE / SBCIN.

- ISOW (Isocero del termómetro húmedo).

- LPI (Lightning Potential Index).

- Entornos favorables a granizo grande (PEFMA).

\section{Supercélulas y Tornados}

En este epígrafe se citan y comentan, con todas las posibles limitaciones, algunos campos, índices y parámetros importantes de cara a la identificación de los entornos favorables a la aparición de supercélulas y tornados.

- CAPE / CIN / SBCAPE / SBCIN.

- Humedad relativa y geopotencial en $925,850,700$ y $500 \mathrm{hPa}$.

- Cizalladura en varios niveles: CIZ1 / CIZ3 / ClZ6.

- Viento y geopotencial en SFC, 925, 850 y $700 \mathrm{hPa}$.

- SRH1 / SRH3 respecto del viento medio (método clásico).

- SRH1 / SRH3 derecha / izquierda (método de Bunkers).

- Helicidad relativa a la tormenta de las células divididas calculada por el método de Bunkers en la capa efectiva junto con la base y el espesor de la capa efectiva en $\mathrm{m}$.

- Universal Tornado Index (UTI).

- Significant Tornado Parameter (STP).

- Supercell Composite Parameter (SCP).

- Entornos favorables a Tornados (PEFMA).

- Entornos favorables Supercélulas (PEFMA).

\section{Vientos Convectivos Severos no Tornádicos}

Aquí se caracterizan someramente los campos e índices relevantes en la predicción de entornos típicos de vientos convectivos severos no tornádicos.

- CAPE / CIN / SBCAPE / SBCIN.

- Humedad relativa y geopotencial en $925,850,700$ y $500 \mathrm{hPa}$.

- Viento y geopotencial en SFC, 925, 850 y $700 \mathrm{hPa}$.

- WINDEX.

- DCAPE.

- GUSTEX.

- Entornos favorables a vientos convectivos severos no tornádicos (PEFMA).

\section{Precipitaciones Intensas}

Por último se han recopilado algunos de los campos que influyen decisivamente a la hora de diagnosticar ingredientes favorables a la aparición de precipitaciones intensas.

- Convergencia de humedad y geopotencial en $850 \mathrm{hPa}$.

- Agua precipitable total y en varias capas.

- Viento y flujo de humedad (q*v) en $925,850,700$ y $500 \mathrm{hPa}$.

- Humedad relativa en $925,850,700$ y $500 \mathrm{hPa}$.

- Entornos favorables a precipitaciones intensas en 1 hora (PEFMA).

- Entornos favorables a precipitaciones intensas en 12 horas (PEFMA). 


\section{2.- Campos y parámetros: definición, uso e inconvenientes}

En este epígrafe se va a justificar brevemente el uso de los campos e índices novedosos o complejos propuestos para cada grupo. Para cada uno de ellos se dará una definición y unos criterios de uso y, en su caso, inconvenientes.

\section{SHERB}

\section{Definición:}

Es un parámetro que puede ser útil para la identificación de zonas favorables para el desarrollo de convección severa de pequeño CAPE y elevada cizalladura vertical del viento.

$$
\text { SHERB }=\left(\mathrm{ClZ}_{3} / 26\right) \cdot\left(\mathrm{GTV}_{0-3} / 5,2\right) \cdot\left(\mathrm{GTV}_{700-500} / 5,6\right)
$$

donde:

$\mathrm{ClZ}_{3}$ : cizalladura en los tres primeros kilómetros $(\mathrm{m} / \mathrm{s})$.

$\mathrm{GTV}_{0-3}$ : gradiente térmico vertical en los tres primeros $\mathrm{km}(\mathrm{K} / \mathrm{km})$.

GTV700-500: gradiente térmico vertical entre 500 y $700 \mathrm{mb} \quad(\mathrm{K} / \mathrm{km})$.

Uso: Desde hace tiempo se viene observando la existencia de fenomenología severa asociada a situaciones de convección de elevada cizalladura y bajo CAPE. Son las situaciones HSLC (High Shear Low CAPE). Este tipo de episodios son responsables de una parte importante de tornados, especialmente en la época fría. Los valores iguales o superiores a 1 son significativos (pudiendo provocar potencialmente convección severa de gran cizalladura y bajo CAPE). Se presenta un ejemplo en la figura 2.1.

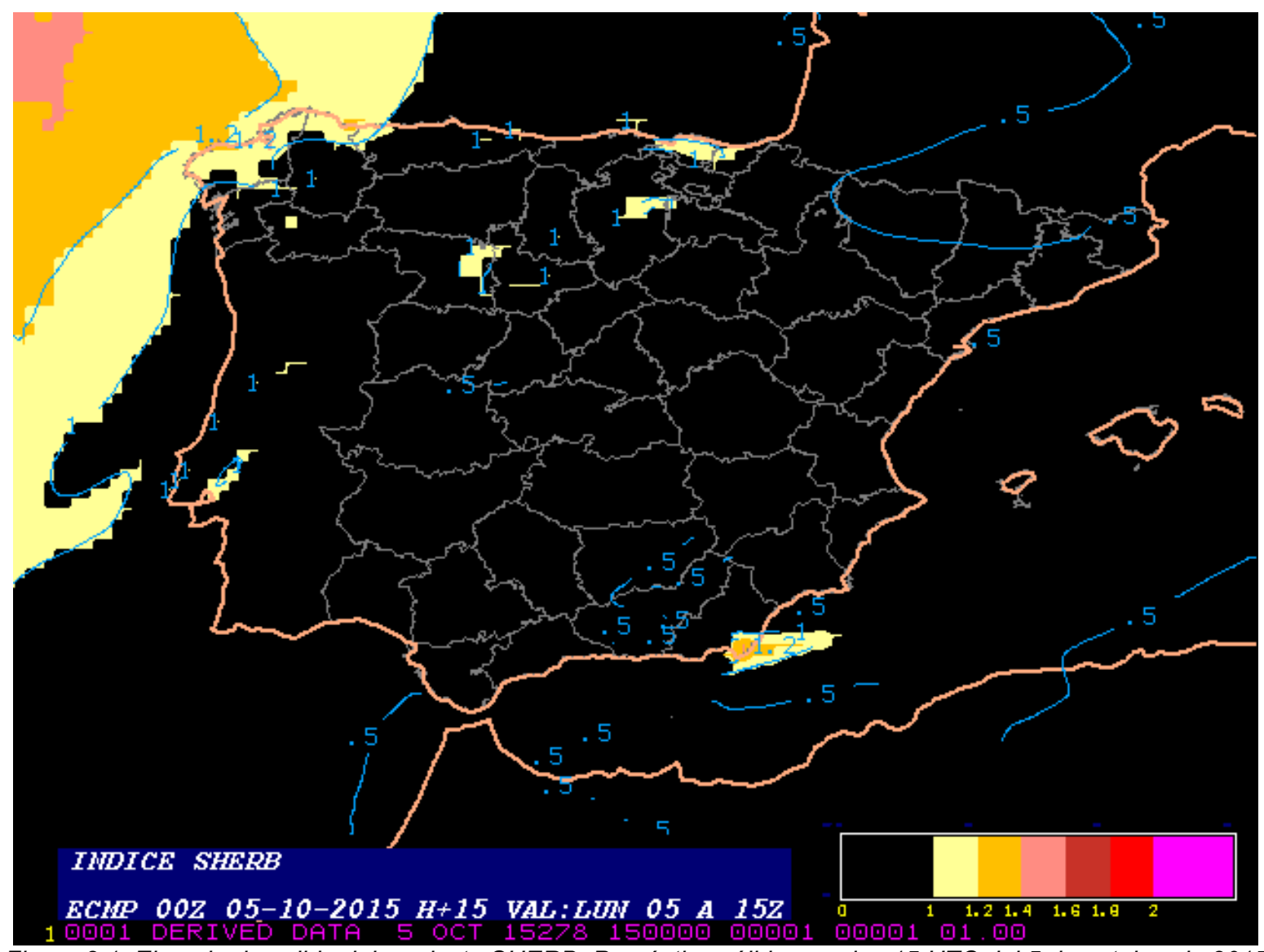

Figura 2.1. Ejemplo de salida del producto SHERB. Pronóstico válido para las 15 UTC del 5 de octubre de 2015 
Justificación básica: La convección debe ser entendida en el sentido de intensas corrientes ascendentes, y no como sinónimo de tormenta eléctrica, cuya generación depende además de otros ingredientes, meso y microescalares. De hecho, por ejemplo pueden existir bastantes casos con troposfera inestable pero "fría" (tropopausa baja) en la que habrá corrientes verticales intensas sin gran desarrollo vertical y por tanto sin rayos. En definitiva este apartado trata de establecer las zonas donde hay entornos favorables a cualquier tipo de manifestación convectiva (somera o profunda; organizada o no organizada, etc.), tal y como se presenta en la figura 2.2. La regla empleada tiene en cuenta los índices Lifted Index (LI: hasta 500, y LI7 hasta $700 \mathrm{hPa}$ ) a partir de una capa mezclada de $100 \mathrm{hPa}$ junto a superficie, así como la existencia de valores de CIN iguales o inferiores a $200 \mathrm{~J} / \mathrm{kg}$ y Precipitación Convectiva prevista por el modelo en las próximas 3 horas, igual o superior a $1 \mathrm{~mm}$.

\section{Regla Entornos convectivos:}

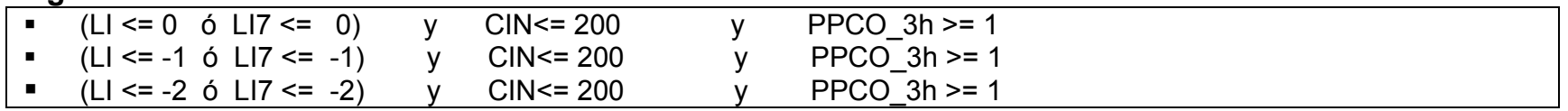

Inconvenientes: Puede haber ocasiones que exista convección que finalmente ha sido disparada por diversos mecanismos locales, tales como convergencias mesoescalares, zonas orográficas, fronteras en capas bajas, etc., que no sean bien reproducidas por el modelo, y erróneamente no sean consideradas en algunos casos como áreas convectivas. Por el contrario, en ocasiones puede aparecer como convectiva alguna zona muy reducida y aislada, sin trazabilidad espacio-temporal, que no esté claramente ligada a existencia de movimientos convectivos. Por último, como se ha comentado, la convección somera, aunque pueda ser intensa, no va en muchos casos ligada a actividad eléctrica.

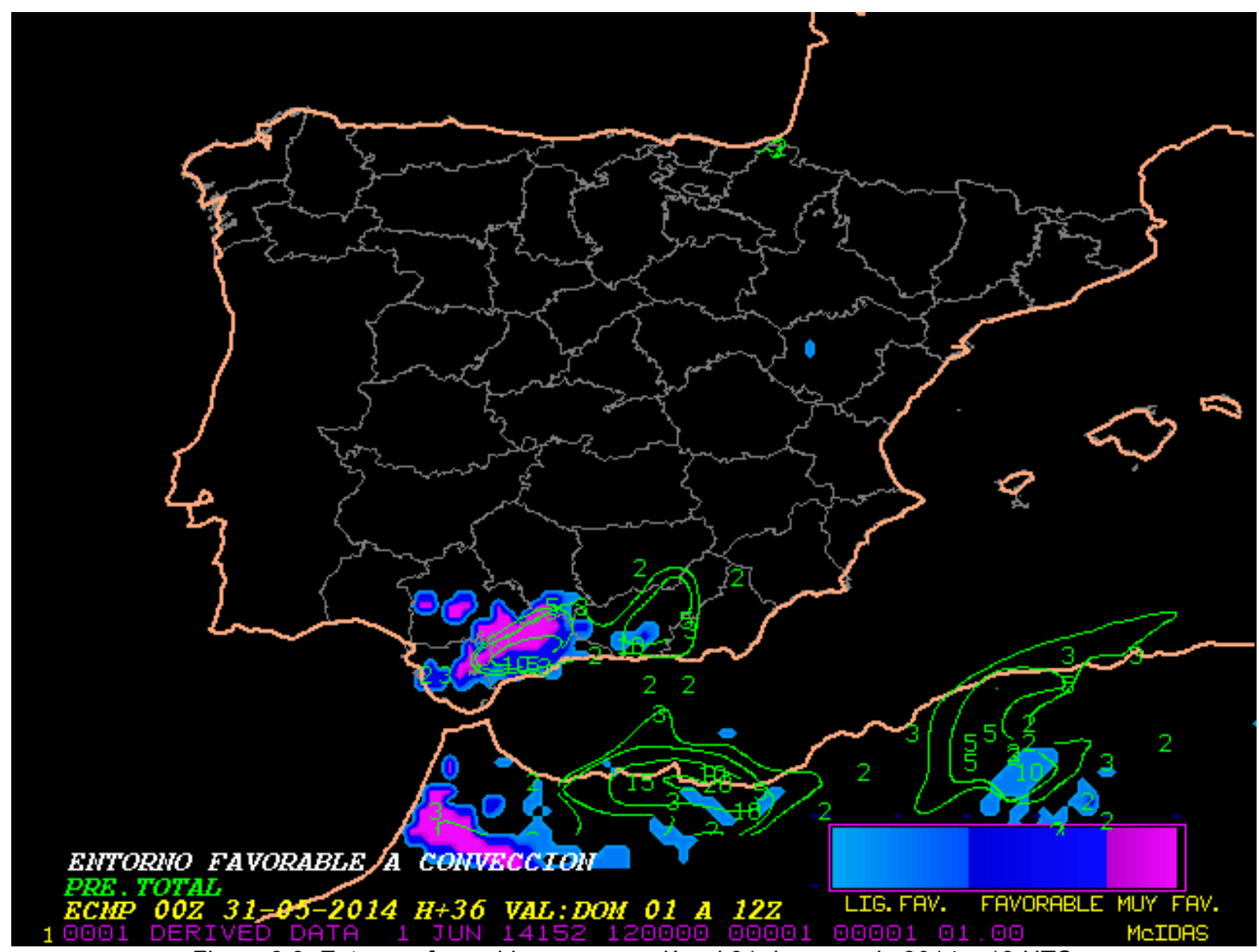

Figura 2.2. Entornos favorables a convección el 31 de mayo de 2014 a 12 UTC. 


\section{Convección Organizada}

Justificación básica: Se trata de discriminar zonas favorables a entornos convectivos organizados (figura 2.3). Así se distinguen tres tipos de entornos convectivos: entorno favorable para convección de cualquier tipo (organizada o no organizada, $\boldsymbol{C}$ ), entorno favorable para convección organizada de elevada cizalladura y bajo CAPE (High Shear Low CAPE, $\boldsymbol{H S L C}$ ) y entorno favorable para convección organizada de elevada cizalladura y elevado CAPE (High Shear High CAPE, $\boldsymbol{H S H C}$ ). Se entiende que los entornos de convección organizada son favorables para la aparición de algún tipo de fenómeno severo en superficie. Para la discriminación del tipo de convención se utilizan fundamentalmente los índices SBCAPE (Surface Based CAPE, que proporciona el CAPE en una evolución que parte exactamente desde superficie), y CIZ6 (cizalladura vertical del viento en la capa de los 6 primeros kilómetros junto a superficie). El umbral de elevada cizalladura se ha establecido en $10 \mathrm{~s}^{-1}$, y el de elevado CAPE en un valor de SBCAPE de $500 \mathrm{~J} / \mathrm{Kg}$.

\section{Regla Convección Organizada}

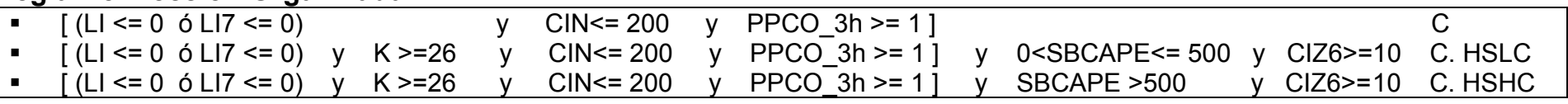

Inconvenientes: La clasificación en estas tres categorías es dificultosa en muchos casos, ya que los umbrales no deben ser excesivamente rígidos, y la organización y el alto valor de CAPE requiere la utilización de umbrales convenidos con cierta carga de subjetividad.

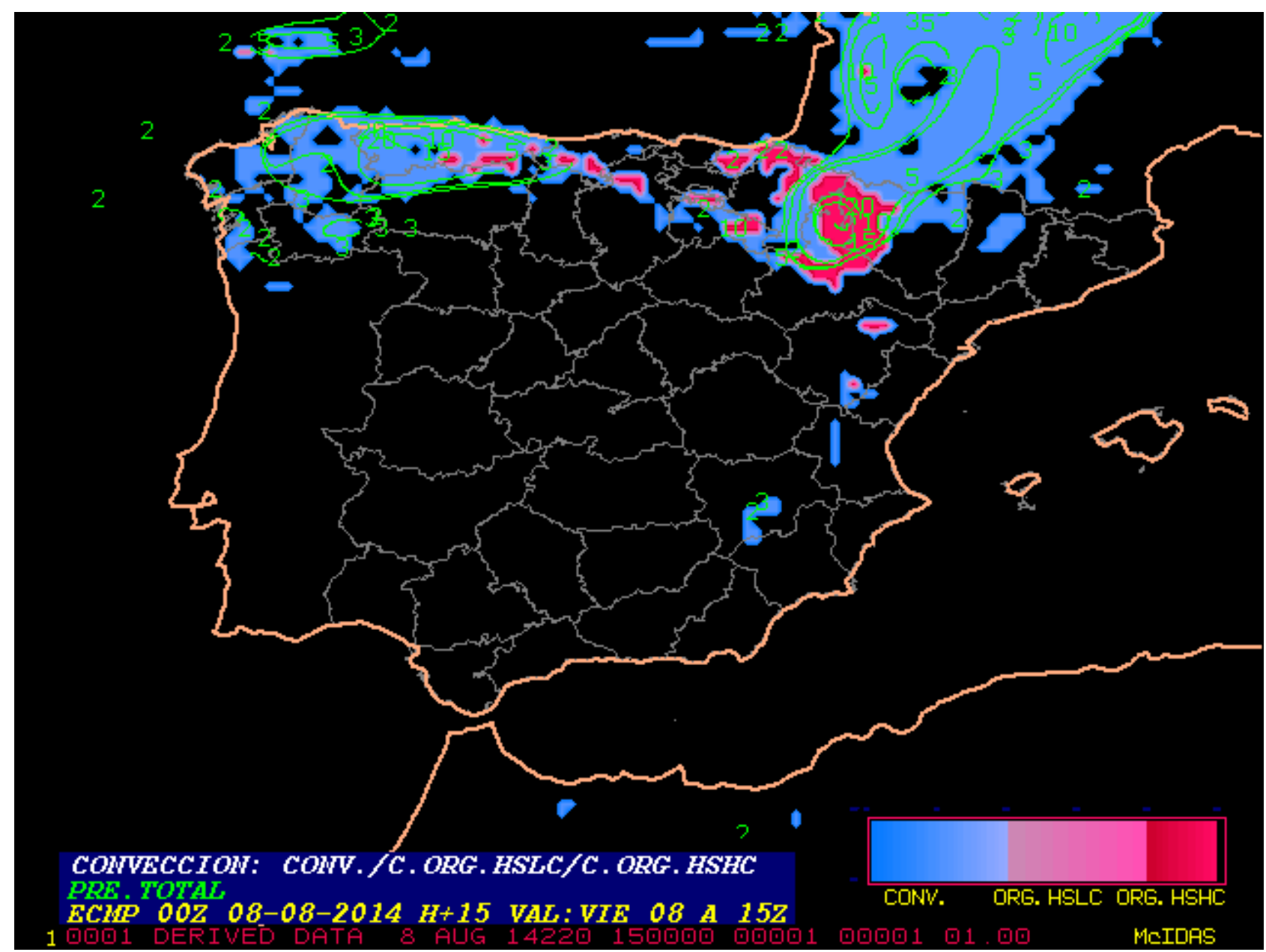

Figura 2.3. Entornos favorables a convección organizada el 8 de agosto 2014 a 15 UTC. En tono rosa se destacan las zonas favorables a convección organizada de bajo CAPE y en rojo las favorables a convección organizada de alto CAPE. 


\section{Área Convectiva}

Definición: Se trata de un índice experimental. Si la convección se inicia, este campo muestra el tipo de convección que puede llegar a desarrollarse. No es un campo de pronóstico de la convección sino del tipo de convección si ésta llega a formarse. Los criterios usados son los que aparecen en las tablas inferiores.

\section{Regla Área Convectiva}

- (LI5 ó LI7) <= 0

- (CAPE $>=0$ ó SBCAPE $>=300)$

- $\mathrm{CIN}<=200$

\section{Regla Área Organizada}

- $\quad \mathrm{ClZ6}>=9 \mathrm{~m} / \mathrm{s}$

- $\mathrm{SBCAPE}>=600$

- $\mathrm{RH}<=60 \%$

Uso: En el ejemplo de la figura 2.4 se puede ver el producto área convectiva correspondiente al día 08/08/2014 a 12 UTC. Hay que recalcar que puede haber zonas clasificadas como área organizada (píxeles naranjas) en las que ni siquiera llegue a haber rayos. En general se puede afirmar que las zonas de convección deberían quedar dentro de la zona marcada como área convectiva, pero no se puede afirmar que en toda zona marcada como convectiva habrá convección, ya que ésta dependerá de que la convección se inicie o no dependiendo de la existencia de diversos ingredientes (convergencia en superficie, energía de inhibición, temperatura de disparo, etc.).

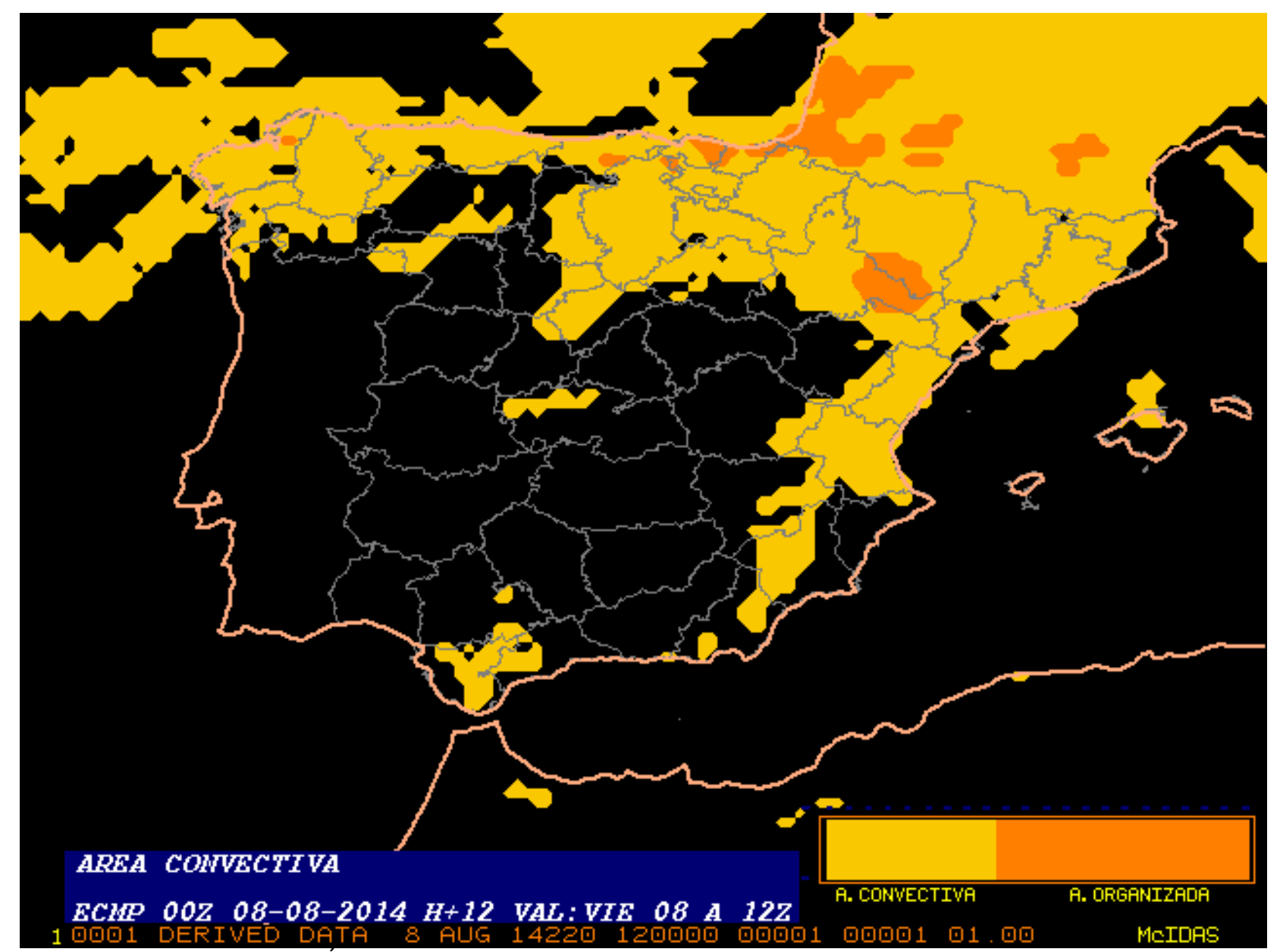

Figura 2.4. Área Convectiva correspondiente al día 08 de agosto de 2014 a 12 UTC. 


\section{Parámetro Frontal Térmico (PFT)}

Definición: El parámetro frontal térmico es la derivada direccional del gradiente de temperatura potencial del termómetro húmedo en la dirección de este gradiente.

$$
P F T=-\bar{U}_{\nabla \theta_{\omega}} \nabla\left|\nabla \theta_{\omega}\right|
$$

Uso: Este parámetro es útil para señalar de forma objetiva fronteras entre masas de aire, como el frente que se encuentra afectando al noroeste peninsular en la figura 2.5. En la ventana propuesta se muestra en tono morado el parámetro frontal térmico en las zonas donde la humedad relativa es igual o superior al $80 \%$, junto al geopotencial para los niveles de $925,850,700$ y $500 \mathrm{hPa}$. Las zonas azules y rojas muestran el carácter frío y cálido, respectivamente de la advección térmica.
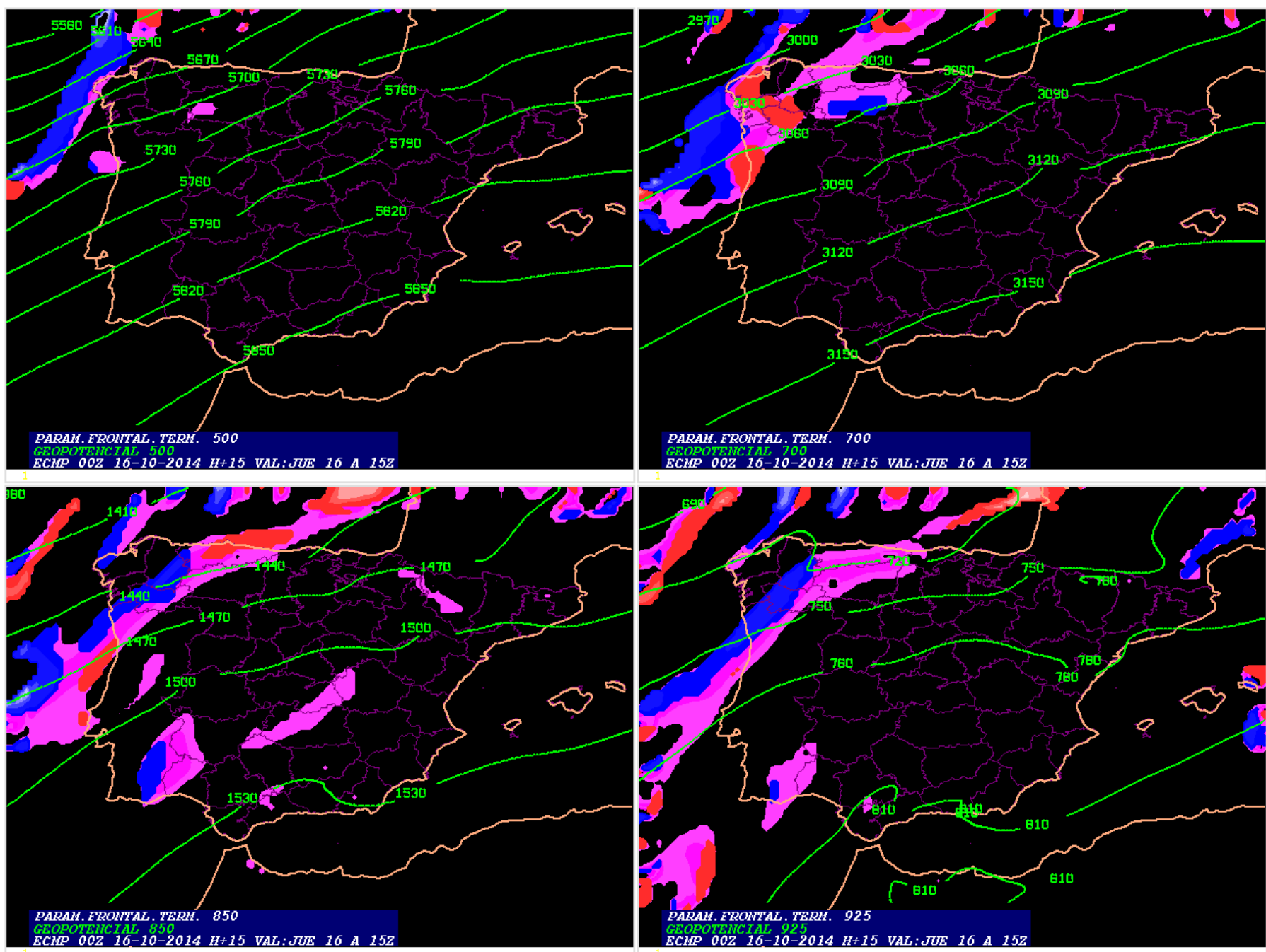

Figura 2.5. Parámetro Frontal Térmico (PFT), con advecciones cálida en rojo y fría en azul, junto a los geopotenciales en varios niveles. Arriba izquierda: PFT y geopotencial en 500 hPa. Arriba derecha: PFT y geopotencial en 700 hPa. Abajo izquierda: PFT y geopotencial en $850 \mathrm{hPa}$. Abajo derecha: PFT y geopotencial en $925 \mathrm{hPa}$. 
Definición: Es la velocidad vertical proporcionada como salida directa de los modelos numéricos, expresada en Pascales/segundo.

Uso: Esta variable muestra las zonas donde se están produciendo ascensos (valores negativos) o descensos (valores positivos). El uso simultáneo en varios niveles puede dar idea de la profundidad de los ascensos verticales desde el punto de vista del modelo. En la ventana propuesta (figura 2.6) se muestra para los niveles de 925, 850, 700 y $500 \mathrm{hPa}$.
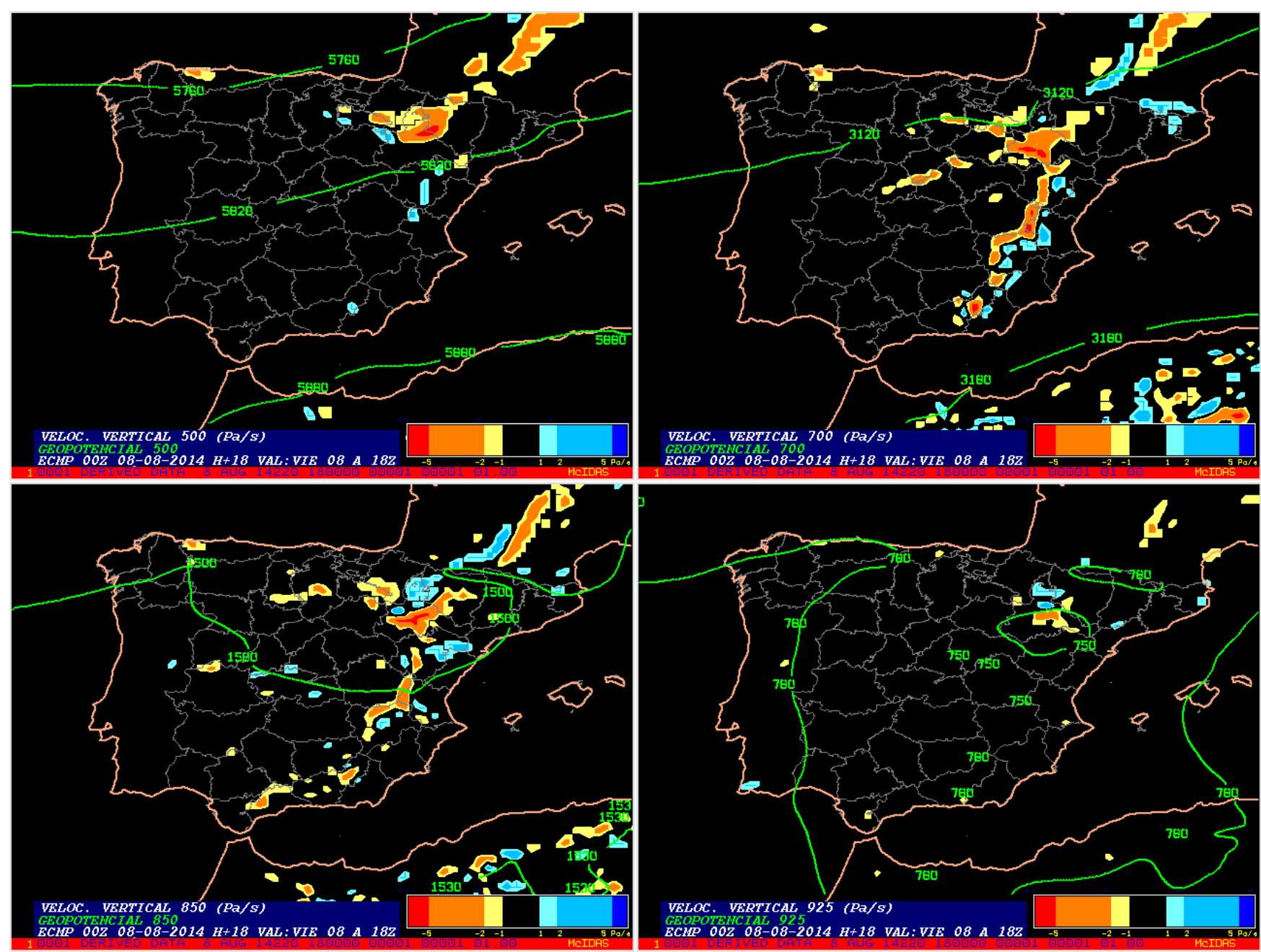

Figura 2.6. Velocidad vertical (w) y geopotencial en 500, 700, 850 y 925 hPa. Colores cálidos: ascensos. Colores fríos: descensos. 


\section{Presión al nivel del mar (PSL), Viento y Convergencia del Viento en Superficie}

Definición: En este panel se muestra la presión al nivel del mar (contorneada en intervalos de $2 \mathrm{hPa}$ ), el viento en superficie (representado en flechas y módulo en Kt), y la convergencia del viento en superficie (mostrada en colores: los colores cálidos indican convergencia y los fríos divergencia).

Uso: Estos campos nos permiten delimitar las zonas de convergencia (figura 2.7) en las que puede iniciarse la convección, así como observar el movimiento de éstas y poder anticipar el probable movimiento de las células convectivas desarrolladas.

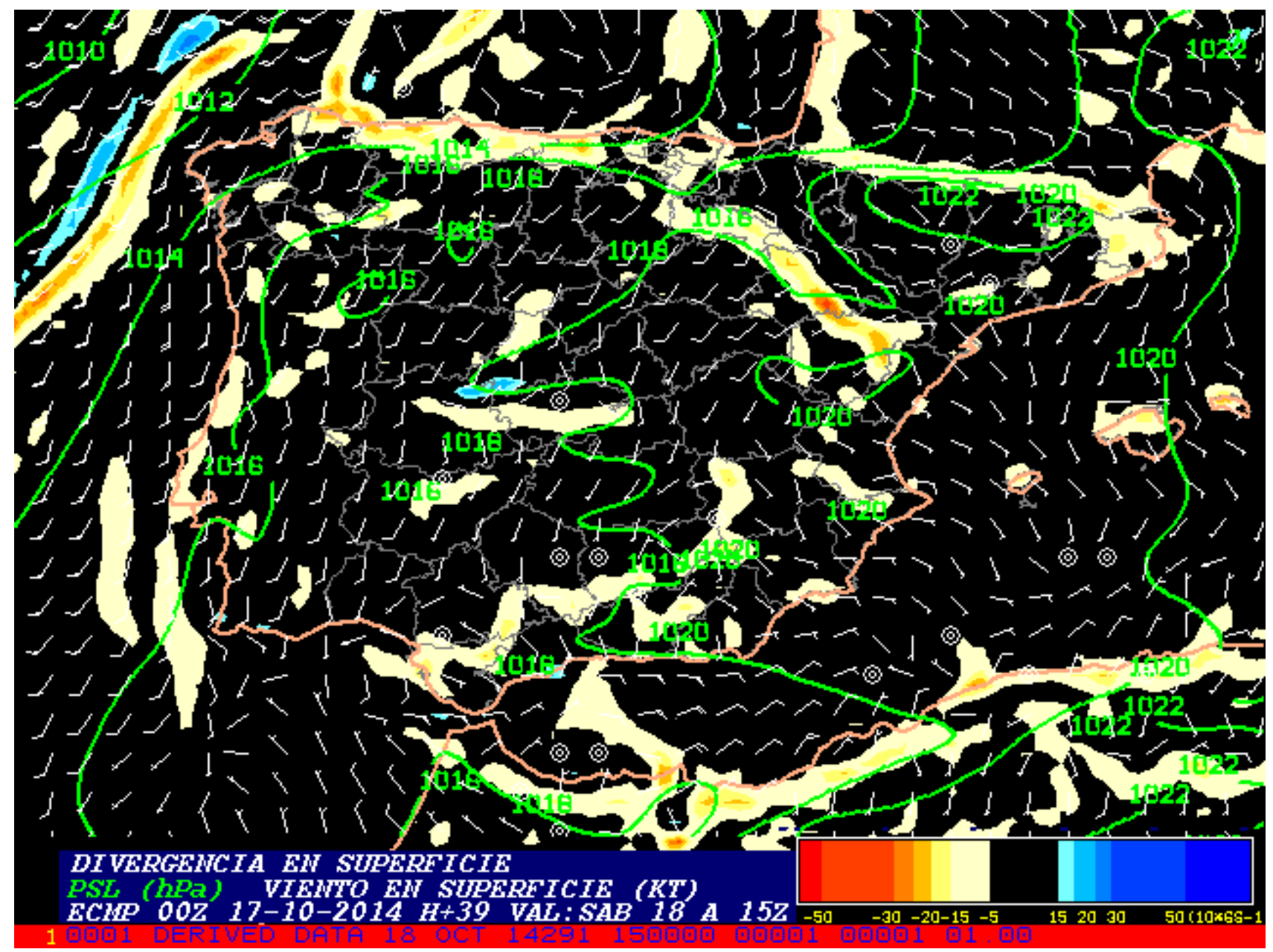

Figura 2.7. PSL, viento y convergencia del viento en superficie (colores calidos: convergencia; colores fríos: divergencia). 
Definición: El índice Liftex calculado en $700 \mathrm{hPa}(500 \mathrm{hPa})$ es la diferencia entre la temperatura ambiente en 700 (500 $\mathrm{hPa}$ ) y la de una burbuja que evolucionara adiabaticamente desde las condiciones medias de los 100 primeros milibares, hasta el nivel de $700(500) \mathrm{hPa}$. Es una medida de la flotabilidad de la burbuja a ese nivel.

$$
\text { LI5 }=\mathrm{T}_{\mathrm{a}}^{500}-\mathrm{T}_{\mathrm{p}}^{500} \quad \mathrm{LI} \quad=\mathrm{T}_{\mathrm{a}}{ }^{700}-\mathrm{T}_{\mathrm{p}}{ }^{700}
$$

\begin{tabular}{|c|l|}
\hline Valor LI & \multicolumn{1}{|c|}{ Grado de Estabilidad } \\
\hline$>\mathbf{0}$ & Estable. \\
\hline 0 a -3 & Inestable. \\
\hline-3 a -6 & Moderadamente inestable. \\
\hline-6 a -9 & Muy inestable. \\
\hline$<-9$ & Extremadamente inestable. \\
\hline
\end{tabular}

Uso: Los índices LI7 y LI5 nos dan una visión general de la flotabilidad en niveles medios y medios/altos de la atmósfera (figura 2.8). Utilizar dos índices simultáneamente reduce el error que podría haber al utilizar sólo uno por la presencia de inversiones. EL LI7 es un buen índice para predecir convección poco profunda en invierno en zonas bajas y del litoral, así como complemento de LI5 en verano en zonas del interior.

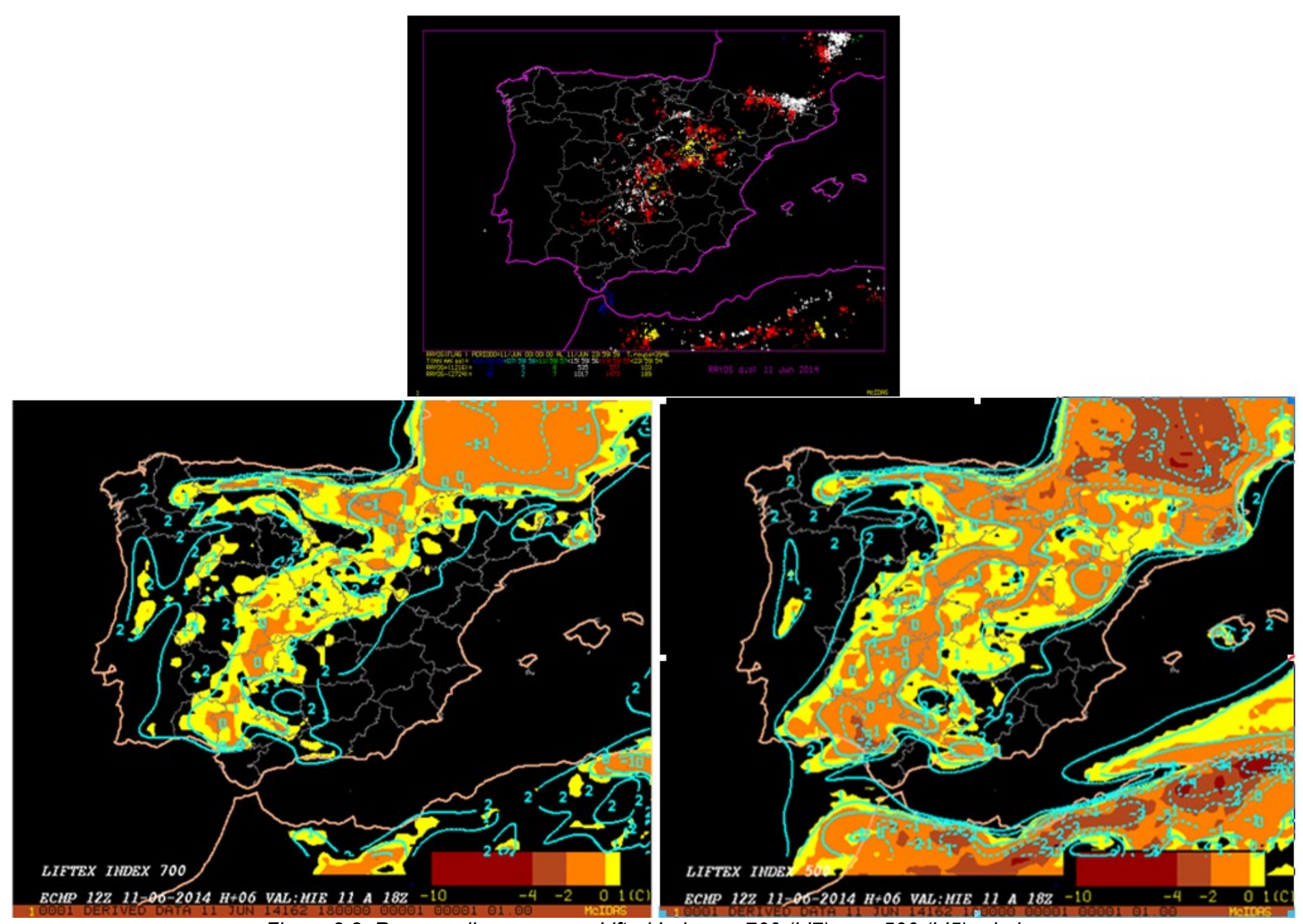

Figura 2.8. Rayos arriba y campos Lifted Index en 700 (LI7) y en 500 (LIS), abajo.

Nota: Los campos SBLI500 y SBLI700 son análogos pero para una burbuja que parte desde superficie (SB: "Surface Based"). 


\section{Índice $\mathrm{K}\left[{ }^{\circ} \mathrm{C}\right]$}

Definición: Su cálculo toma en cuenta tanto el perfil vertical de humedad como el de temperatura en los niveles de 850 , 700 y $500 \mathrm{hPa}$, y los puntos de rocío en los niveles de 850 y $700 \mathrm{hPa}$. Cuanto mayor es la humedad y la diferencia de temperatura entre los niveles de 850 y $500 \mathrm{hPa}$, tanto mayor el $\mathrm{K}$ y el potencial de convección.

$$
K=\left(T_{850}-T_{500}\right)+T d_{850}-\left(T_{700}-T d_{700}\right)
$$

\begin{tabular}{|c|c|}
\hline Valor del índice $\mathbf{K}$ & Probabilidad de tormentas (\%) \\
\hline $\mathrm{K}<15$ & 0 \\
\hline $15<=\mathrm{K}<=20$ & 20 \\
\hline $21<=\mathrm{K}<=25$ & 20 a 40 \\
\hline $26<=\mathrm{K}<=30$ & 40 a 60 \\
\hline $31<=\mathrm{K}<=35$ & 60 a 80 \\
\hline $36<=\mathrm{K}<=40$ & 80 a 90 \\
\hline $40<\mathrm{K}$ & Cerca de 100 \\
\hline
\end{tabular}

Uso: El índice $\mathrm{K}$ es una herramienta muy útil para diagnosticar el potencial de convección (figura 2.7). Resulta de particular utilidad para identificar ambientes productores de convección y lluvia fuerte. Sin embargo, no se puede usar para inferir la intensidad de la convección.
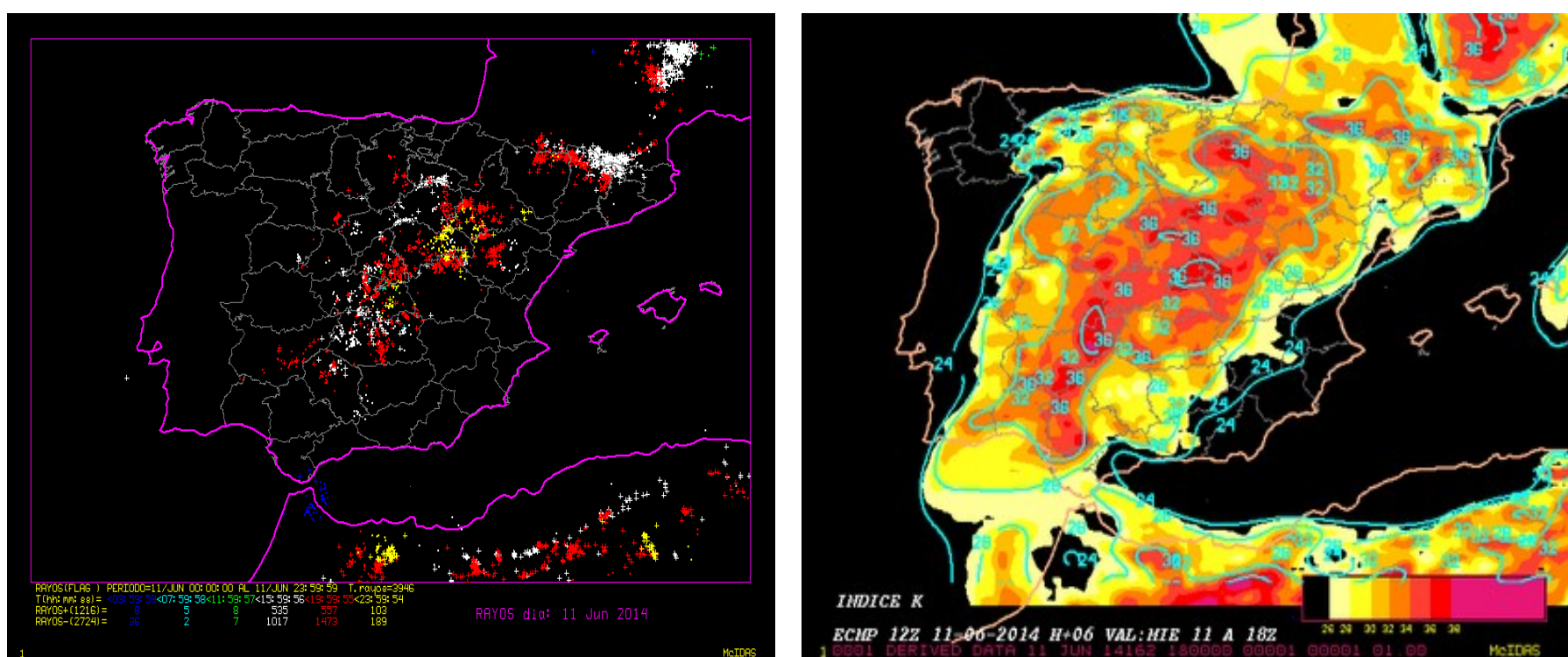

Figura 2.7. Rayos (izda) e índice K (dcha). 
Definición: El índice TT se calcula a partir de la temperatura y el punto de rocío en $850 \mathrm{hPa}$ y la temperatura en $500 \mathrm{hPa}$. Cuanto mayores sean la temperatura y el punto de rocío en $850 \mathrm{hPa}$ y menor la temperatura en $500 \mathrm{hPa}$, tanto mayor serán la inestabilidad y el valor de TT.

$$
T T=T d_{850}+T_{850}-2 T_{500}
$$

\begin{tabular}{|c|c|}
\hline Valor del índice TT & Tiempo esperado \\
\hline Menor 44 & Estable \\
\hline 44 a 50 & Tormentas \\
\hline 50 a 54 & Posibilidad de tormentas severas \\
\hline Mayor de 54 & Posibilidad de tormentas severas con tornado \\
\hline
\end{tabular}

Uso: El índice total de totales es un índice de tormenta severa muy utilizado y fácil de calcular. Sin embargo, tiene la limitación de que usa datos de únicamente dos niveles obligatorios (850 y $500 \mathrm{hPa}$ ) y por tanto no toma en cuenta el efecto de las inversiones o de las capas húmedas o secas que existan entre estos niveles. Además, no funciona en lugares en que el nivel de $850 \mathrm{hPa}$ se encuentra cerca de la superficie o debajo del suelo.

En la figura 2.8 se muestran los rayos del día 11 de junio de 2014 y los valores que toma dicho índice TT a las 18 UTC de ese día (predicción para un alcance de 6 horas según la pasada de las 12 UTC).
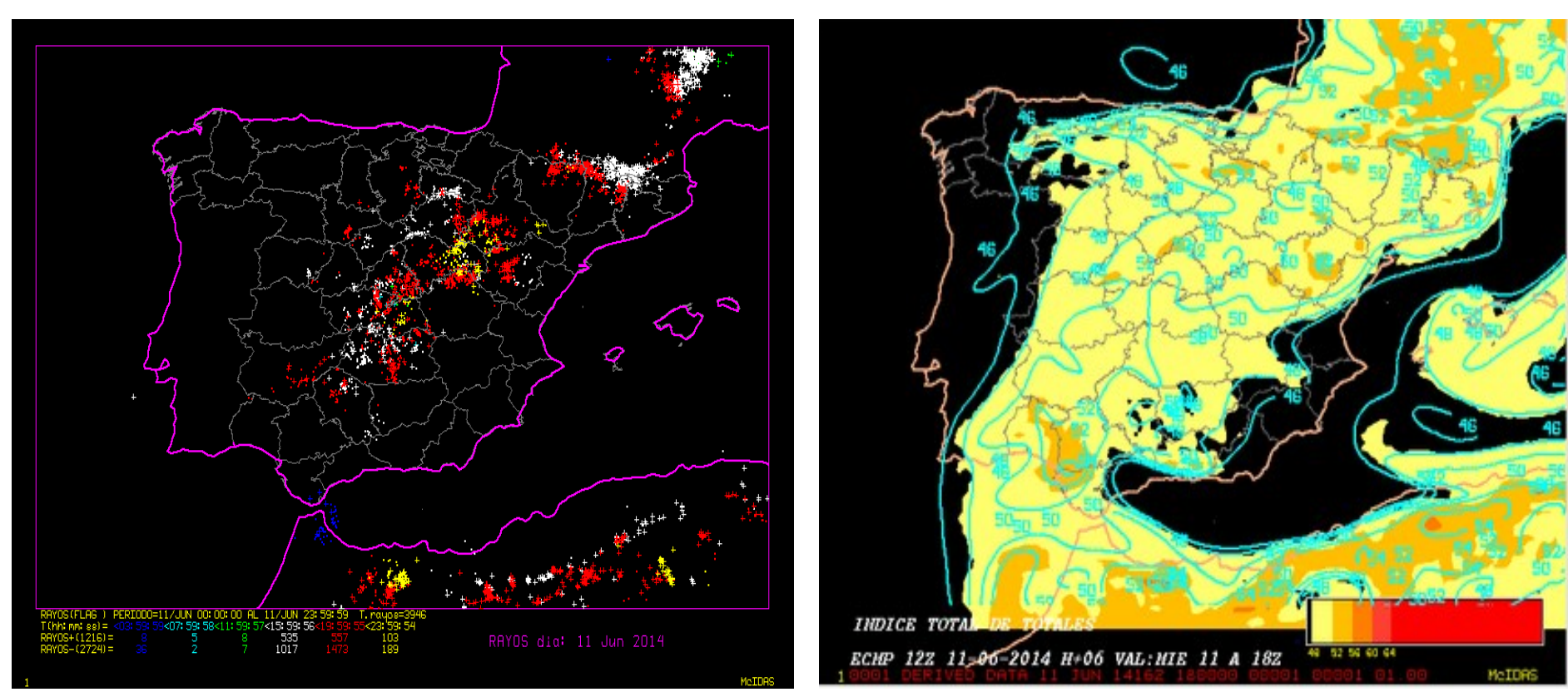

Figura 2.8. Rayos (izda) e índice TT (dcha) contorneado y coloreado según escala adjunta. 
Definición: Es una medida de la flotabilidad de una burbuja en la troposfera. Representa la energía disponible para acelerar una burbuja en movimiento vertical, o la cantidad de trabajo que sobre una burbuja se realiza para acelerarla hacia arriba. La CAPE es el área positiva representada en un sondeo, comprendida entre la adiabática húmeda de la evolución de la burbuja y la curva de estado desde el nivel de convección libre (NCL) hasta el nivel de equilibrio (NE), como se puede apreciar en la figura 2.9. Cuanto mayor sea la diferencia de temperatura entre la burbuja ascendente y cálida y el entorno más frío, mayor será la CAPE, y la aceleración vertical ascendente producirá fuerte convección. La CAPE está relacionada teóricamente con la máxima velocidad vertical que adquiere la burbuja que asciende. Se muestran en una tabla los valores de CAPE y el grado de inestabilidad según la bibliografía norteamericana (en el caso concreto de España, valores muy inferiores de CAPE que los considerados en Estados Unidos, pueden representar un grado importante de inestabilidad).

$$
C A P E=g \int_{N C L}^{N E}\left[\frac{T_{v b}-T_{v a}}{T_{v a}}\right] d z
$$

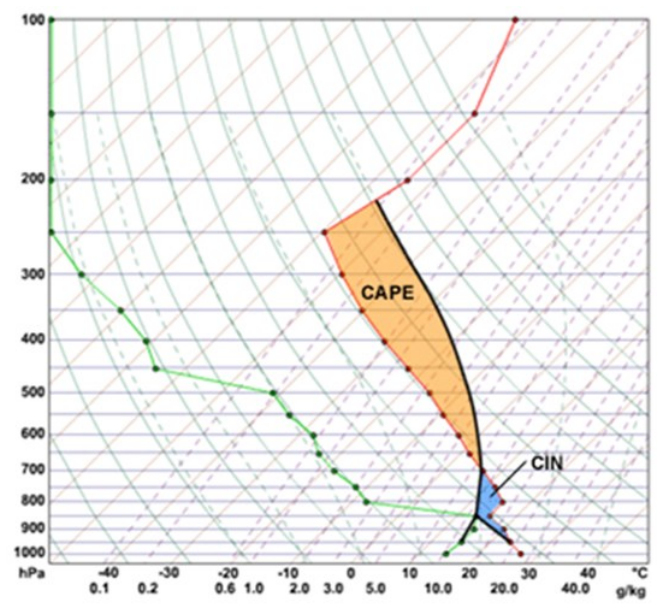

\begin{tabular}{|c|c|}
\hline Valor de CAPE & Grado de Estabilidad \\
\hline$<0$ & Estable. \\
\hline 0 a 1000 & Inestable. \\
\hline 1000 a 2500 & Moderadamente inestable. \\
\hline 2500 a 3500 & Muy inestable. \\
\hline$>3500-4000$ & Extremadamente inestable. \\
\hline
\end{tabular}

Figura 2.9. CAPE y CIN. (Fuente: (COMET)

Uso: El valor de la CAPE se calcula con los valores de una burbuja que evoluciona con las condiciones medias del estrato inferior de $100 \mathrm{hPa}$. Aquí se calculan cuatro versiones: CAPE (calculado con las condiciones medias del estrato inferior de $100 \mathrm{hPa}$ de espesor), CAPE3 (igual que el anterior pero limitado hasta $3 \mathrm{~km}$ por encima de superficie), SBCAPE (Surface Based CAPE: calculado desde exactamente las condiciones de superficie) y MUCAPE (Most Unstable CAPE: correspondiente al nivel de mayor temperatura potencial equivalente). Las cuatro versiones se presentan de forma simultánea en cuatro paneles (figura 2.10).
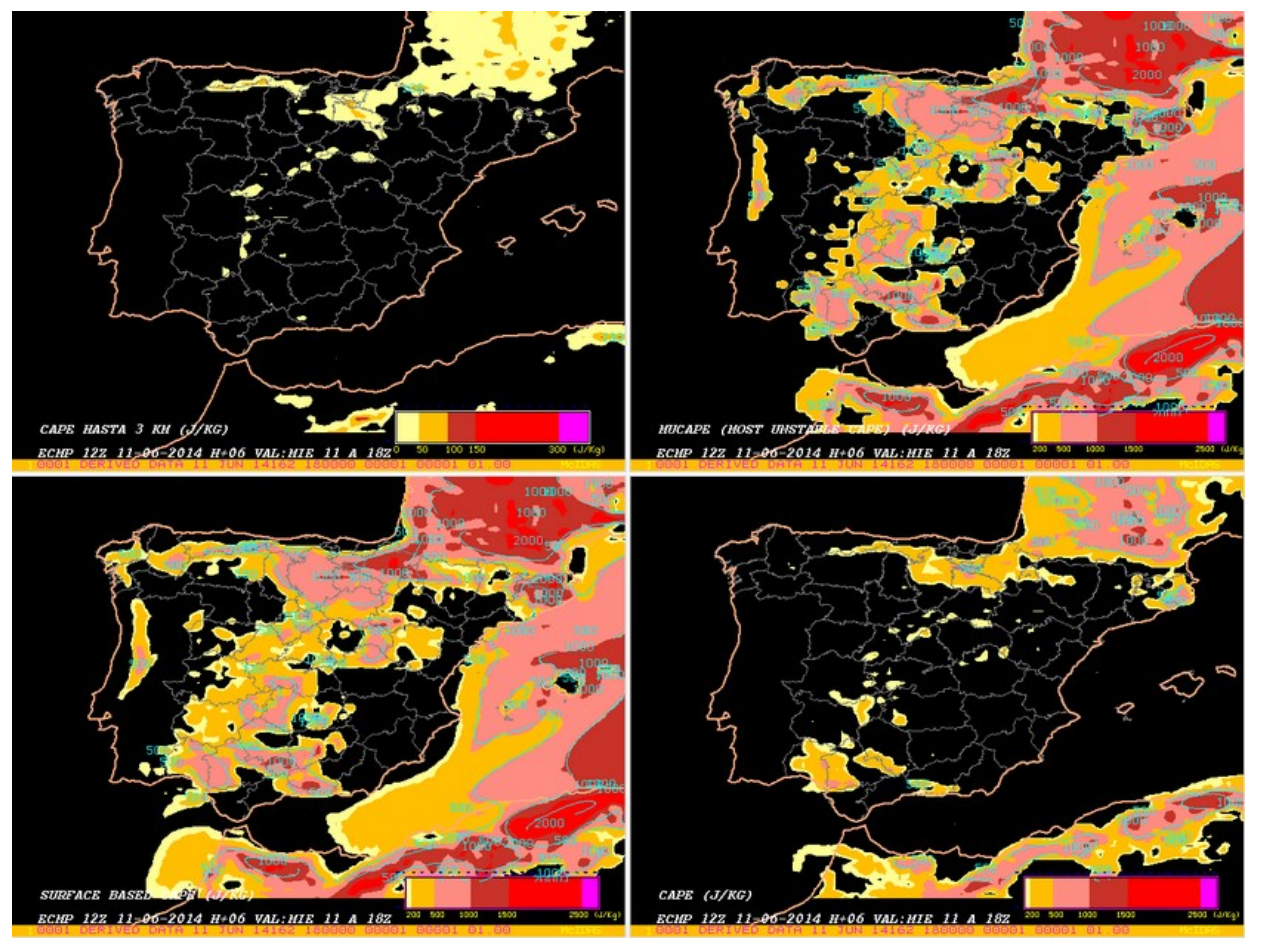

Figura 2.10. Panel de CAPEs (J/Kg). Arriba izquierda: CAPE $3 \mathrm{~km}$, arriba derecha: MUCAPE, abajo izquierda: SBCAPE, abajo derecha: CAPE. 


\section{Energía de Inhibición Convectiva CIN, SBCIN [J.kg-1]}

Definición: Representa la cantidad de energía disponible para inhibir o suprimir la aceleración vertical ascendente o la cantidad de trabajo que debe hacer el entorno sobre la partícula para alcanzar el Nivel de Convección Libre, NCL (figura 2.9). Se representa por el área encerrada entre la curva de evolución (adiabática seca hasta el Nivel de Condensación por Ascenso, NCA y saturada hasta el NCL) y la de estado.

$$
C I N=g \int_{S F C}^{N C L}\left[\frac{T_{v b}-T_{v a}}{T_{v a}}\right] d z
$$

Uso: Cuanto menor (mayor) sea el valor de CIN, tanto menor (mayor) deberá ser el forzamiento sinóptico o mesoescalar necesario para elevar la burbuja hasta el nivel NCL. Altos valores de CIN (típicamente por encima de 300) con pequeños o ausentes forzamientos ascendentes pueden suprimir el desarrollo convectivo a pesar de posibles altos valores de CAPE. En la ventana propuesta se muestra el CIN y SBCIN (Surface Based CIN, con evolución exactamente desde el nivel de superficie) junto a la CAPE y SBCAPE (figura 2.11).

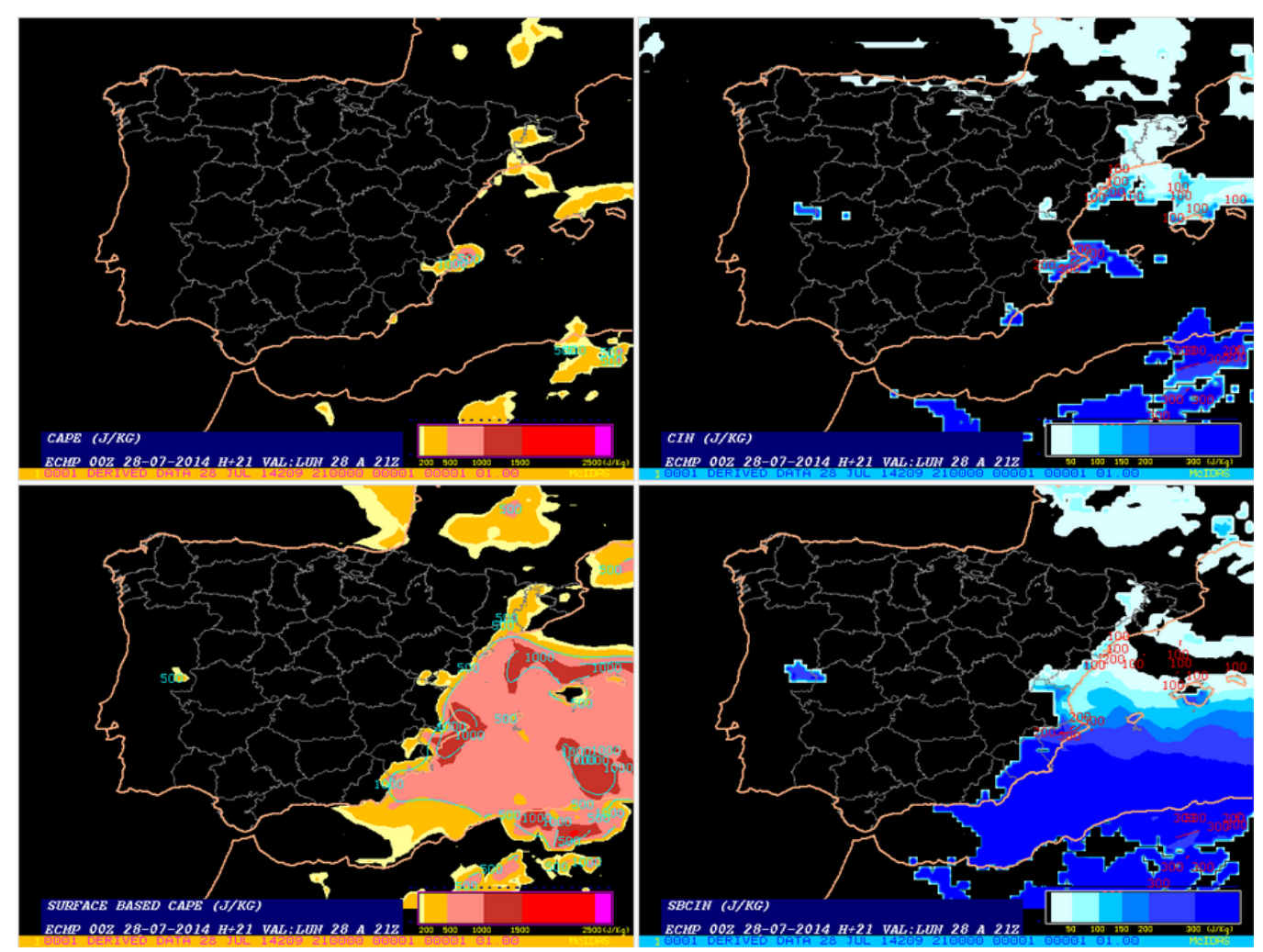

Figura 2.11. Panel de CAPEs y CINs (J/Kg). Arriba izquierda: CAPE, arriba derecha: CIN, abajo izquierda: SBCAPE, abajo derecha: SBCIN. 
Definición: Representa el gradiente vertical de temperatura potencial del termómetro húmedo. Para cada nivel de cálculo se toman como niveles inferior y superior, los mostrados en la tabla.

$$
E S T W=-\frac{\alpha}{\theta_{w}} \frac{\partial \theta_{w}}{\partial p}
$$

\begin{tabular}{|c|c|c|}
\hline Nivel & Nivel inferior & Nivel superior \\
\hline 925 & 975 & 850 \\
\hline 850 & 925 & 700 \\
\hline 700 & 850 & 500 \\
\hline 500 & 700 & 400 \\
\hline
\end{tabular}

Uso: Valores negativos de ESTW indican existencia de inestabilidad potencial, y valores positivos estabilidad potencial. Es conveniente calcularlo en varios niveles, y a ser posible que se superpongan para detectar en capas profundas inestables, la presencia de capas estables. Una capa potencialmente inestable se convierte en condicionalmente inestable al elevarla.

En el ejemplo de la ventana propuesta para este campo (figura 2.12) se muestra ESTW en los niveles de 925, 850 y 700 $\mathrm{hPa}$ junto al gradiente térmico vertical en el estrato 700-500 hPa.

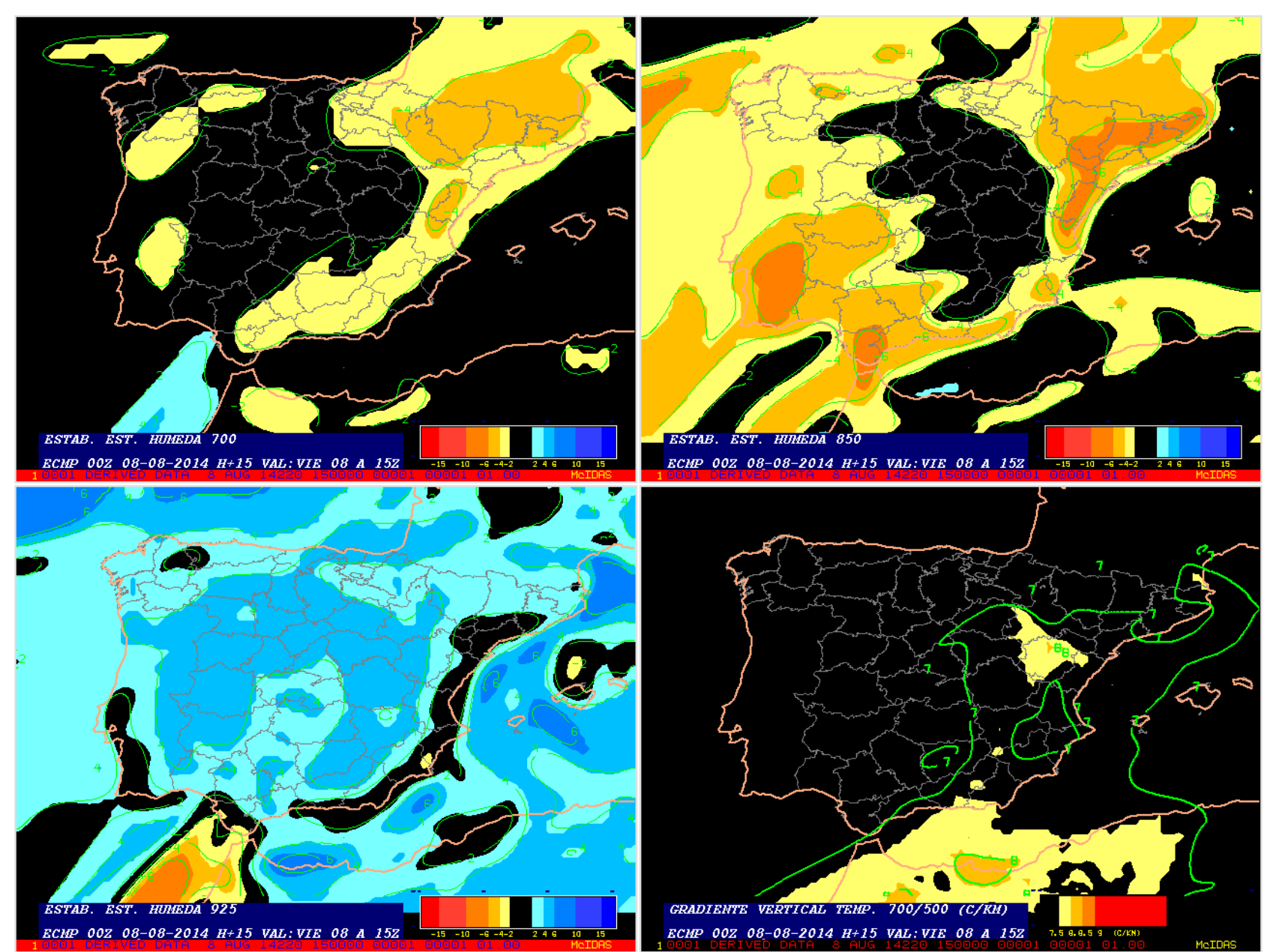

Figura 2.12. Arriba izquierda: ESTW en $700 \mathrm{hPa}\left(\mathrm{J}^{*} \mathrm{Kg}^{-1 *} \mathrm{~Pa}^{-2}\right)$, arriba derecha: ESTW en $850 \mathrm{hPa}$, abajo izquierda: ESTW en $925 \mathrm{hPa}$, abajo derecha: gradiente vertical de $T$ (entre 700 y $500 \mathrm{hPa})\left({ }^{\circ} \mathrm{C} / \mathrm{Km}\right)$. 


\section{Temperatura Potencial Equivalente $\left[{ }^{\circ} \mathrm{C}\right]$ y su Advección $\left[{ }^{\circ} \mathrm{C} / 12 \mathrm{~h}\right]$}

Definición: Es la temperatura que una parcela de aire húmedo adquiere si es elevada hasta una altura en la que todo el vapor de agua se condensara y abandonara dicha parcela y fuera entonces adiabaticamente comprimida hasta la presión de $1000 \mathrm{hPa}$.

Uso: Este parámetro es ideal para distinguir masas de aire con características distintas en cuanto a temperatura y/o contenido de humedad. Cuando se representa en varios niveles ayuda a determinar áreas donde existe inestabilidad potencial (zonas donde la temperatura potencial equivalente disminuye con la altura).

La ventana propuesta (figura 2.13) muestra la temperatura potencial equivalente (contorneada en intervalos de $4^{\circ} \mathrm{C}$ ) y su advección $\left({ }^{\circ} \mathrm{C} / 12 \mathrm{~h}\right)$ en los niveles de 925, 850, 700 y $500 \mathrm{hPa}$.

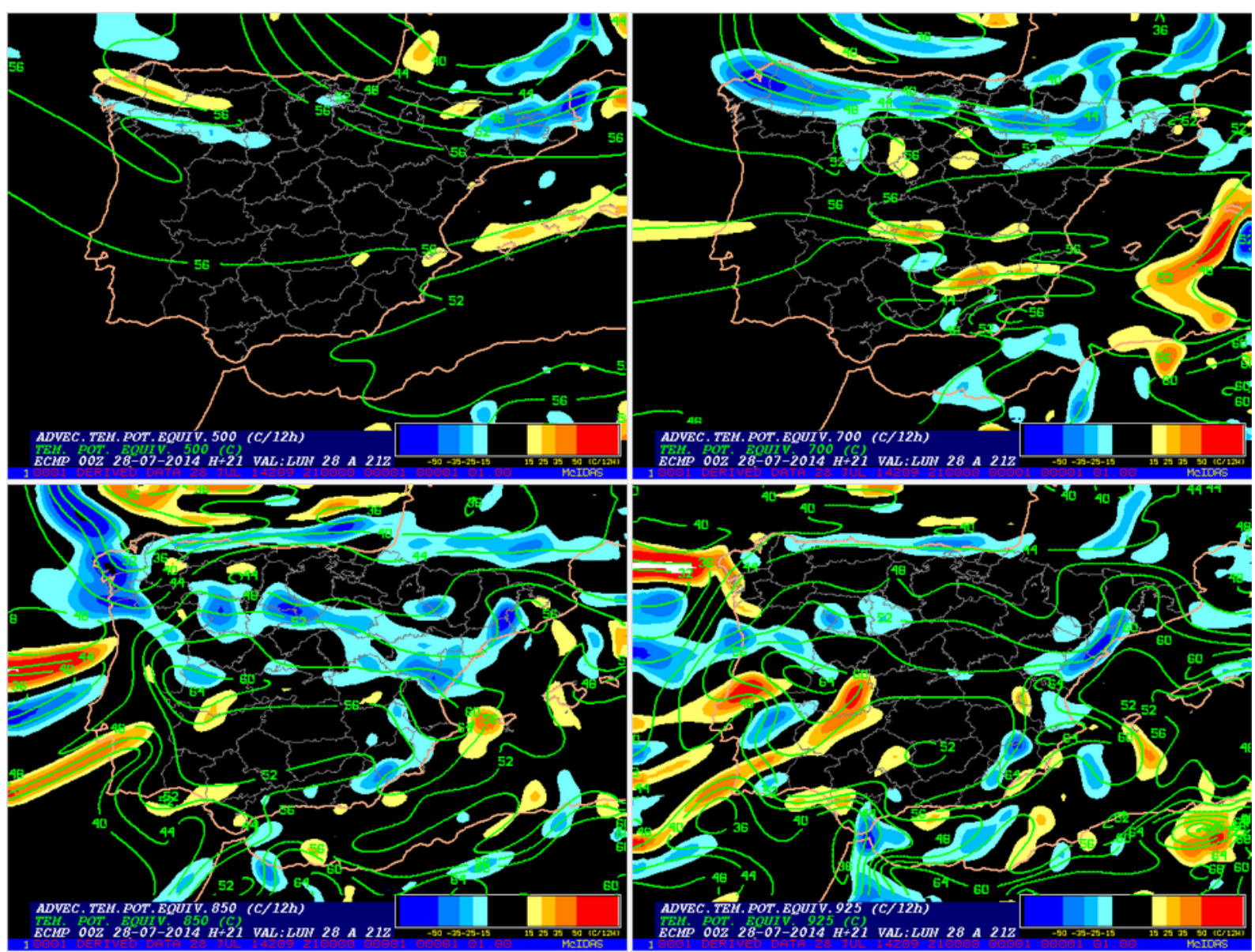

Figura 2.13. Temperatura Potencial Equivalente (THE) en ${ }^{\circ} \mathrm{C}$ y su advección en 925, 850, 700 y 500 hPa en ( ${ }^{\circ} \mathrm{C} / 12$ h). 


\section{Niveles de Condensación: NCA / NCC / NCL / NE [m]}

Definición: En este producto se muestra la altura $(\mathrm{m})$ sobre el terreno, del nivel de condensación por ascenso (NCA), nivel de condensación convectivo (NCC), nivel de convección libre (NCL) y nivel de equilibrio (NE).

Uso: Permite visualizar de forma conjunta todos los niveles de condensación junto con el nivel de convección libre. Al mostrarse también el nivel de equilibrio (NE) nos permite estimar la profundidad de la convección si ésta se inicia (figura 2.14).
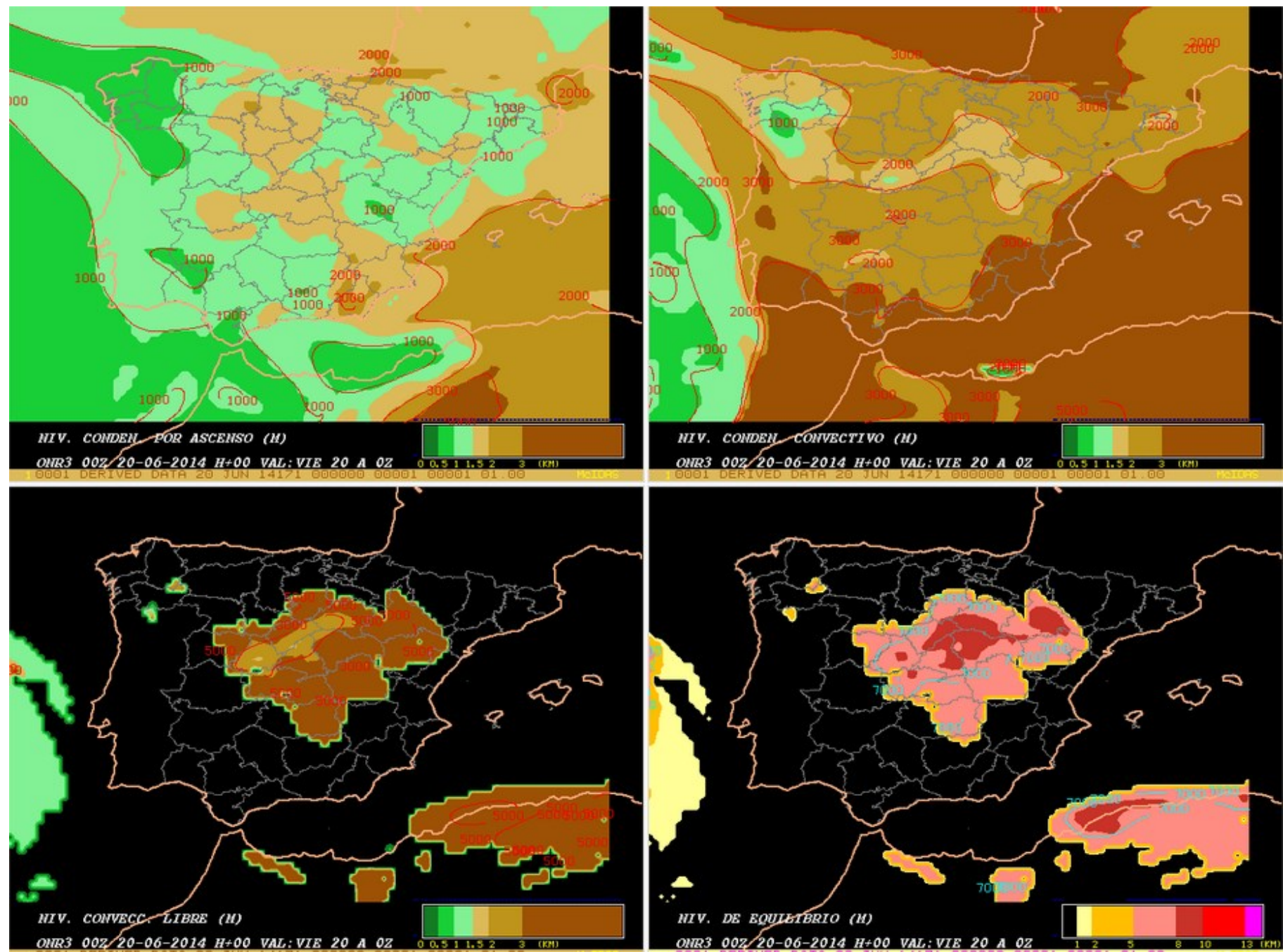

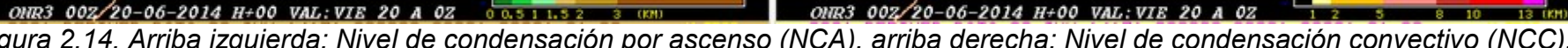

Figura 2.14. Arriba izquierda: Nivel de condensación por ascenso (NCA), abajo derecha (NE). Unidades en metros.
abajo izquierda: Nivel de convección libre (NCL), 


\section{Nivel de Equilibrio en unidades de Temperatura $\left[{ }^{\circ} \mathrm{C}\right]$}

Definición: En este producto se muestra el nivel de equilibrio (NE) teórico en unidades de temperatura, correspondiente a la evolución de una parcela de aire con las condiciones medias del estrato inferior de $100 \mathrm{hPa}$ proporcionado por el modelo.

Uso: Al presentarse este campo en unidades de temperatura, aparece como una imagen comparable al canal infrarrojo coloreado. Tonos ocres representan niveles de equilibrio bajos (cálidos) y tonos de azul intenso indican niveles de equilibrio altos (fríos). Se pretende mostrar de forma muy visual, la profundidad de la convección si ésta llega a iniciarse (figura 2.15).

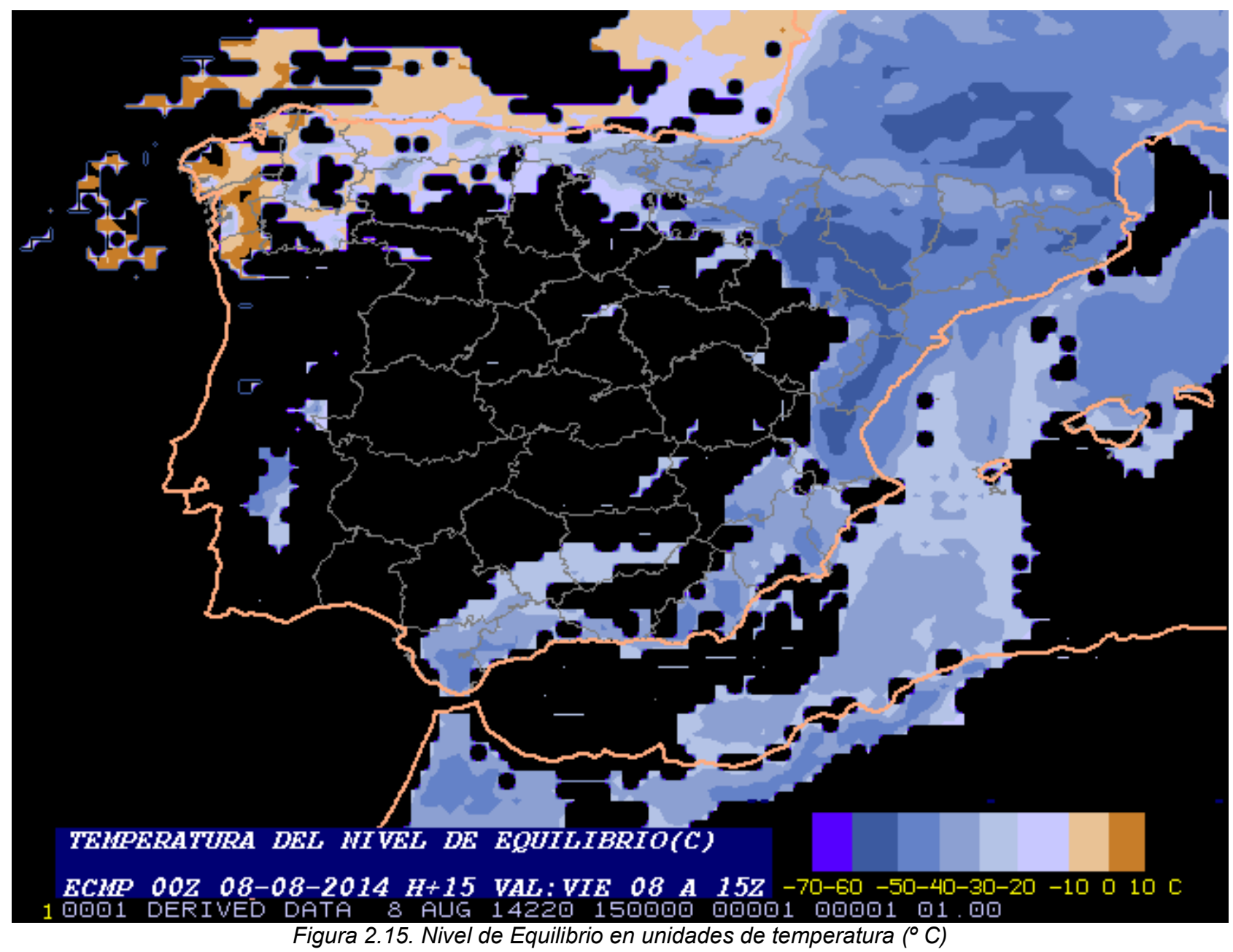


Definición: Diferencia de altura entre los niveles de convección libre (NCL) y de condensación por ascenso (NCA) expresada en metros. Se representa junto al campo NCA.

Uso: Este índice (NCL-NCA) es representativo del forzamiento adicional necesario para que una vez iniciada la convección, ésta se dispare por encima del nivel de convección libre (NCL). Este índice debe usarse en combinación con otros y tan sólo cuando se espere que la convección se inicie. En situaciones de inestabilidad puede marcar las zonas donde la convección es más probable.

En la figura 2.16 se puede ver un ejemplo de uso correspondiente al día 8 de agosto de 2014. El área convectiva abarcaba zonas del norte peninsular. En el campo (NCL-NCA) observamos que en zonas con valores superiores a 2000 $\mathrm{m}$. no se llegó a producir convección. En cambio las áreas donde esa diferencia de niveles era inferior a $1000 \mathrm{~m}$. se ajusta bastante bien a la zona donde se registraron las descargas.

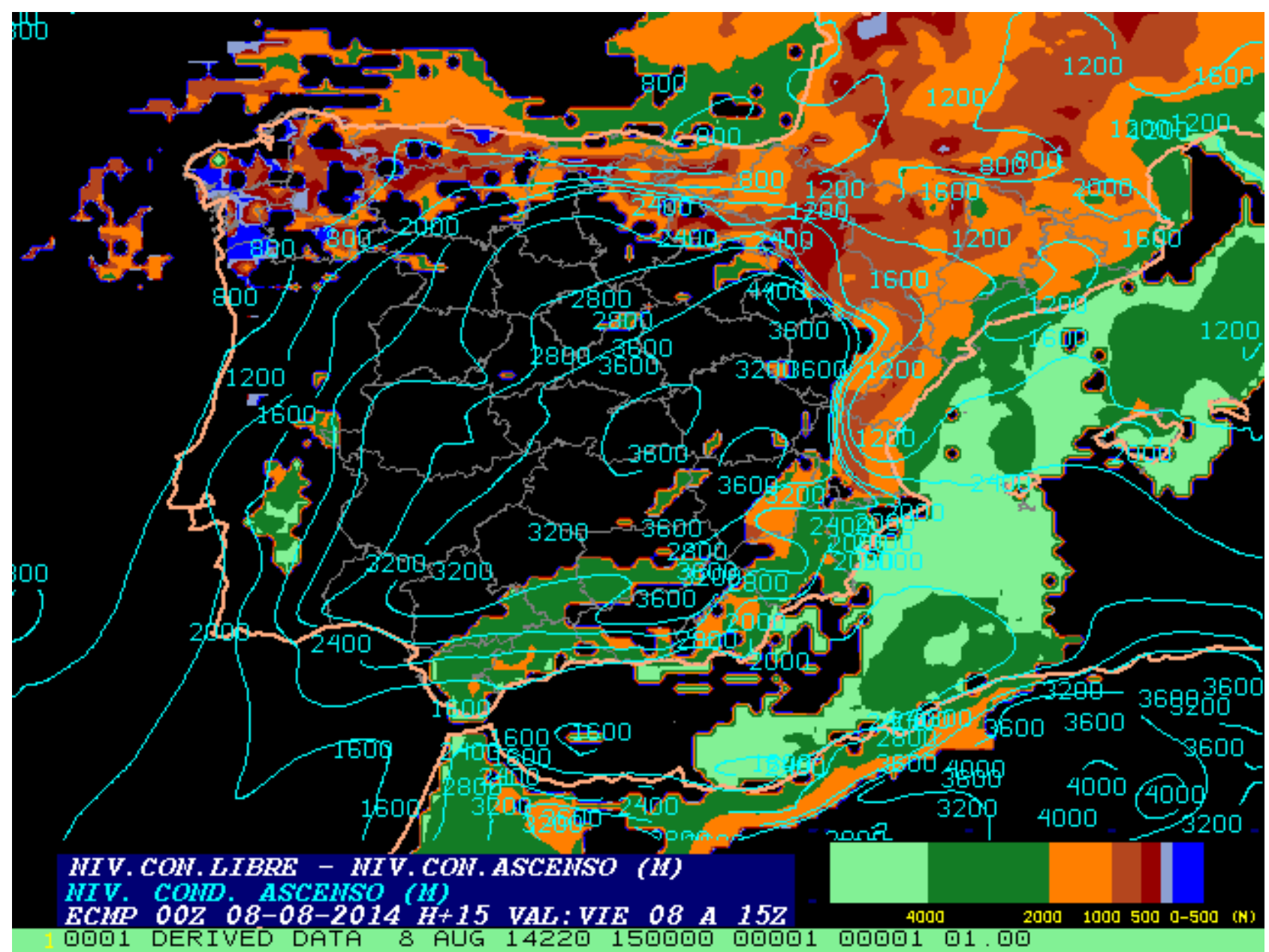

Figura 2.16. NCL-NCA coloreado y NCA contorneado, para el día 8 de agosto de 2014 a 12 UTC. Unidades en metros. 


\section{Nivel de condensación convectivo NCC [m] y temperatura de disparo $\left[{ }^{\circ} \mathrm{C}\right]$}

Definición: El nivel de condensación por convección (NCC) es la altitud a la que una burbuja de aire que se calienta lo suficiente desde abajo, subirá adiabáticamente hasta saturarse. Normalmente corresponde a la altura de la base de las nubes cumuliformes formadas por la convección térmica producida exclusivamente por el calentamiento de la superficie al alcanzar la temperatura de disparo (figura 2.17).

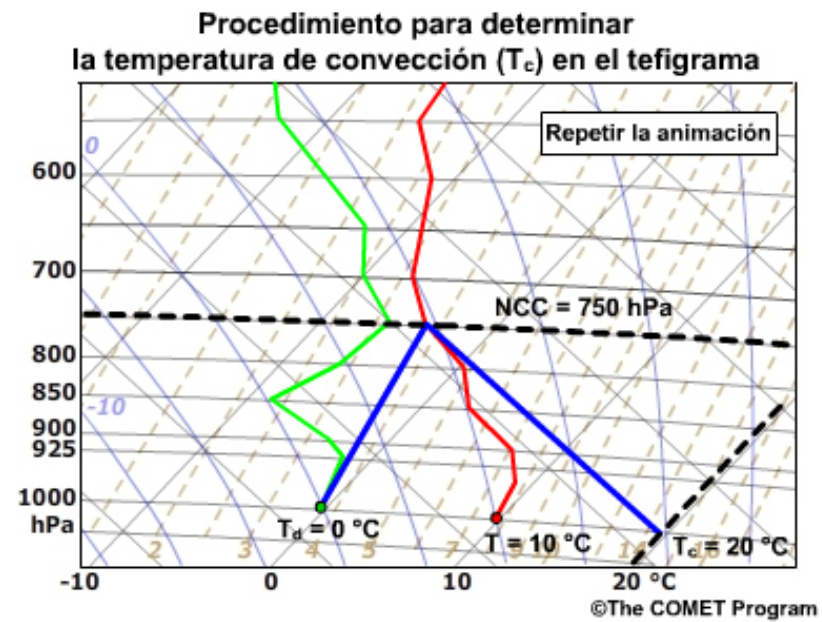

Figura 2.17. Cálculo gráfico de la temperatura de disparo (también llamada temperatura de convección) (Fuente: COMET).

Uso: En el panel propuesto se muestra el nivel de condensación convectivo contorneado cada $1000 \mathrm{~m}$. y la temperatura de disparo coloreada en intervalos de $5^{\circ} \mathrm{C}$ (figura 2.18).

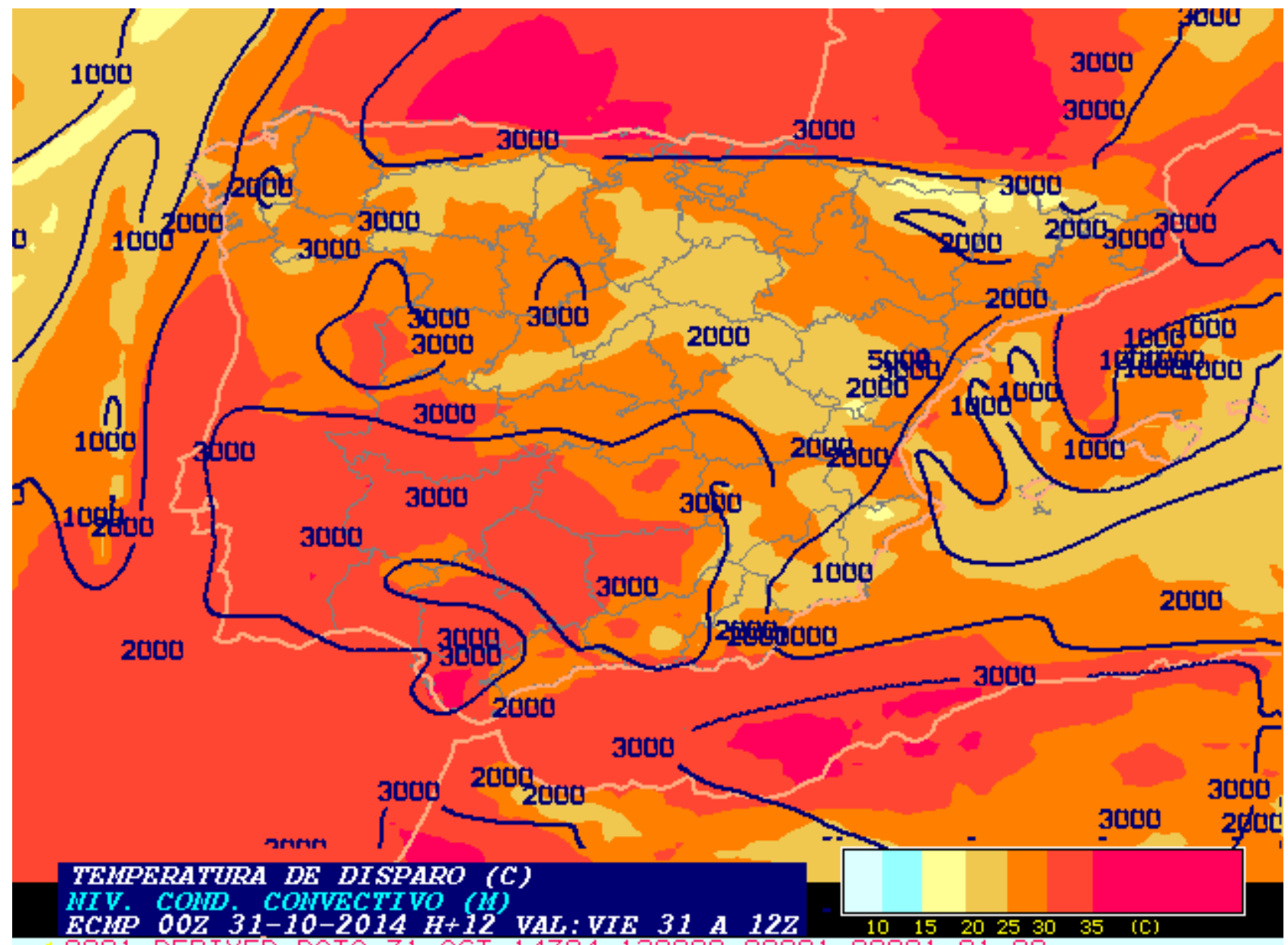

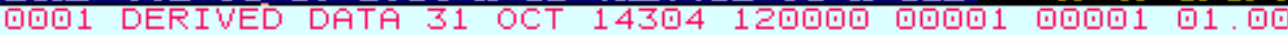

Figura 2.18. Nivel de Condensación Convectivo $(m)$ y Temperatura de disparo $\left({ }^{\circ} \mathrm{C}\right)$. 


\section{Flotabilidad de la Columna}

Definición: En el campo de flotabilidad de la columna se muestra la diferencia entre la temperatura potencial equivalente de una burbuja que evoluciona desde un nivel determinado y la temperatura potencial equivalente saturante de cada uno de los niveles que se encuentran por encima. Se presenta de izquierda a derecha para burbujas que evolucionan desde $1000,925,850$ y $700 \mathrm{hPa}$ (figura 2.19).

Uso: Nos permite chequear la flotabilidad y la profundidad de la convección para burbujas que evolucionan por vía adiabática desde distintos niveles, si la convección se llega a iniciar. Por ejemplo, si para una determinada zona la flotabilidad es positiva en todos los paneles que se encuentran por encima hasta uno dado, significa que la convección se puede extender en la vertical hasta ese nivel.

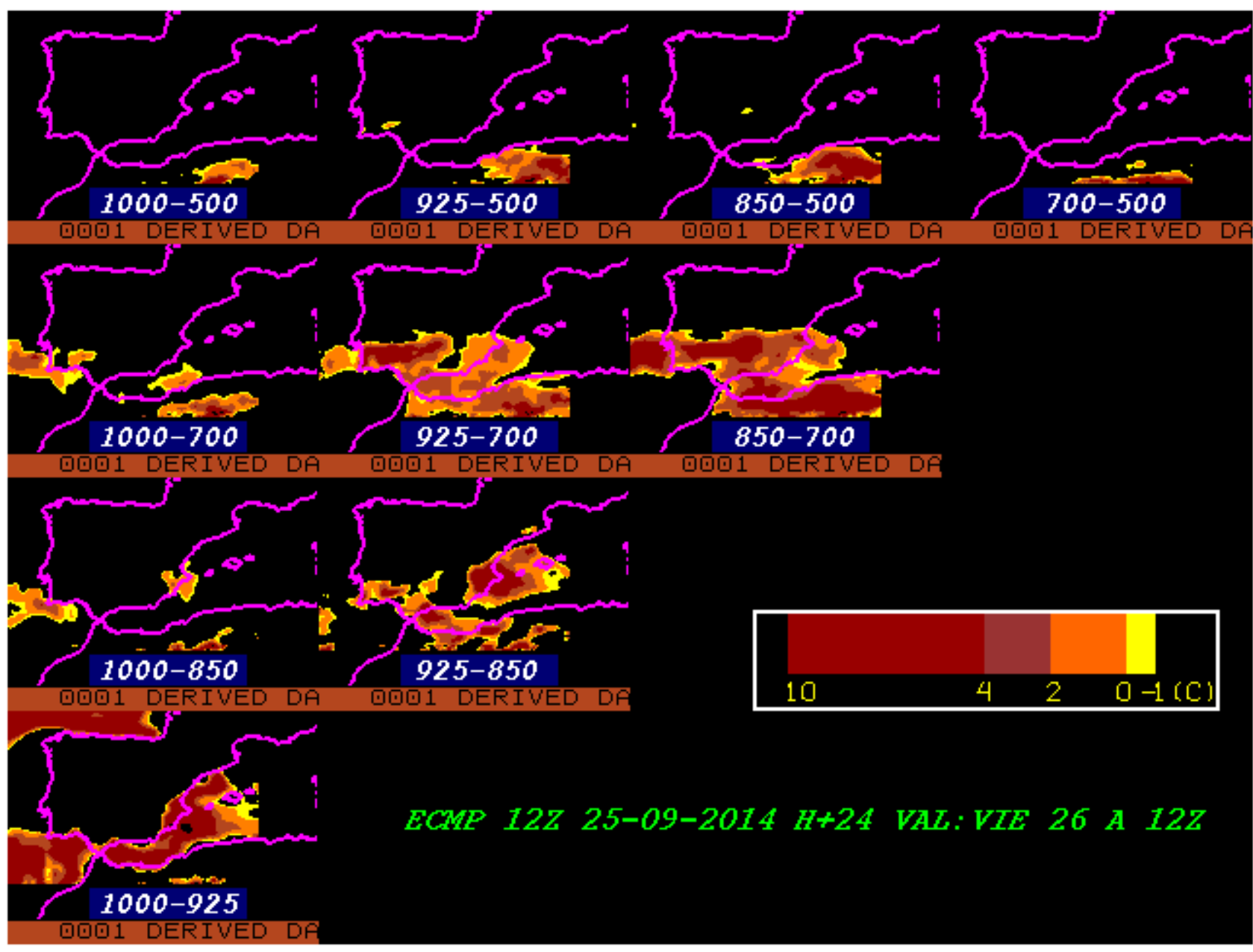

Figura 2.19. Flotabilidad de la columna (explicación en el texto). 


\section{Índice Helicidad-Energía, EHI [adimensional]}

Definición: Combina la helicidad relativa a la tormenta (SRH) y la inestabilidad (CAPE) en un único índice.

$$
\mathrm{EHI}=\left(\mathrm{SRH}{ }^{*} \mathrm{CAPE}\right) / 160000
$$

Uso: En EEUU se ha observado que distintas combinaciones de SRH y CAPE pueden dar lugar a supercélulas con tornados. Los casos extremos serian: en ambientes "no muy inestables" (CAPE <1000) y altas helicidades $(\mathrm{SRH}>400)$, y en ambientes muy inestables (CAPE > 3500) y helicidades no muy altas ( $\mathrm{SRH}<200)$. Entre ambos habría un continuo de casos. En general se admite que valores de EHI mayores de 2.5 son significativos, e indicativos de supercélulas con tornados asociados. Sin embargo, para las condiciones reinantes en la Península lbérica se ha encontrado que valores por encima de 0.2 pueden ser significativos.

En la ventana propuesta (figura 2.20) se presenta el EHI coloreado según la escala asociada, y además el contorneo del Número de Richardson Global (NRG).

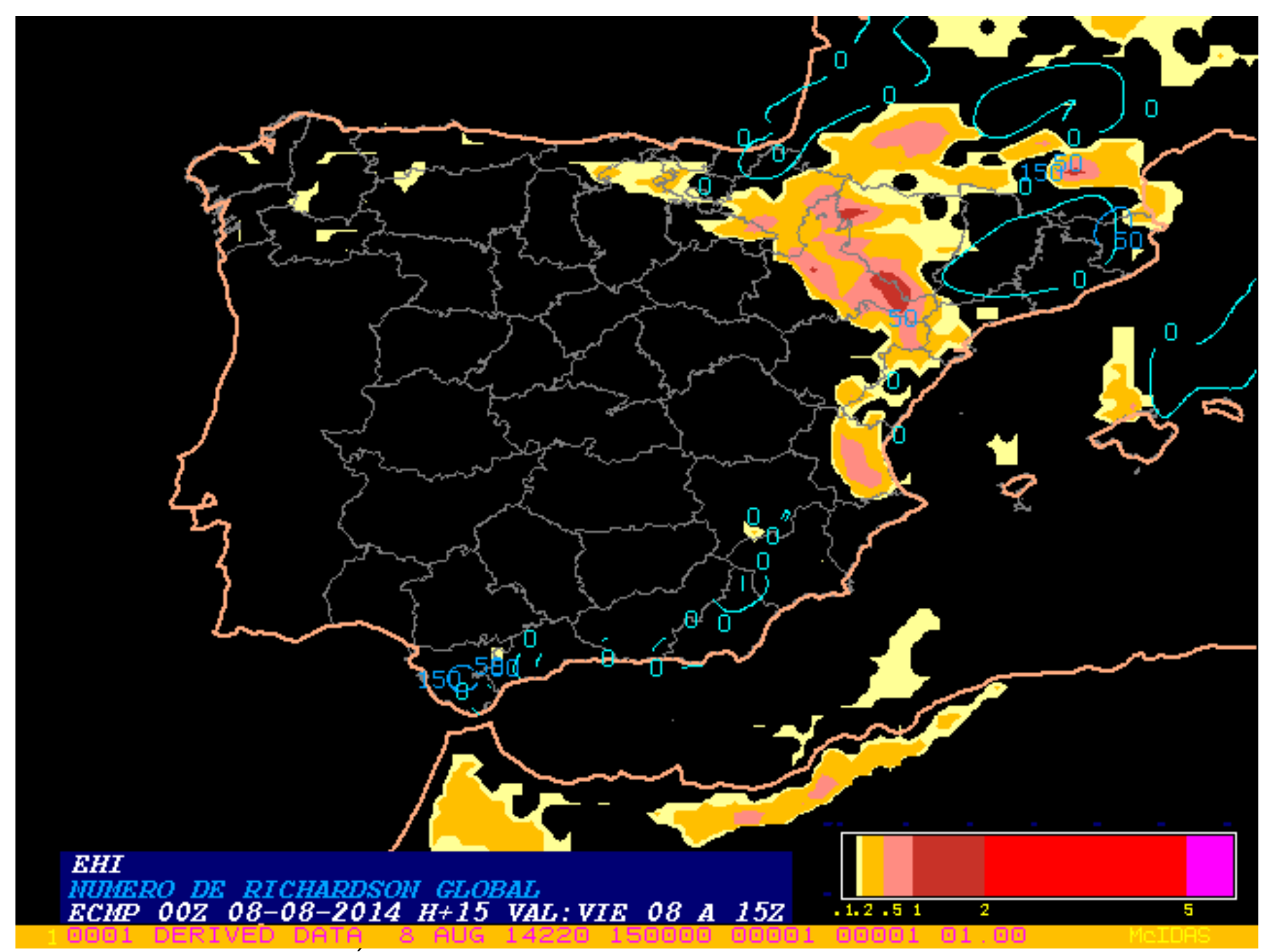

Figura 2.20. Índice Helicidad-Energía (EHI) y Número de Richardson Global (NRG). 


\section{Número de Richardson Global}

Definición: El número de Richardson global (BRN) es una relación entre el empuje hidrostático (medido con la CAPE) y la cizalladura vertical del viento del entorno. La intensidad de las corrientes ascendentes está directamente relacionada con la CAPE, mientras que la estructura de la tormenta (su organización) y su movimiento están relacionados con la cizalladura vertical (figura 2.21).

$$
B R N=\frac{C A P E}{\frac{1}{2}\left(U_{6 k m}-U_{500 m}\right)^{2}}
$$

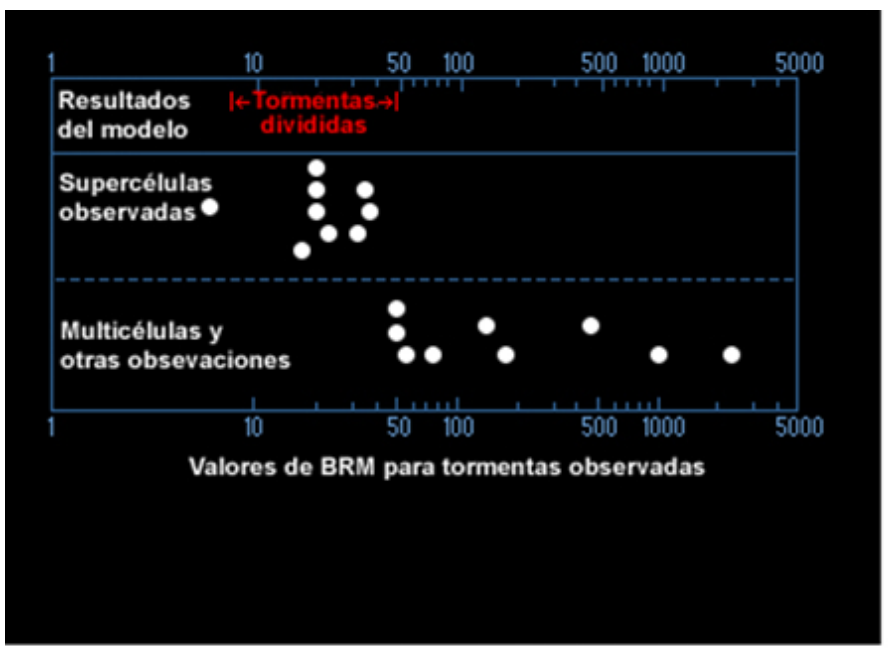

Adaptado de Weisman y Klemp 1982

Figura 2.21. Tipos de tormentas organizadas y valores de BRN. Fuente: COMET

Uso: En la figura 2.22 se muestran los valores de BRN relacionados con el tipo de tormenta. En términos generales, si BRN es inferior a 10, la cizalladura es más intensa que el empuje hidrostático y las tormentas tienden a ser destruidas por la cizalladura. Cuando el BRN se encuentra entre 10 y 35, el balance entre la cizalladura y el empuje vertical tiende a favorecer las supercélulas. Cuando el BRN es mayor a 50, el empuje hidrostático domina sobre la cizalladura y es más probable que se produzcan tormentas aisladas o multicelulares.

En el panel propuesto se representa el BRN contorneado, junto al índice Helicidad-Energía

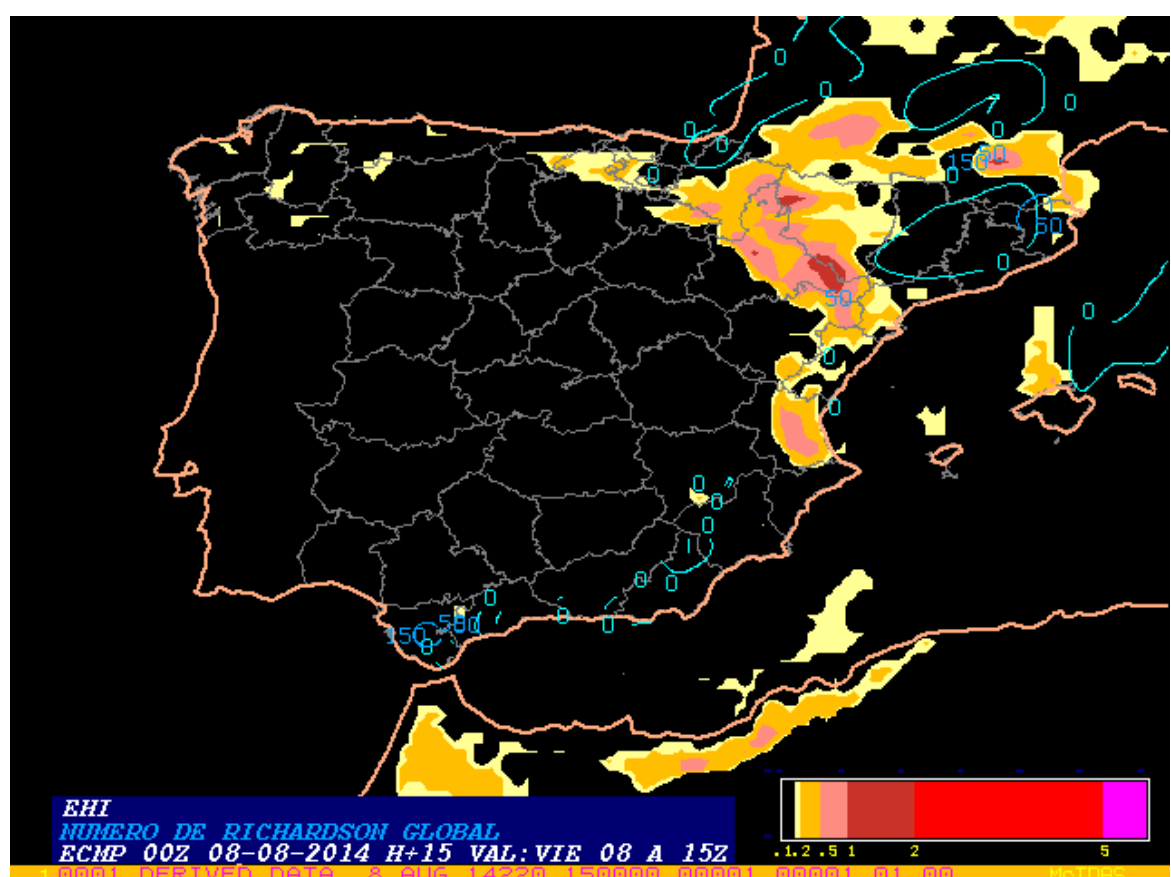

Figura 2.22. Índice de Helicidad-Energía (EHI) y Número de Richardson Global (NRG). 
La Helicidad $(\mathrm{H})$ es el grado en el que el vector velocidad de un fluido está alineado con la vorticidad horizontal de dicho fluido (figura 2.23). En Meteorología se calcula la helicidad respecto del movimiento del fluido (SRH).

$H=\int\left(\vec{V}_{h}\left(\vec{\nabla} \times \vec{V}_{h}\right) d z=\int V_{h} \zeta_{h} d z\right.$

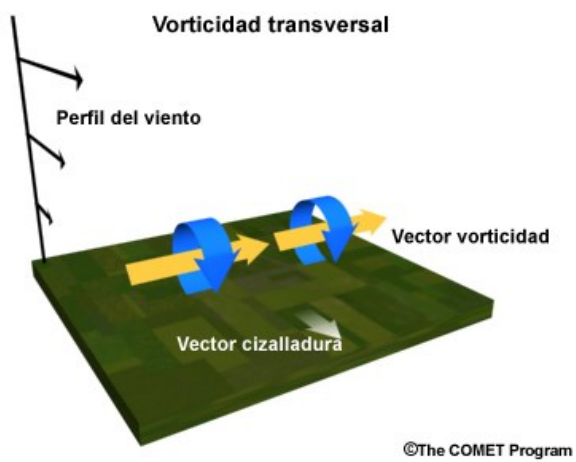

$$
S R H=\int_{z_{1}}^{z_{2}}\left(\vec{V}_{h}-\vec{C}\right)\left(\vec{\nabla} \times V_{h} \overrightarrow{)} d z\right.
$$

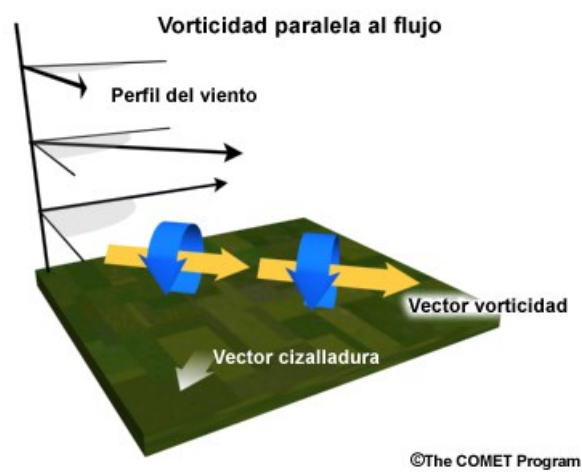

Figura 2.23. Vector vorticidad horizontal en ambientes con cizalladura vertical del viento (Fuente: COMET).

En un ambiente con cizalladura vertical del viento se genera vorticidad horizontal que, como vemos en las figuras, tendrá dos componentes: una normal y otra paralela a la dirección del flujo. La helicidad relativa a la tormenta (SRH) está muy relacionada con la generación del mesociclón característico de las supercélulas. Se admite que valores de SRH superiores a $150 \mathrm{~m}^{2} / \mathrm{s}^{2}$ en ambientes muy inestables favorece su formación. Para mayor información sobre este índice se puede consultar la dirección web http://www.meted.ucar.edu/mesoprim/skew es/helicity.htm

El valor de la $S R H$, aparte del valor de la vorticidad horizontal del fluido, depende del movimiento de la tormenta (C) y del estrato vertical ( $Z$ ) considerado para su cálculo, que debe ser representativo de la capa que teóricamente está alimentado a la supercélula. Estos dos factores constituyen a su vez las dos fuentes principales de error. En la presente aplicación de diagnóstico convectivo hemos considerado tres alternativas distintas para el cálculo de la $S R H$.

\section{- Escenario Clásico (SRH)}

Se supone que las células convectivas se mueven en la dirección del viento medio del estrato inferior de $6 \mathrm{~km}$, girado $30^{\circ}$ hacia la derecha y con una velocidad correspondiente al $75 \%$ del viento medio. Se calcula para los estratos inferiores de 1 y $3 \mathrm{~km}$ y aparece etiquetado en la aplicación web como $S R H 1 \mathrm{~km}$ y SRH $3 \mathrm{~km}$ (figura 2.24).
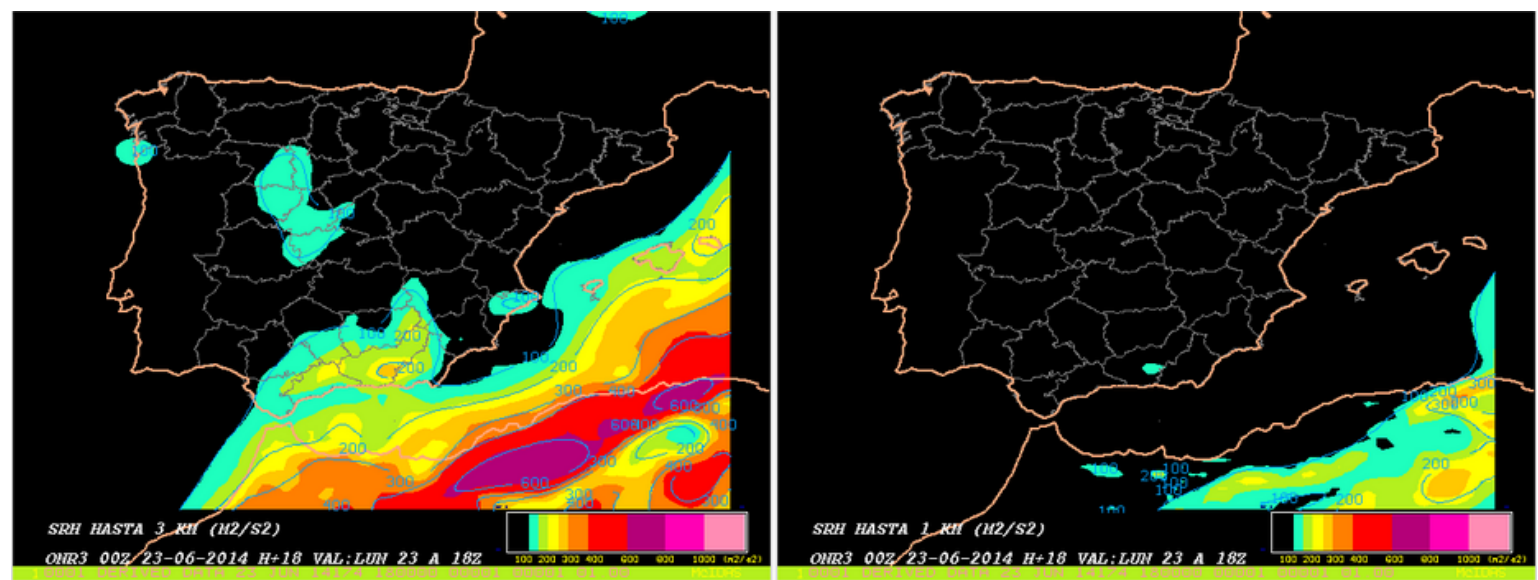

Figura 2.24. Helicidades calculadas según el método clásico $\left(\mathrm{m}^{2} / \mathrm{s}^{2}\right)$. Izquierda: helicidad en la capa de $3 \mathrm{~km}$ junto al suelo, derecha: helicidad en la capa de $1 \mathrm{~km}$ junto al suelo. 
Bunkers et al. en el año 2002 desarrollaron un método (llamado método de la Dinámica Interna) para el cálculo del movimiento de las supercélulas (SC) basado en datos observados. Se trataba de incluir el movimiento anómalo observado de algunas SC que lo hacían hacia la izquierda del viento medio en vez de a la derecha como la mayoría. Se concluyó que el movimiento de las SC era el resultado de la interacción de la propia dinámica interna de la SC con el ambiente. El movimiento de las células que se movían a derecha (VRM) e izquierda (VLM) del viento medio que mejor se ajustaban a los valores observados era el que muestra la figura 2.25: sobre la hodógrafa tomar dos puntos a $7.5 \mathrm{~m} / \mathrm{s}$ del viento medio (VMean) del estrato inferior de $6 \mathrm{~km}$ sobre una línea perpendicular al vector cizalladura del estrato inferior de $6 \mathrm{~km}$. Para más información sobre el Método de la Dinámica Interna se puede consultar el trabajo original 'Predicting Supercell Motion Using A New Hodograph Technique (Bunkers, 2002)

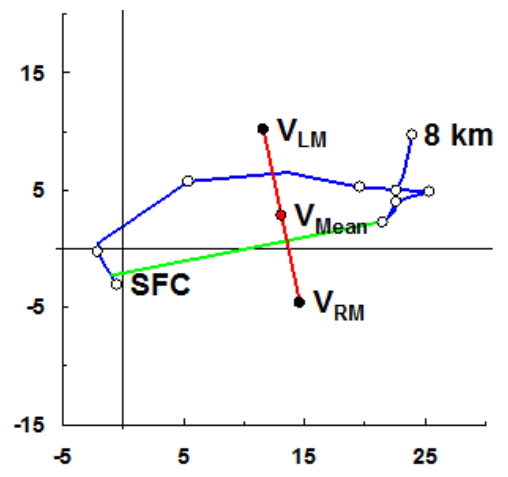

Figura 2.25. Movimiento según Bunkers (Fuente: COMET).

En la ventana propuesta para "SRH Bunkers 1 y $3 \mathrm{~km}$ ", se presenta la helicidad relativa a la tormenta calculada por el método de Bunkers, para las células que se mueven a derecha e izquierda del viento medio, en los estratos inferiores de $1 \mathrm{~km}$ y $3 \mathrm{~km}$. Se representan junto con el vector velocidad $(\mathrm{m} / \mathrm{s})$ de las células convectivas que se mueven a derecha (VRM) y a izquierda (VLM), respectivamente (figura 3.26).

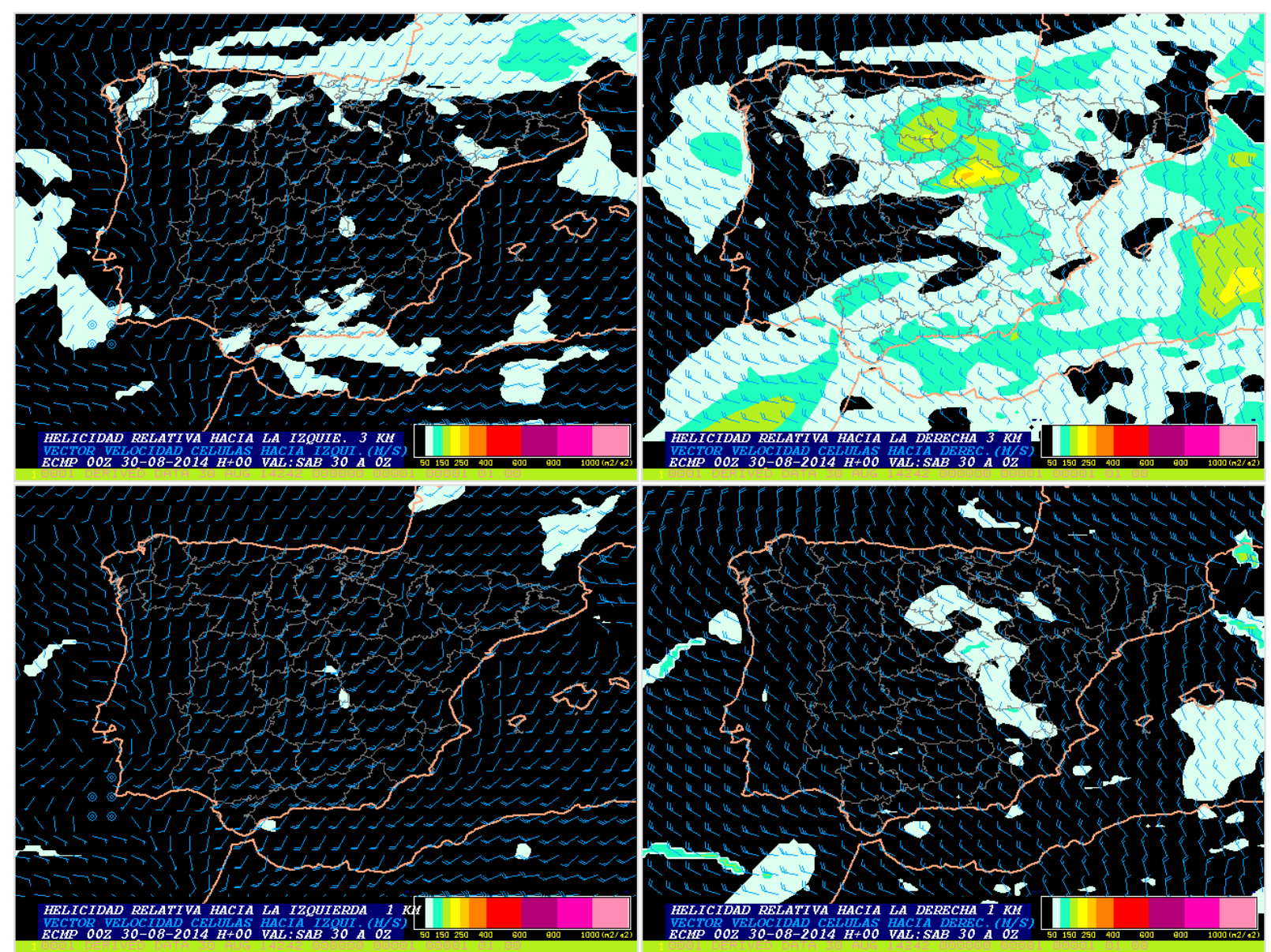

Figura 2.26. SRH calculada por el método de Bunkers $\left(\mathrm{m}^{2} / \mathrm{s}^{2}\right)$. Arriba izquierda: SRH en la capa de $3 \mathrm{~km}$ sobre el suelo junto con el vector velocidad $(\mathrm{m} / \mathrm{s})$ de las células convectivas que se mueven a la izquierda del viento medio, arriba derecha: $S R H$ en la capa de 3 $\mathrm{km}$ sobre el suelo junto con el vector velocidad $(\mathrm{m} / \mathrm{s})$ de las células convectivas que se mueven a la derecha del viento medio, abajo izquierda: SRH en la capa de $1 \mathrm{~km}$ sobre el suelo junto con el vector velocidad ( $\mathrm{m} / \mathrm{s}$ ) de las células convectivas que se mueven a la izquierda del viento medio, abajo derecha: SRH en la capa de $1 \mathrm{~km}$ sobre el suelo junto con el vector velocidad ( $\mathrm{m} / \mathrm{s})$ de las células convectivas que se mueven a la derecha del viento medio. 


\section{- Cálculo de la Helicidad en la Capa Efectiva}

La introducción del método de la Dinámica Interna supuso una mejora en el cálculo de SRH al mejorar el movimiento estimado de las supercélulas. Con la inclusión del concepto de Capa Efectiva se trata de delimitar el estrato (identificando su base y tope) en el que es más probable que las SC se estén alimentando, y no limitarlo a los estratos inferiores de $1 \mathrm{~km}$ y $3 \mathrm{~km}$ que si bien pueden tener algún fundamento son un tanto arbitrarios.

La idea es que no todas las parcelas están en condiciones de formar parte del flujo que alimenta una supercélula. Aquellas parcelas que tienen asociado un alto CIN (Energía de Inhibición Convectiva), o que teniendo un bajo CIN desarrollen poco CAPE, difícilmente van a formar parte de flujo que alimenta una SC. Tan sólo aquellas con una combinación adecuada de CIN y CAPE lograrán formar parte del flujo alimentador. Esta combinación fue determinada por Richard L. Thompson en el trabajo 'Efective Storm-Relative Helicity in Supercell Thunderstorm Environments (Richard L. Thompson, Roger Edwards, and Corey M. Mead, 2004)'.

En la ventana propuesta se presenta la SRH calculada por el método de Bunkers pero en el estrato definido por la capa efectiva, junto al vector velocidad de las células tormentosas que se mueven a derecha e izquierda (VRM $y$ $V L M$ ), la base y el espesor de la capa efectiva (figura 2.27). Aparece etiquetado como 'SRH Capa Efectiva'.
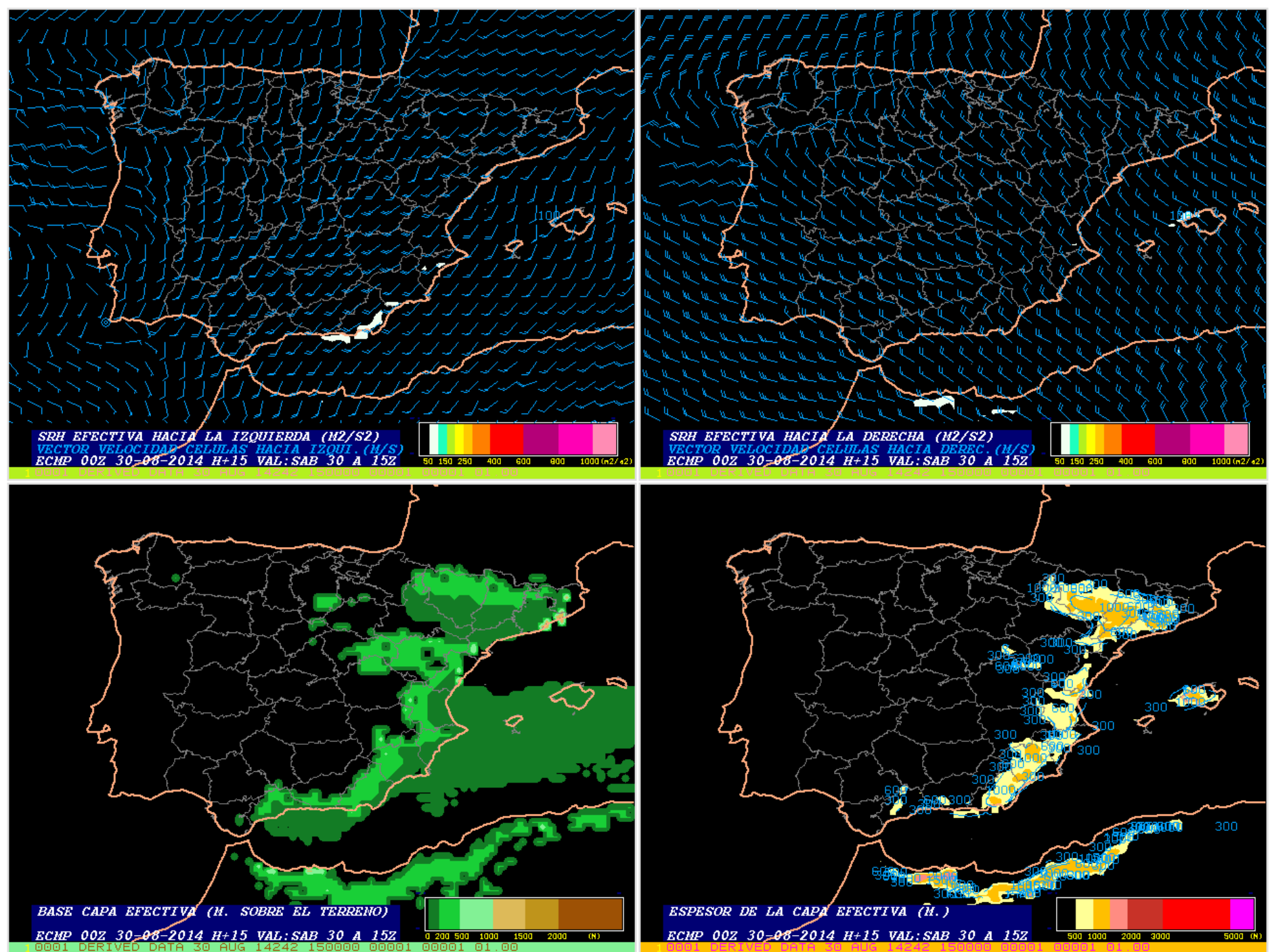

Figura 2.27. SRH calculada en la capa efectiva $\left(\mathrm{m}^{2} / \mathrm{s}^{2}\right)$. Arriba izquierda: $S R H$ junto con el vector velocidad $(\mathrm{m} / \mathrm{s})$ de las células convectivas que se mueven a la izquierda, arriba derecha: $S R H$ junto con el vector velocidad $(\mathrm{m} / \mathrm{s})$ de las células convectivas que se mueven a la derecha, abajo izquierda: base de la capa efectiva sobre el terreno $(m)$, abajo derecha: espesor de la capa efectiva ( $m$ ). 


\section{Lightning Potential Index (LPI)}

Definición: Es un índice desarrollado por la NOAA. Distingue zonas favorables a la generación de descargas eléctricas.

Se define como:

$$
L P I=(A+B)\left(T_{850}-272\right) \quad \text { (limitado entre } 0 \text { y 20000) }
$$

- $A=-R H^{2}\left(\frac{\partial \theta_{e}}{\partial z}\right)_{600 h P a}^{2}(\min (L I, 0))^{2}$

- $B=0.001 * M U C A P E * P W^{*} R H$

donde intervienen la humedad relativa, el gradiente vertical de temperatura potencial equivalente en $600 \mathrm{hPa}$, el índice $\mathrm{LI}$, el agua precipitable (PW), y el CAPE de la parcela más inestable (muCAPE) en los 3000 metros inferiores junto al suelo.

Uso: Se muestra la intensidad "posible o potencial" de actividad eléctrica (número de rayos en unidad de área y tiempo), según varios intervalos del índice LPI: débil, moderada y alta (figura 2.28).

- Débil

$2500<=\mathrm{LPI}<5000$

- Moderada

$5000<=\mathrm{LPI}<9000$

- Alta

$\mathrm{LP} \mid>=9000$

Nota: en algunos casos con $\mathrm{LPI}<=2500$ también puede haber rayos, pero en general "pocos".

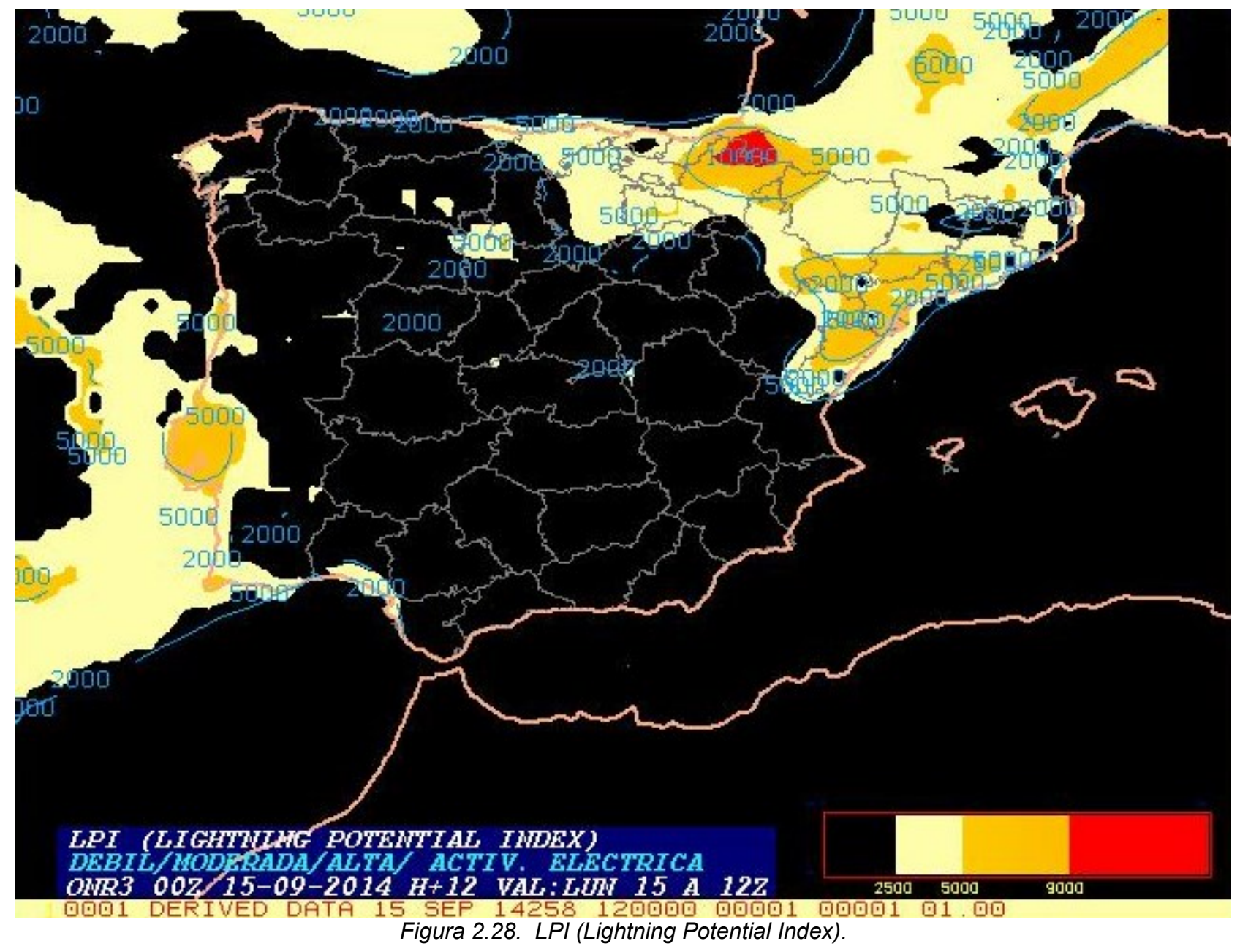


Justificación básica: El algoritmo empírico indica que en general en las situaciones de granizo grande existe un entorno favorable a convección profunda con valores muy destacables de SBCAPE, con alturas de la isocero del termómetro húmedo (ISOH) respecto al suelo que no sean ni muy grandes ni muy pequeñas (figura 2.29). El ajuste se ha realizado a partir de una muestra de varias situaciones históricas de granizo grande.

Es importante recalcar que en este producto se tiene en cuenta sólo el granizo de diámetro superior a $2 \mathrm{~cm}$. Por tanto no se considera aquí el granizo pequeño aunque pueda acumularse en un espesor considerable junto al suelo.

\section{Regla Granizo Grande ( $>2 \mathrm{~cm}$ )}

\begin{tabular}{|c|c|c|c|c|c|c|}
\hline $\begin{array}{l}\text { Ligeramente favorable } \\
\text { - } \quad \text { (SBCAPE >=700 } \\
\text { (SBCAPE >=2000 } \\
\text { Favorable }\end{array}$ & $\begin{array}{l}y \\
y\end{array}$ & $\begin{array}{l}\mathrm{CIN}<=200) \\
\mathrm{CIN}<=200)\end{array}$ & $\begin{array}{l}y \\
y\end{array}$ & $\begin{array}{l}\text { PPCO_3H >= } \\
\text { PPCO_3H >= }\end{array}$ & $\begin{array}{l}\mathrm{y} \\
\mathrm{y}\end{array}$ & $\begin{array}{l}2000<=I S O H<=3000 \\
3000<=I S O H<=3800\end{array}$ \\
\hline $\begin{array}{l}\text { (SBCAPE >=1000 } \\
\text { Muy Favorable }\end{array}$ & $y$ & $\mathrm{CIN}<=200)$ & $y$ & PPCO_3H >= 1 & $y$ & $2000<=\mid \mathrm{ISOH}<=3000$ \\
\hline (SBCAPE > $=1500$ & $y$ & $\mathrm{CIN}<=200)$ & $y$ & PPCO $3 \mathrm{H}>=1$ & $y$ & $2400<=\mid \mathrm{SOH}<=3000$ \\
\hline
\end{tabular}

Inconvenientes: La regla se fundamenta casi únicamente en la existencia de SBCAPE con valores significativos y la elevación de la isocero.

Como se ha comentado, la herramienta ha sido calibrada sólo para pedrisco (granizo grande, de tamaño al menos de $2 \mathrm{~cm}$ de diámetro), por lo que no es el objetivo de este producto detectar granizo pequeño aunque sea intenso, que con cierta frecuencia se genera durante el invierno o finales del otoño en determinadas zonas, pudiendo acumularse en un espesor considerable sobre el terreno.

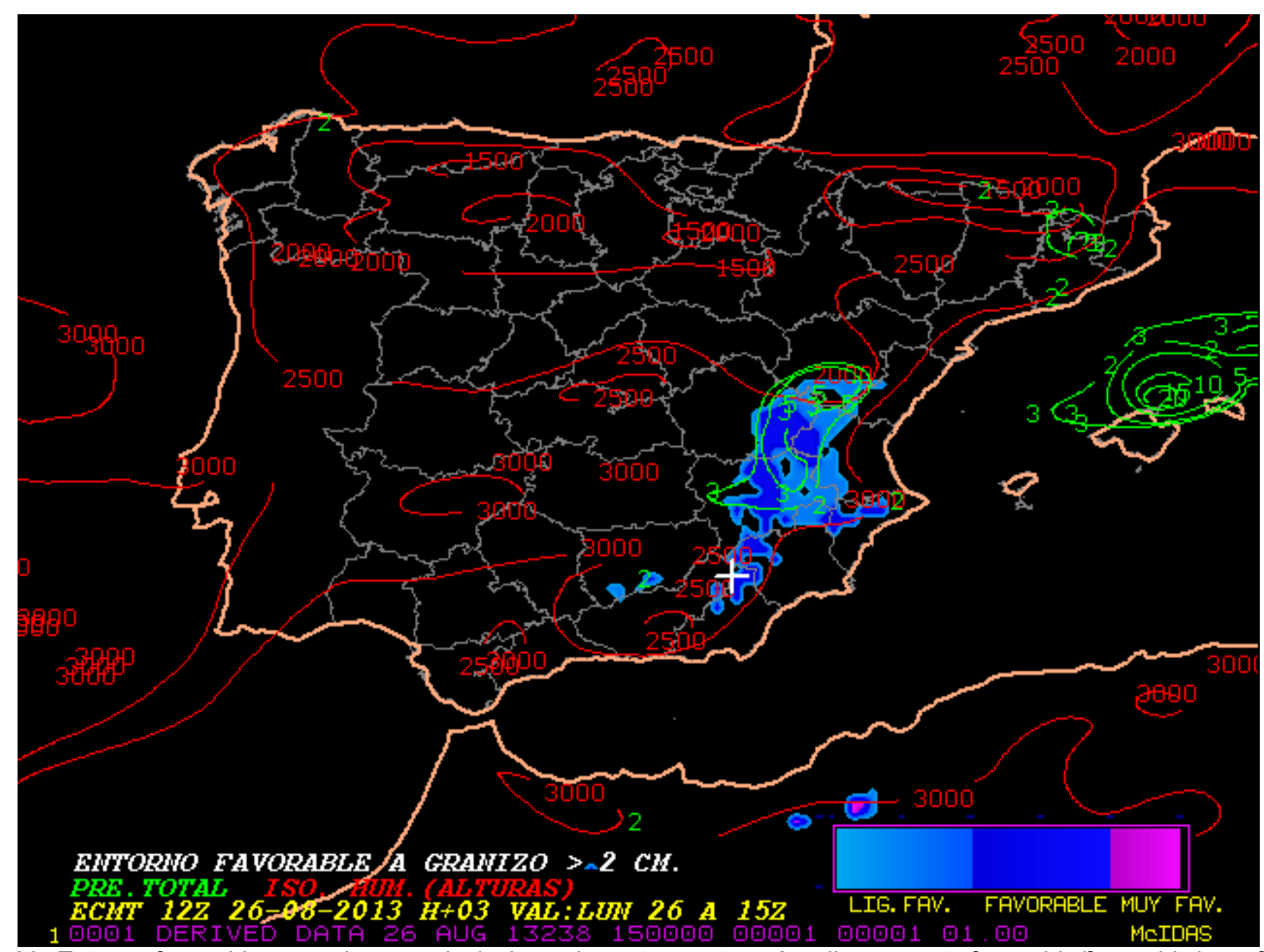

Figura 2.29. Entorno favorable a granizo grande (coloreado en tres categorías: ligeramente favorable/favorable/muy favorable) el 6 de agosto de 2013 a 18 UTC. 


\section{Universal Tornado Index (UTI)}

Definición: El objetivo del índice UTI es pronosticar entornos favorables para tornados "débiles" no mesociclónicos o para tornados mesociclónicos intensos (figura 2.30).

$$
\left.\mathrm{UTI}=\left(\left(\mathrm{CAPE} * \mathrm{SRH}_{0-1 \mathrm{~km}} *\left(5\left(\mathrm{ClZ}_{0-6 \mathrm{~km}}-20\right)+(2000-\mathrm{LCL}) / 10\right)\right)+\mathrm{CAPE}_{3 \mathrm{~km}}+\mathrm{SRH}_{1 \mathrm{~km}} / 4\right) / 1000\right) *\left(\mathrm{ClZ}_{0-6} \mathrm{~km} / 12\right) *\left(q_{0-500} / 10\right)
$$

donde,

- Si $\mathrm{SRH}_{0-1 \mathrm{~km}}<0 \quad \mathrm{~m} 2 / \mathrm{s} 2$, entonces $\mathrm{SRH}_{0-1 \mathrm{~km}}=0$

- $\quad$ Si LCL > $1500 \mathrm{~m}$, entonces UTI =0

- $\quad$ Si CAPE $=0$, entonces UTI =0

Uso: Se ha probado en Europa Central con buenos resultados, siendo válido tanto para la época fría como para la cálida. Deben evaluarse los valores para España, aunque inicialmente se podrían "adpotar" los siguientes umbrales:

- UTI $<0.3$

- UTI entre 0.3 y 0.5

- UTI entre 0.5 y 0.75

- UTI >0.75 (bajo riesgo de tornados)

(riesgo moderado de tornados)

(riesgo alto de tornados)

(riesgo muy alto de tornados)

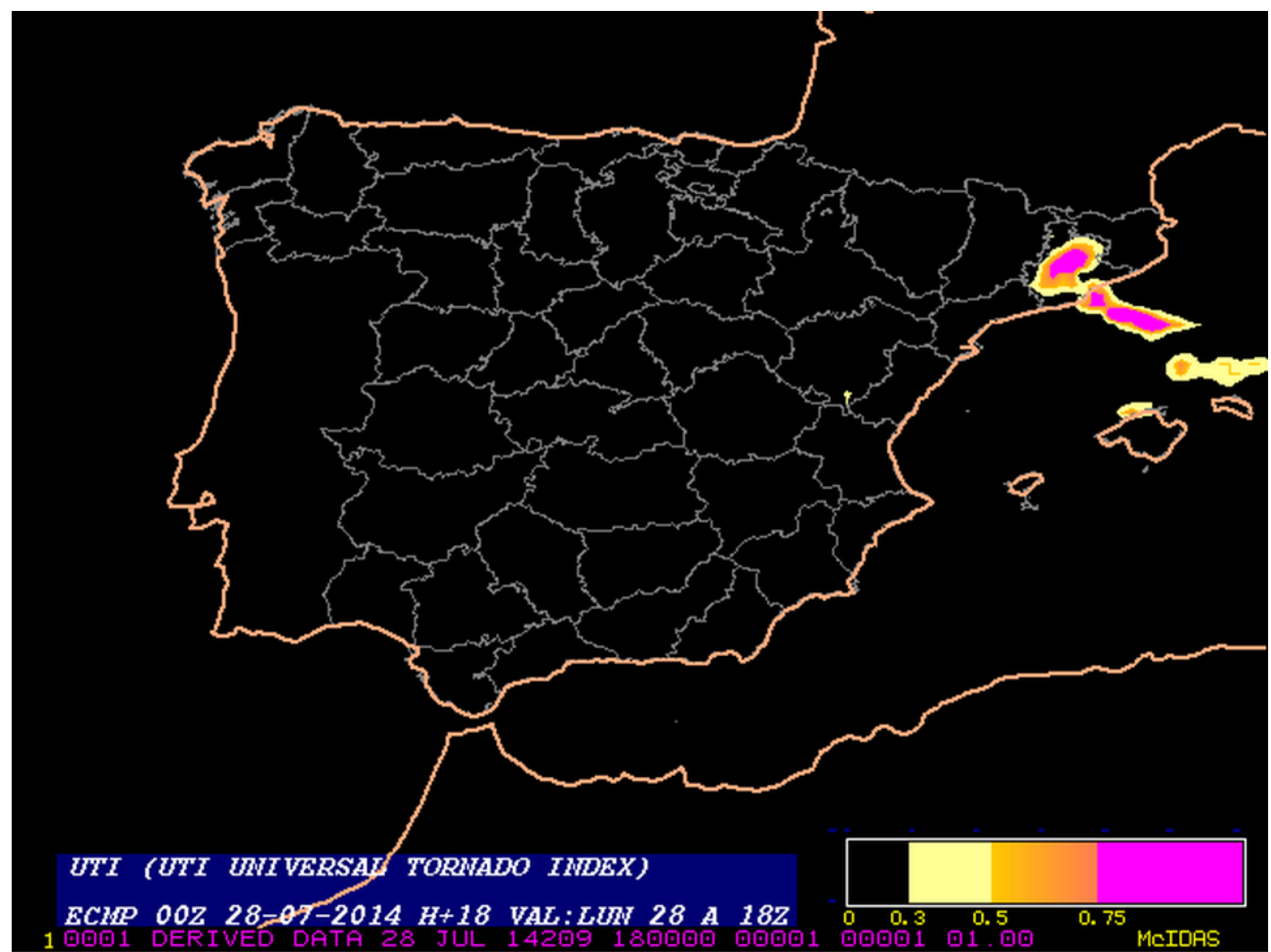

Figura 2.30. UTI (Universal Tornado Index). 


\section{Significant Tornado Parameter (STP)}

Definición: El índice STP (figura 2.31) sólo sirve para pronosticar entornos favorables a tornados significativos (o sea EF2 o de categorías superiores). Su expresión es:

$$
\mathrm{STP}=\left(\mathrm{ClZ}_{0-6 \mathrm{~km}} / 20\right) *\left(\mathrm{SRH}_{0-1 \mathrm{~km}} / 100\right) *(\mathrm{SBCAPE} / 1500) *\left(\left(2000-\mathrm{LCL}_{\mathrm{sB}}\right) / 1500\right) *((100+\mathrm{SBCIN}) / 150)
$$

donde,

\begin{tabular}{|c|c|}
\hline $\begin{array}{l}\text { - } \quad \text { LCLSB } \\
\text { - } \quad \text { CICIN } \\
\text { CIZ-6 km }\end{array}$ & $\begin{array}{l}=1 \\
=1 \\
=1.5\end{array}$ \\
\hline
\end{tabular}

Uso: Este índice se usa operativamente en Estados Unidos, donde abundan tornados significativos (EF2 o superiores). En cambio en España la inmensa mayoría de los tornados son no mesociclónicos, y de categoría EF0 ó EF1. Por tanto la utilidad de este índice debe ser validada para España. De momento se puede empezar con las siguientes referencias aproximadas.

- $\quad$ STP $>1$ para la mayoría de tornados significativos (EF2 o superiores)

- $\quad$ STP $<1$ para los tornados no supercelulares

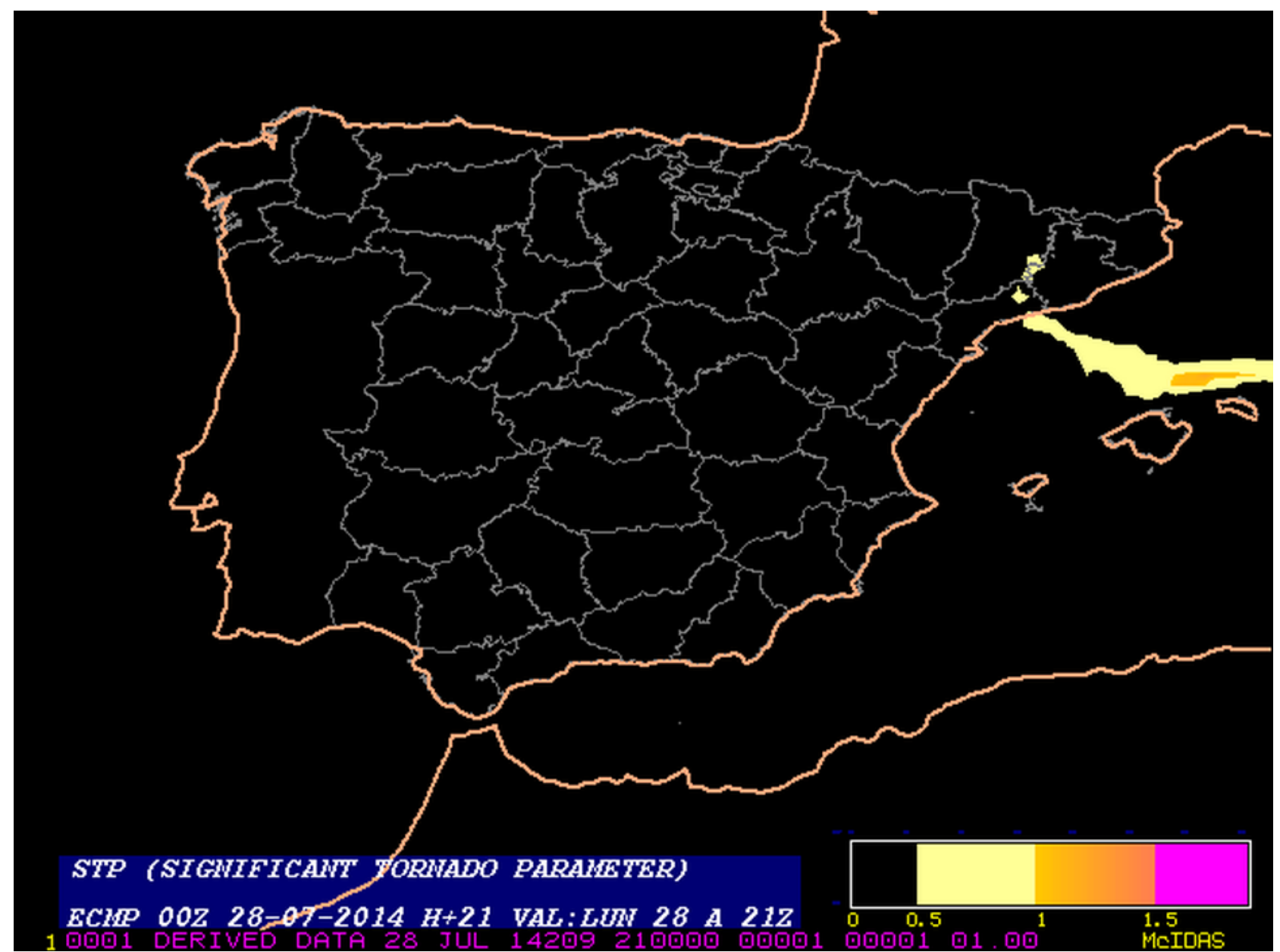

Figura 2.31. STP (Significant Tornado Parameter). 
Justificación básica: En España los tornados suelen débiles (tipo EF0 ó EF1). Se presentan básicamente con inestabilidad al menos "débil", e importantes valores de cizalladura y helicidad relativa a la tormenta en los primeros 3 kilómetros. Los hay fundamentalmente de tres variedades principales: tipo landspout o waterspout (por estiramiento vertical convectivo de vórtices preexistentes en capas bajas debido fundamentalmente a zonas fronteras o discontinuidades en superficie), los asociados a convección somera invernal y de gran cizalladura en un ambiente en general también favorable a minisupercélulas, y los que se generan en entornos de convección profunda organizada en primavera-verano en interior peninsular o bien en otoño o finales de verano en zonas Mediterráneas. En la siguiente tabla se presentan los valores empíricos de los umbrales de algunos parámetros clave encontrados en una muestra de diversas situaciones de tornado. No obstante a veces surgen tornados con valores fuera de los intervalos generales, especialmente en caso de tornados débiles cuyo entorno local reducido no es bien representado por los modelos. Por ello se debe superponer el índice EHI, y se introduce una "precategoría" de posibilidad (zona a estudiar por si acaso...), tal y como aparece en la figura 2.32 .

\section{Regla Tornados}

\section{Posibilidad}

- $|\mathrm{EHI}|>=0,2$

Ligeramente favorable

- $(\mathrm{LI}<=1$ ó LI7 <= 1) y CAPE $>0$ y $\mathrm{CIN}<=100$ y $\operatorname{SBCAPE~}>=80$ y $\mathrm{CIZ3}>=12$ y $|\mathrm{SRH} 3|>=180$

Favorable

- $(\mathrm{LI}<=1$ ó $\mathrm{LI} 7<=1)$ y $\mathrm{CAPE}>0$ y $\mathrm{CIN}<=100$ y $\mathrm{SBCAPE}>=150$ y $\mathrm{CIZ3}>=18$ y $|\mathrm{SRH} 3|>=180$

- $(L I<=1$ ó $L I 7<=1)$ y CAPE $>0$ y $C I N<=100$ y SBCAPE $>=150$ y $C I Z 3>=12$ y $|S R H 3|>=300$

- $(\mathrm{LI}<=1$ ó $\mathrm{LI} 7<=1)$ y $\mathrm{CAPE}>0$ y $\mathrm{CIN}<=100$ y $\operatorname{SBCAPE}>=80$ y $\mathrm{CIZ3}>=18$ y $|\mathrm{SRH} 3|>=300$

Muy Favorable

- $(\mathrm{LI}<=1$ ó $\mathrm{LI} 7<=1)$ y CAPE $>0$ y $\mathrm{CIN}<=100$ y SBCAPE $>=300$ y $\mathrm{CIZ3}>=21$ y $|\mathrm{SRH} 3|>=400$

Inconvenientes: Es difícil establecer en España una caracterización de entornos meteorológicos favorables a tornados, sobre todo teniendo en cuenta que la mayoría son "débiles" en comparación a los tornados significativos (EF2 o superiores) que son los estudiados en la mayor parte de las referencias bibliográficas internacionales. Por tanto esta estimación de entornos potencialmente favorables a la posible generación de tornados debe entenderse como un producto intento de aproximación que debe ser usado con precaución y en combinación con otros. Aparte existen trombas marinas que aparecen con cierta frecuencia en el litoral Mediterráneo que son "bastante débiles" y de muy corta duración y anchura, cuya predicción es harto complicada (a veces sin tormenta). También puede ocurrir que en algunos casos las condiciones mesoescalares favorables para la aparición de tornados no sean duraderas, y queden entre dos periodos de predicción de presentación de información del modelo (3 horas). No se les debe prestar demasiada atención a señales aisladas que no presentan una continuidad espacio-temporal en su evolución. Además en algunos casos podría haber sobreestimación del riesgo al usar este producto, especialmente en zonas frontales con convección embebida. No se debe hacer caso a señales en zonas reducidas y sin continuidad espacio-temporal.

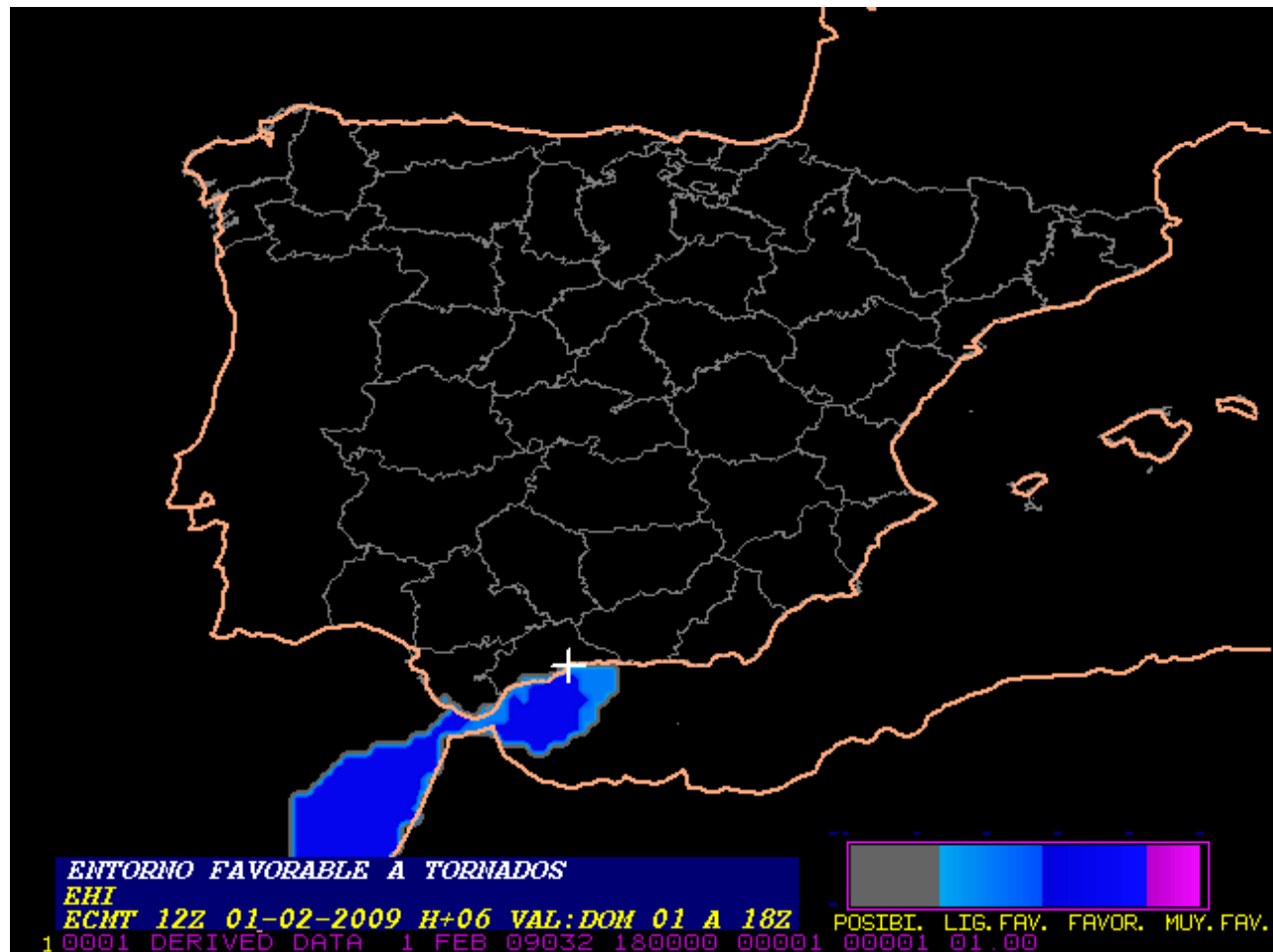

Figura 2.32. Entorno "tornádico" (coloreado en tres categorías: ligeramente favorable/favorable/muy favorable) el 1 de febrero de 2009 a 18 UTC 
Definición: Índice usado en Estados Unidos para diagnosticar entornos favorables para que se desarrollen supercélulas (figura 2.33).

Su expresión es:

$$
\mathrm{SCP}=(\operatorname{MUCAPE} / 1000 \mathrm{~J} / \mathrm{kg}) *\left(\mathrm{SRH}_{0-3} \mathrm{~km} / 100 \mathrm{~m}^{2} / \mathrm{s}^{2}\right) *\left(\mathrm{ClZ}_{0-6} \mathrm{~km} / 40 \mathrm{~m}^{2} / \mathrm{s}^{2}\right)
$$

Uso: Hay que comprobar cómo se comporta este índice para las supercélulas en España. En principio se podrían tener en cuenta estos umbrales y afinar en el futuro.

- $\mathrm{SCP}>4$

- $\quad$ SCP entre 1 y 4

- $\mathrm{SCP}<1$ entorno muy favorable para supercélulas

entorno favorable para supercélulas

entorno no favorable para supercélulas (menos favorable cuanto más pequeño sea)

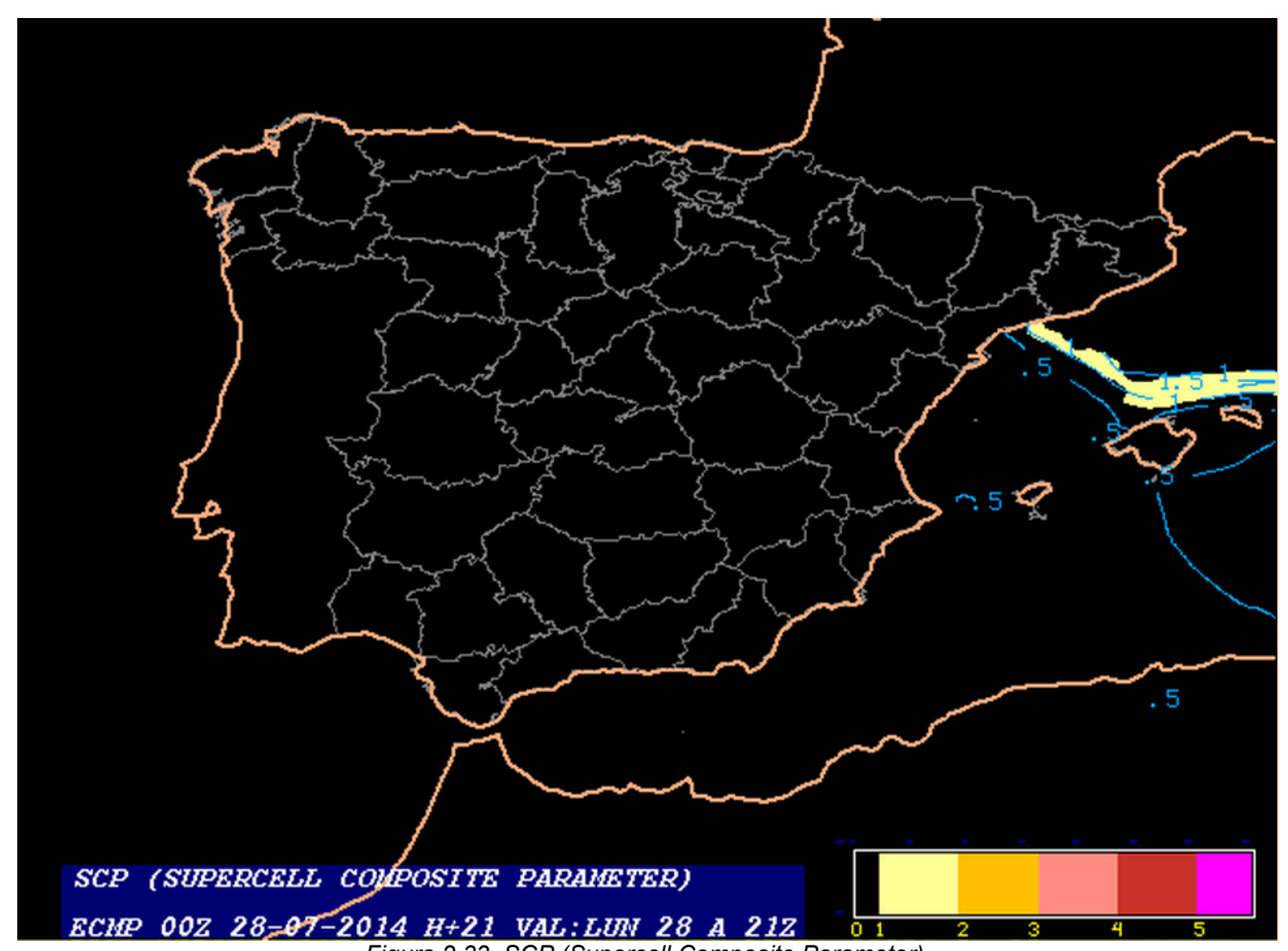

Figura 2.33. SCP (Supercell Composite Parameter). 


\section{Entornos favorables a supercélulas (PEFMA)}

Justificación básica: En España el desarrollo supercelular se presenta en entornos con combinaciones de parámetros clave (SBCAPE, ClZ6 y SRH3) que superan ciertos valores umbrales, en general no tan elevados como los típicos de las clásicas supercélulas de las Llanuras de Estados Unidos. A veces no hay valores previstos demasiado elevados de $\mathrm{SRH} 3$, y esto es así porque existen mecanismos que generan un incremento importante de helicidad relativa a la tormenta a una escala que no es bien simulada por los modelos (por ejemplo en zonas frontera y splitting storms). Hay también que tener en cuenta que en algunos casos se observan minisupercélulas (low topped supercells), en las que el desarrollo vertical no es demasiado profundo. Por último en ocasiones estas variables fundamentales pueden no ser bien simuladas por los modelos en determinados ámbitos reducidos, pudiendo aparecer supercélulas con valores por debajo de los umbrales de referencia. Es por ello interesante en cualquier caso superponer el índice de Helicidad-Energía a este campo. Además se ha introducido una categoría inicial de posibilidad que indica zonas a estudiar por si acaso (figura 2.34).

\section{Regla Supercélulas}

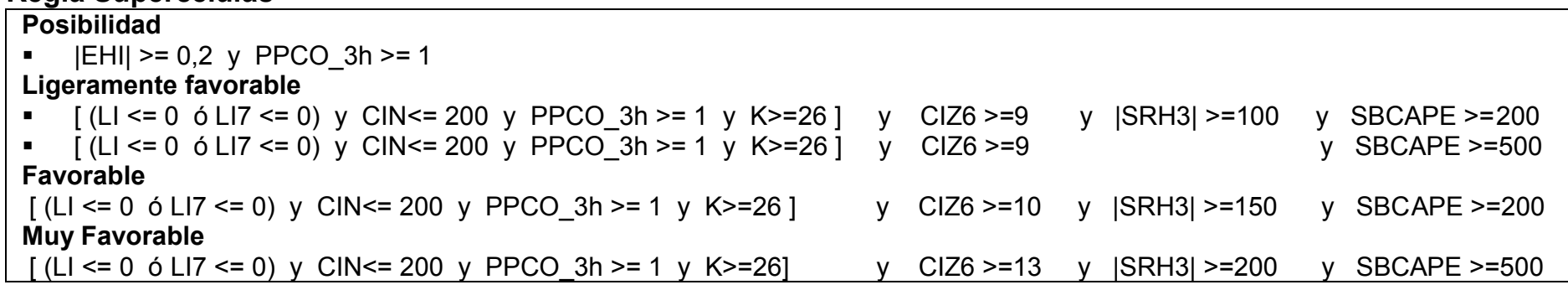

Inconvenientes: Los umbrales deben ser entendidos como aproximaciones preliminares de referencia orientativa. A veces pueden surgir algunas señales muy localizadas y sin continuidad espacio-temporal, a las cuales en general no debería prestárseles demasiada importancia. También hay que tener en cuenta que los ciclos de vida de muchas supercélulas en España pueden quedar entre dos periodos de predicción de presentación de información del modelo (3 horas), aparte de tener una escala espacial limitada. Por ello esta herramienta sólo se puede entender como indicadora de entornos mesoescalares potencialmente favorables al desarrollo supercelular, y debe usarse con gran precaución y siempre en combinación de otros índices y herramientas de diagnóstico. Por supuesto hay que tener presente que aunque una zona sea favorable no implica necesariamente que se vaya a producir en ella alguna supercélula.

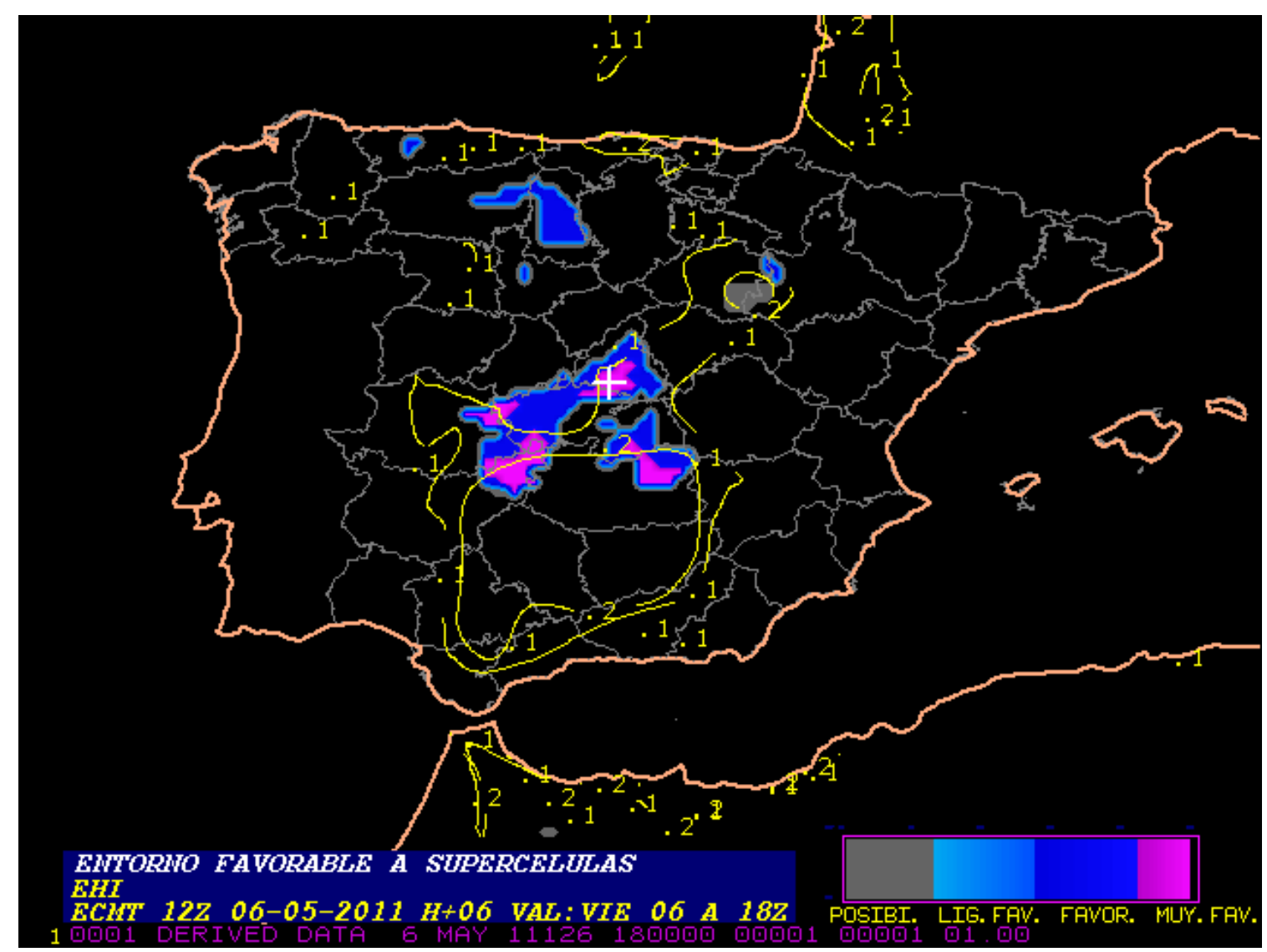

Figura 2.34. Entorno supercelular (coloreado según categorías) el 6 de mayo de 2011 a 18 UTC. 
Definición: Es una estimación de la hipotética máxima racha en superficie, proporcionada por la expresión que se muestra abajo y que es el resultado de una investigación directa sobre 'microbursts' realizada por la US Air Force.

$$
\text { WINDEX }=5 \sqrt{H_{M} R_{Q}\left(\Gamma^{2}-30+Q_{L}-2 Q_{M}\right)} \quad(\mathrm{Kt}), \quad \text { donde }
$$

- $H_{M}$ es la altura del nivel de la isocero (punto de fusión).

- $R_{Q}=Q_{L} / 12$ (pero sin superar el valor de 1 ).

- $Q_{L}$ es la proporción media de mezcla en el primer $\mathrm{km}$ (en $\mathrm{g} / \mathrm{kg}$ ).

- $Q_{\mathrm{M}}$ es la proporción de mezcla en la isocero.

- $\Gamma$ es el gradiente térmico vertical desde la isocero hasta superficie $\left(\mathrm{en}^{\circ} \mathrm{C} / \mathrm{km}\right)$.

Uso: En la ventana propuesta (figura 2.35) se representa la racha máxima esperada (en $\mathrm{km} / \mathrm{h}$ ) de forma coloreada a partir del valor de $70 \mathrm{~km} / \mathrm{h}$. Debe entenderse como un valor aproximado de la máxima e hipotética racha convectiva esperada.

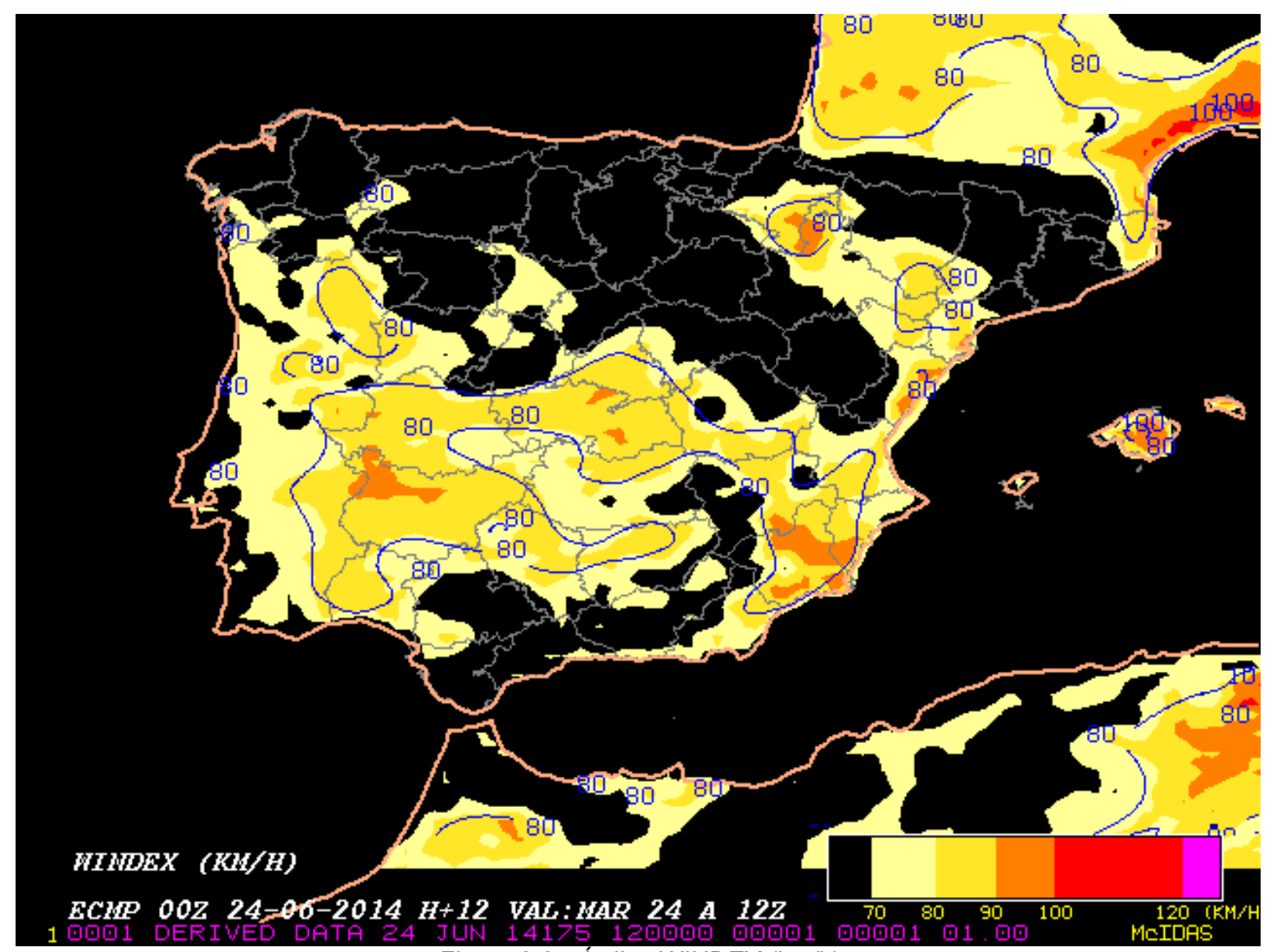

Figura 2.35. Indice WINDEX $(\mathrm{km} / \mathrm{h})$ 
Definición: EI DCAPE es la energía potencia disponible en los descensos y su raíz cuadrada se aproxima a la racha máxima en superficie.

\section{Expresión:}

$$
D C A P E=g \int_{z s f c}^{z_{n}} \frac{\bar{\theta}(z)-\theta(z)}{\bar{\theta}(z)} d z
$$

donde,

- La integral se extiende desde superficie hasta el nivel Zn ó "Free Sink" (LFS), que es aproximadamente la altitud en la que la temperatura del termómetro húmedo es cero.

- $\bar{\theta}(z)$ es la temperatura potencial del ambiente y

- $\theta(z)$ es la temperatura potencial saturante de la parcela descendente

Uso: En la ventana propuesta (figura 2.36) se muestra el valor de DCAPE. Valores superiores a 500 son significativos, y los superiores a $1000 \mathrm{~J} / \mathrm{Kg}$ son muy significativos.

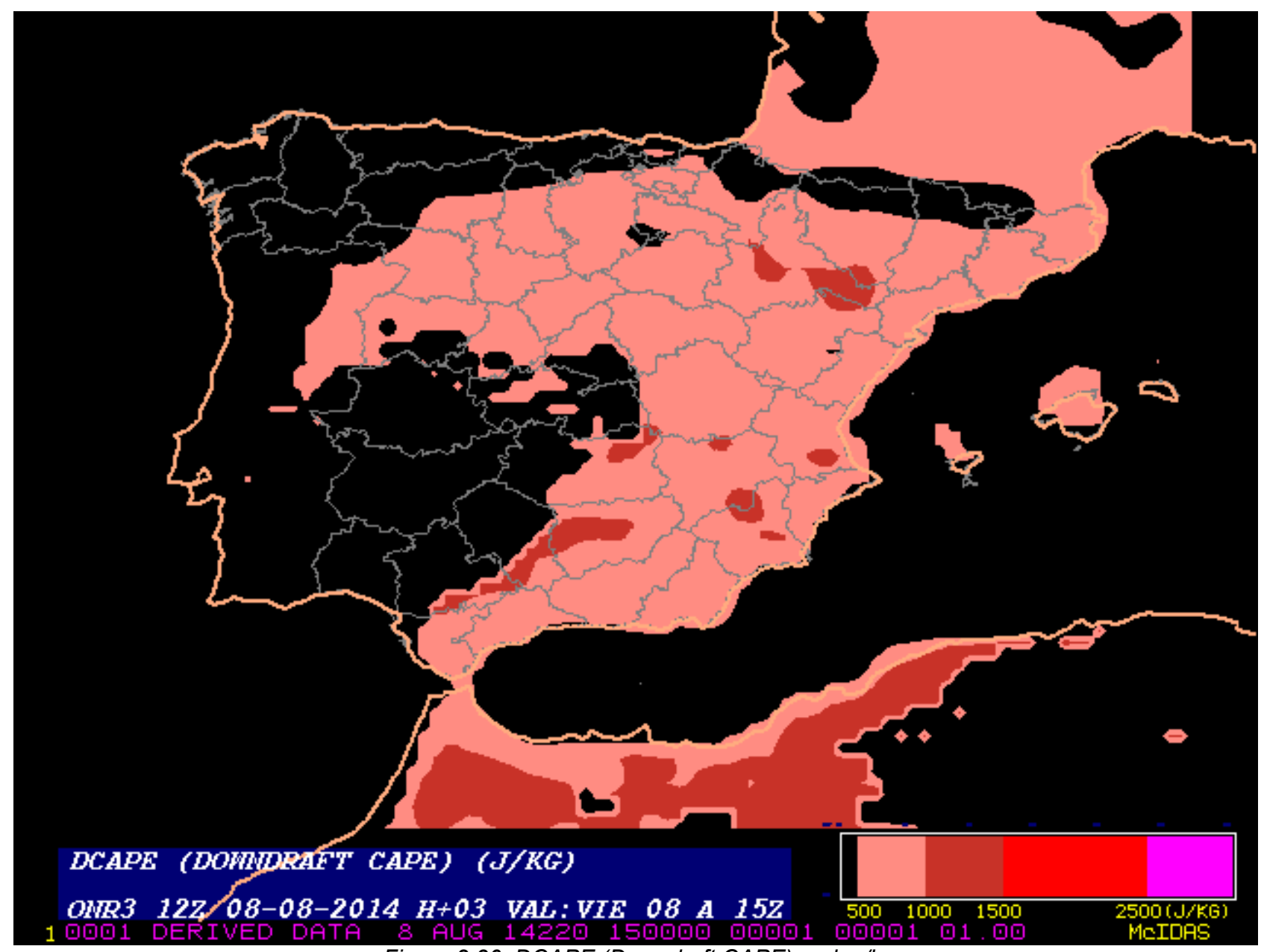

Figura 2.36. DCAPE (Downdraft CAPE) en $\mathrm{km} / \mathrm{h}$. 


\section{GUSTEX}

Definición: Es un índice relacionado con la racha convectiva máxima esperada.

$$
\mathrm{GU}=\mathrm{a} W \mathrm{WI}+0.5 \mathrm{U}_{500}
$$

donde,

- U500: modulo del viento medio en $500 \mathrm{hPa}(\mathrm{kt})$

- WI: WINDEX (Kt),

- a: constante, $0<a<1$

El factor 0.5 sale de la conservación del momento horizontal como momento transferido desde $500 \mathrm{hPa}$ a superficie ( $r 500 / r 1000) \sim 0.5$, donde $r$ es la densidad del aire. No obstante el factor 'a' se debe escoger de manera que la media de GU iguale la media de las rachas máximas observadas.

Uso: En Australia utilizan un factor a $=0,60 \mathrm{y}$, aunque correlaciona mejor con el valor observado que el WINDEX, realiza algo de sobreestimación para valores observados inferiores a $50 \mathrm{Kt}$, y en cambio infraestimaciones para valores observados superiores a $55 \mathrm{Kt}$. El índice propuesto se ha calculado para un factor a=0.5, y transformado para mostrar los resultados en $\mathrm{km} / \mathrm{h}$. Debe entenderse como un valor aproximado de la máxima e hipotética racha convectiva esperada (figura 2.37). Referencia: http://www-das.uwyo.edu/ geerts/papers/waf_gusts/

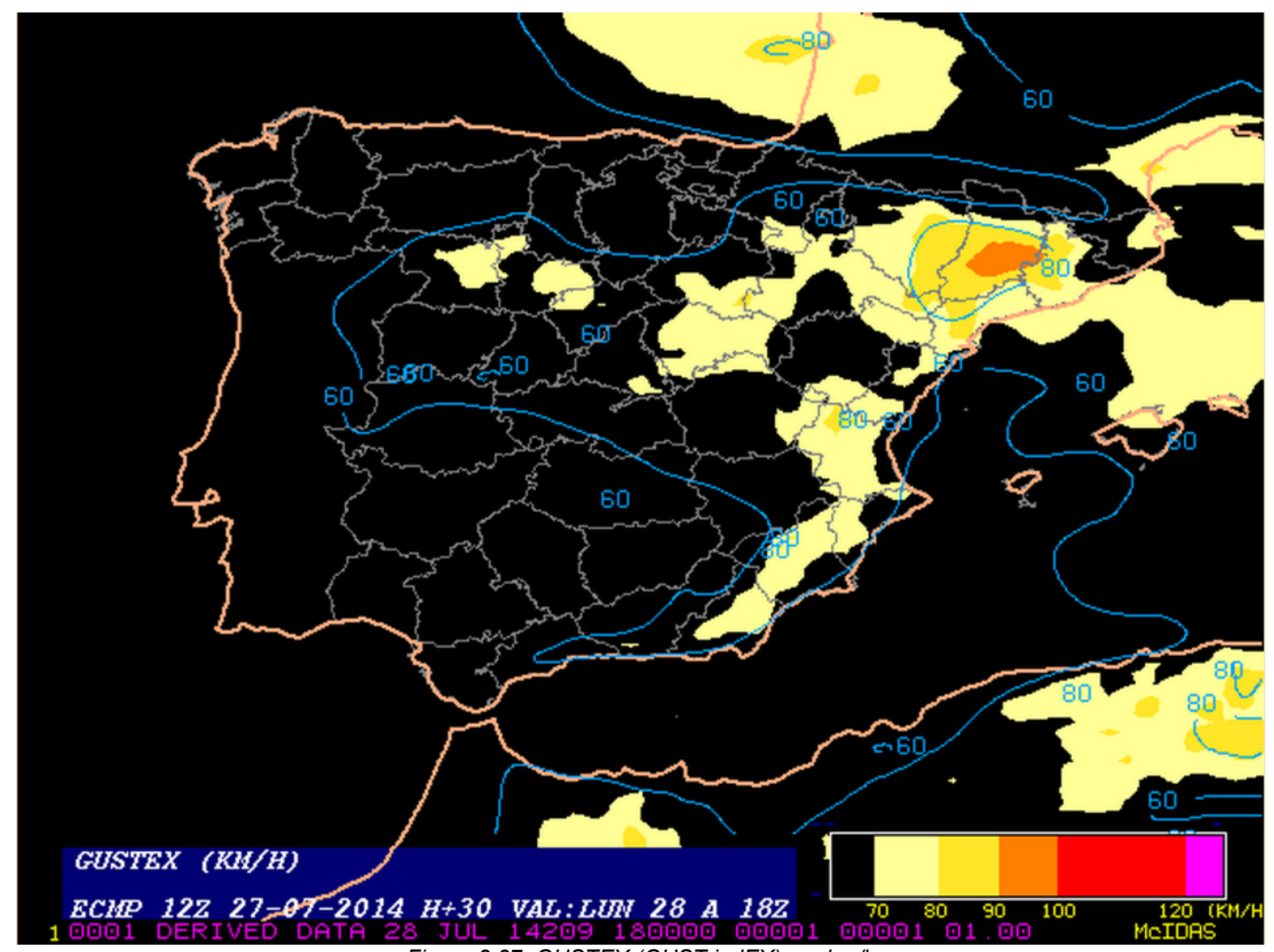

Figura 2.37. GUSTEX (GUST indEX), en $\mathrm{km} / \mathrm{h}$ 


\section{Rachas convectivas severas no tornádicas}

Justificación básica: El algoritmo simplemente tiene en cuenta índices de inestabilidad (LI, LI7) y el DCAPE (Downdraft CAPE), así como el índice GUSTEX (GU) para estimación de rachas convectivas. En este caso no se exige precipitación convectiva por parte del modelo. Debe entenderse como una discriminación de zonas con riesgo de que hipotéticamente se puedan producir rachas convectivas muy intensas (figura 2.38).

\section{Regla Rachas Convectivas Severas no Tornádicas}

\begin{tabular}{lllll}
$\begin{array}{l}\text { Ligeramente favorable } \\
(\mathrm{LI}<=1 \text { ó LI7 }<=1)\end{array}$ & y & DCAPE $>=500$ & y & $\mathrm{GU}>=40 \mathrm{KT}$ \\
$\begin{array}{l}\text { Favorable } \\
(\mathrm{LI}<=1 \text { ó LI }<=1)\end{array}$ & y & DCAPE $>=800$ & y & $\mathrm{GU}>=45 \mathrm{KT}$ \\
$\begin{array}{l}\text { Muy Favorable } \\
(\mathrm{LI}<=1 \text { ó LI }<=1)\end{array}$ & y & DCAPE $>=1000$ & y & $\mathrm{GU}>=50 \mathrm{KT}$ \\
\hline
\end{tabular}

Inconvenientes: La regla se basa fundamentalmente en la habilidad del índice GU para representar las áreas susceptibles de rachas al menos muy fuertes (aproximadamente superiores a $70 \mathrm{~km} / \mathrm{h}$ ), en entornos en principio propicios para la convección, con determinados umbrales de DCAPE. En determinadas ocasiones el índice GU no afina la racha todo lo esperado, por lo que este campo debe ser usado con mucha precaución.

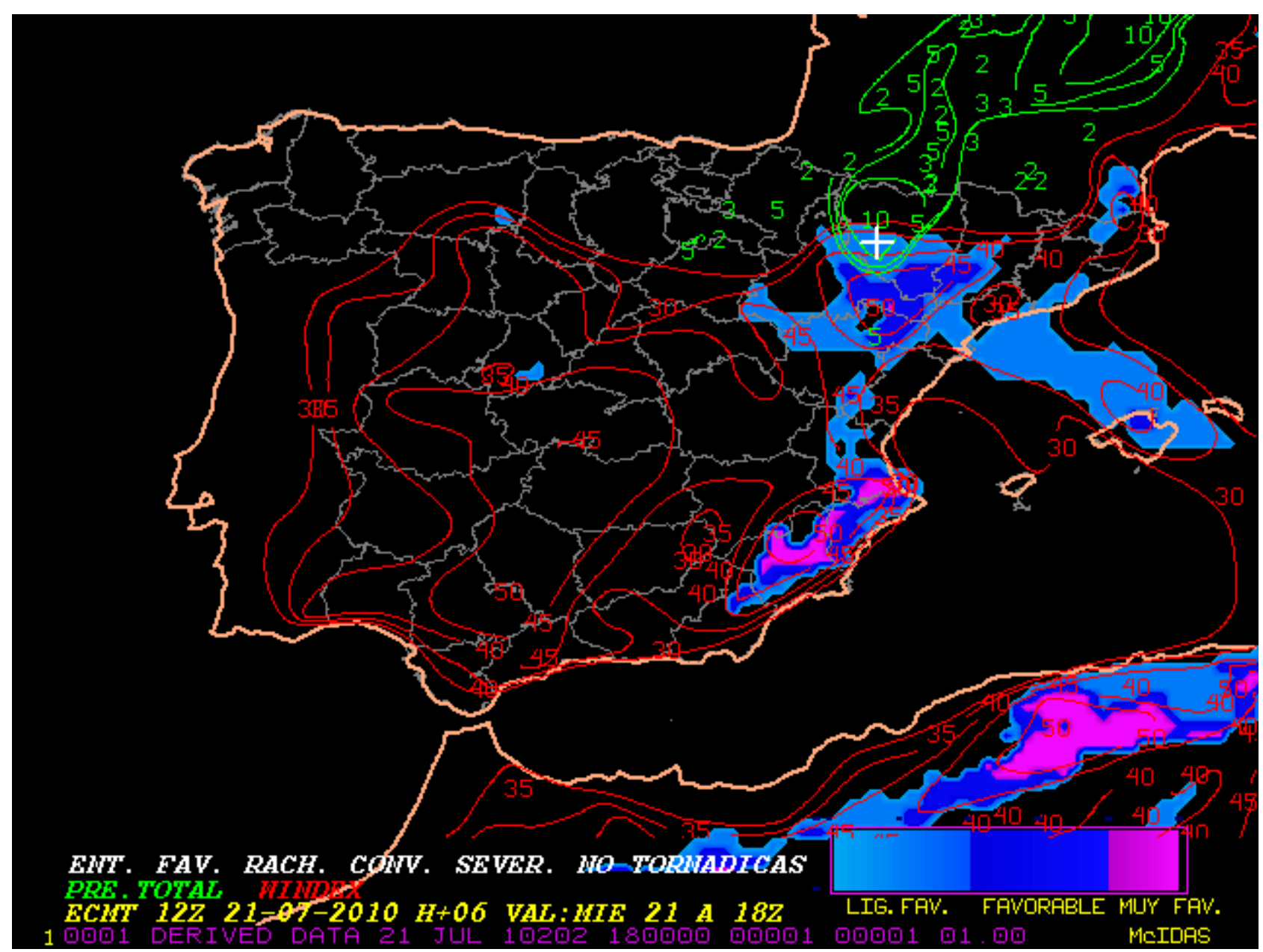

Figura 2.38. Entorno de rachas convectivas severas no tornádicas (coloreado en tres categorías: ligeramente favorable/favorable/muy favorable), el 21 de julio de 2010 a 18 UTC. 


\section{AGUA PRECIPITABLE [mm]}

Definición: Es la cantidad total de agua contenida en una columna de aire de sección unidad que se extendiese desde el suelo hasta el nivel de $300 \mathrm{hPa}$, expresada en $\mathrm{mm}$. Es un ingrediente más de lluvias intensas, en este caso asociadas a tormentas, de producirse éstas.

Uso: En la ventana propuesta (figura 2.39) se muestra el campo de agua precipitable en diversas capas y el acumulado total.
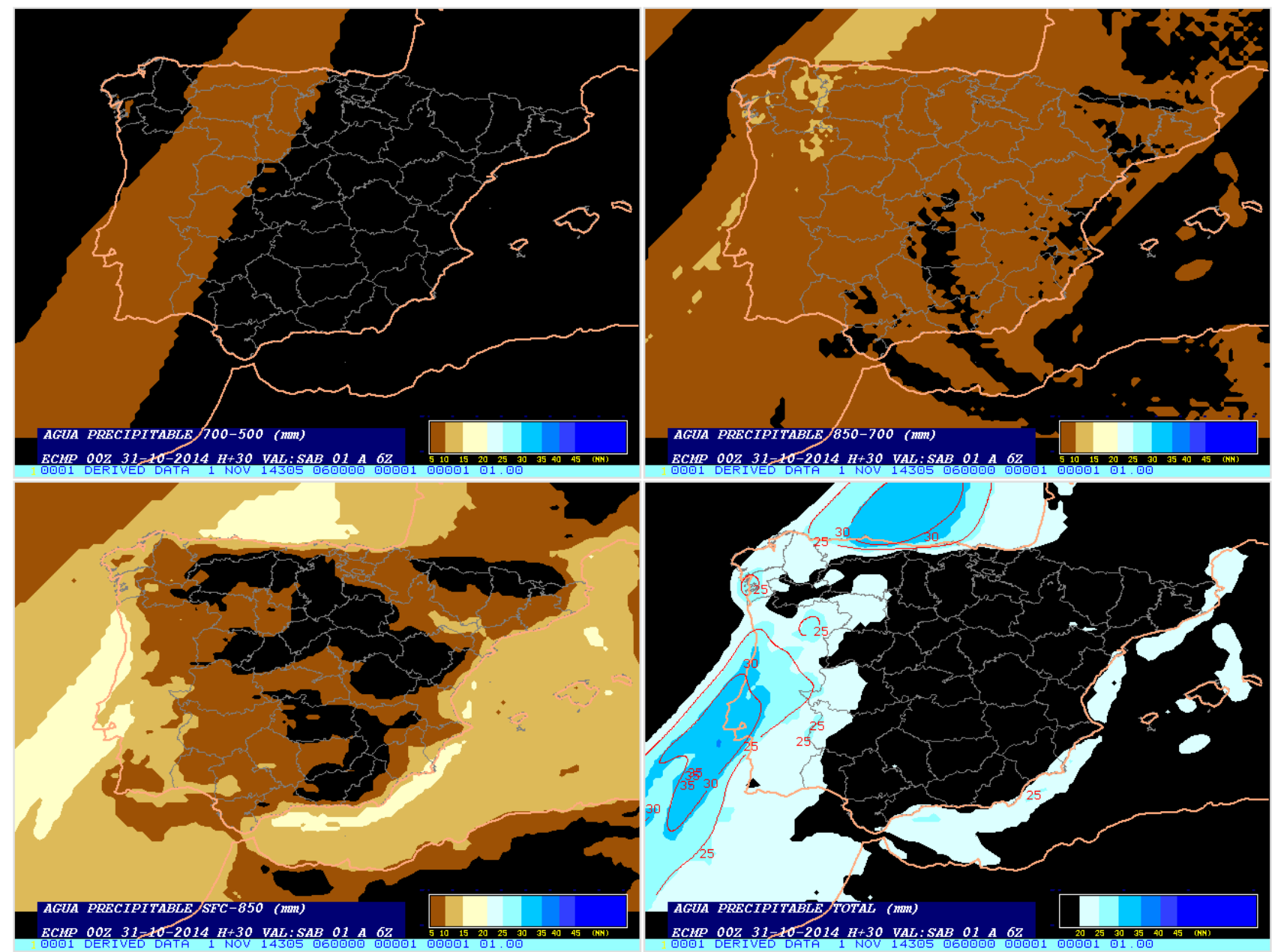

Figura 2.39. Agua precipitable (PW) en distintas capas $(\mathrm{mm})$. Arriba izquierda: $P W$ en la capa 700-500 hPa, arriba derecha: $P W$ en la capa 850-700 hPa, abajo izquierda: PW en la capa desde superficie hasta $850 \mathrm{hPa}$, abajo derecha: PW en toda la columna. 


\section{Flujo de humedad $\left(q^{*} v\right)\left[(\mathbf{g} / \mathbf{k g})^{*}(\mathbf{k t})\right]$}

Definición: Es el producto de la proporción de mezcla y el vector velocidad del viento

Uso: A mayor intensidad del flujo de humedad en niveles bajos, mayor es el viento y/o el contenido de humedad, lo que provocará un ambiente más favorable para precipitaciones intensas.

En la figura 2.40 se muestra el flujo de humedad junto al geopotencial para los niveles de 500, 700, 850 y $925 \mathrm{hPa}$.
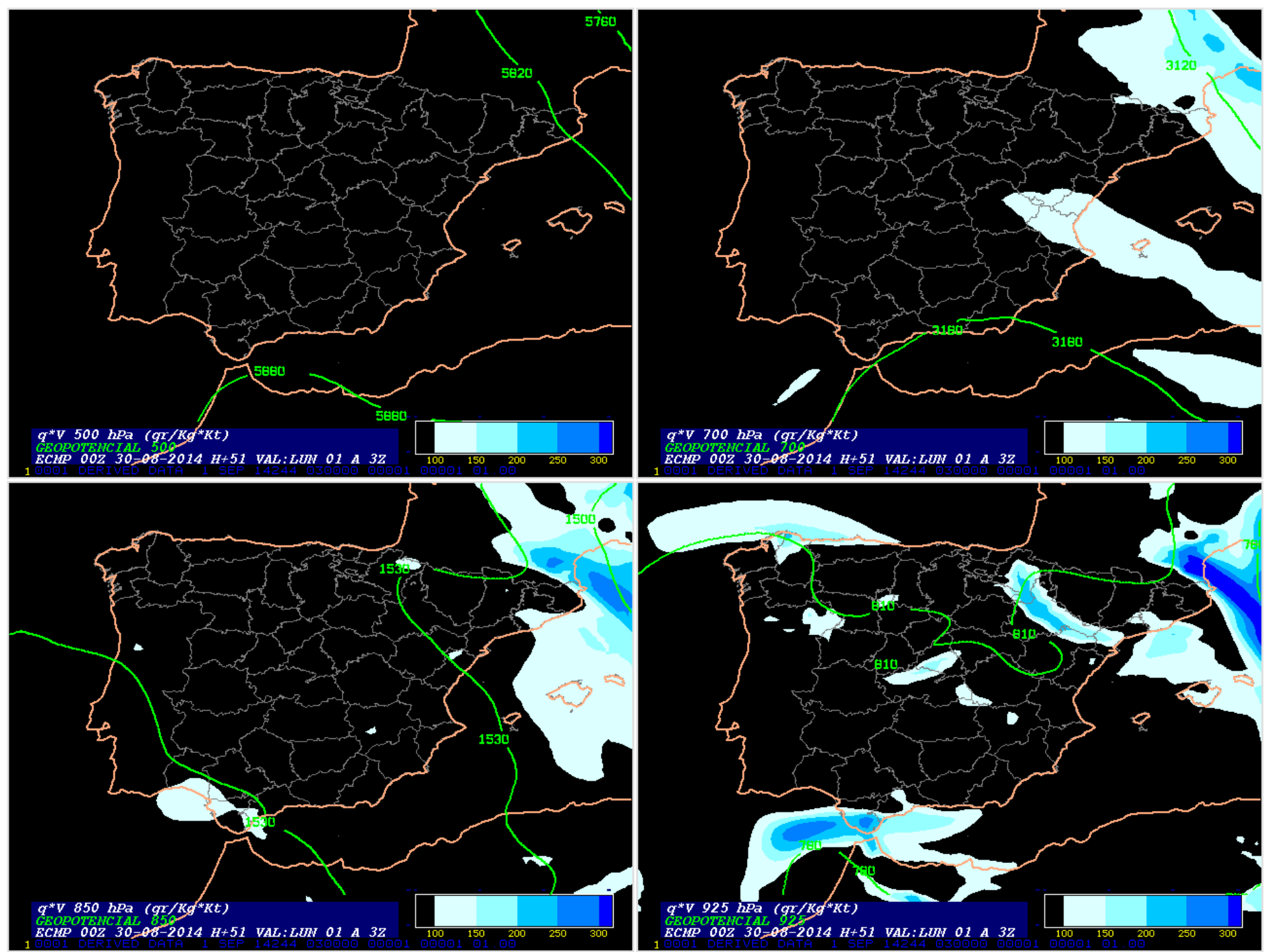

Figura 2.40. Flujo de humedad (q*v) en ((g/kg). Kt) y geopotencial (m) en 500, 700, 850 y $925 \mathrm{hPa}$. 


\section{Convergencia del flujo de humedad $[(\mathrm{g} / \mathrm{kg}) / \mathrm{s}]$}

Definición: La divergencia del flujo de humedad, viene dada por:

$$
\vec{\nabla}(q \vec{V})=q * \operatorname{div} \vec{V}-\vec{V} * \bar{\nabla}(q) \quad \text { donde, }
$$

- $q$ es la humedad específica, y

- $\quad$ es la velocidad del viento.

Uso: La convergencia del flujo de humedad es un campo muy útil en el diagnóstico-pronóstico de la convección ya que muestra las zonas donde además de existir convergencia se está produciendo un aporte de humedad, que junto a la presencia de inestabilidad puede disparar la convección.

La existencia de una zona marcada de convergencia de humedad en niveles bajos puede aumentar la inestabilidad potencial en esos niveles. En la figura 2.41 se muestra la convergencia de humedad y el geopotencial en $850 \mathrm{hPa}$.

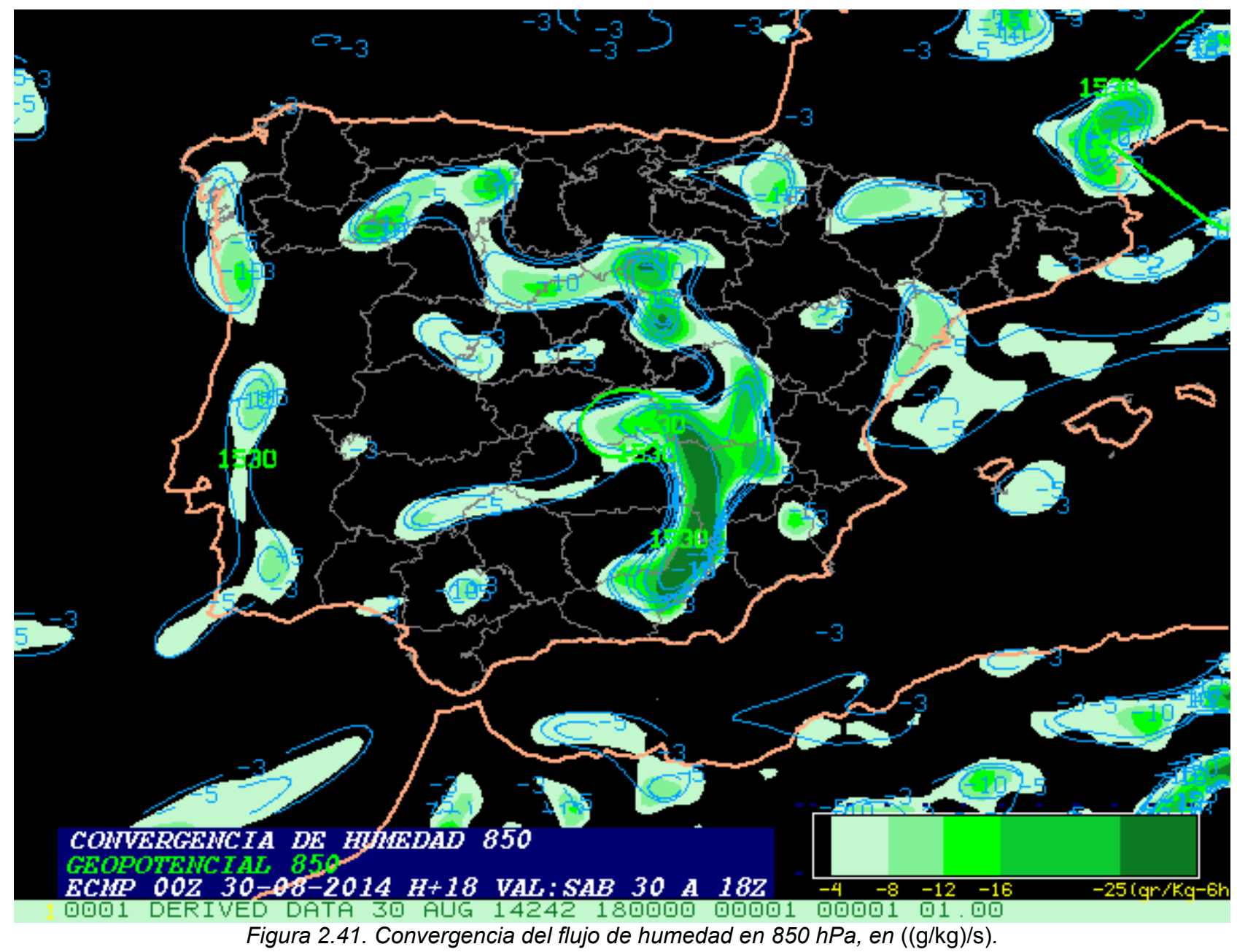




\section{Humedad relativa (\%)}

Definición: Humedad relativa (\%) del aire en varios niveles de presión.

Uso: Lógicamente se necesitan valores próximos a la saturación en capas bajas (al menos hasta $850 \mathrm{hPa}$ ) para que se produzcan precipitaciones intensas. Por otro lado, estratos secos en capas medias pueden favorecer la severidad de las tormentas si se llegan a disparar.

En la figura 2.42 se presenta la humedad relativa a partir del $60 \%$ en distintos niveles $(500,700,850$ y $925 \mathrm{hPa})$.

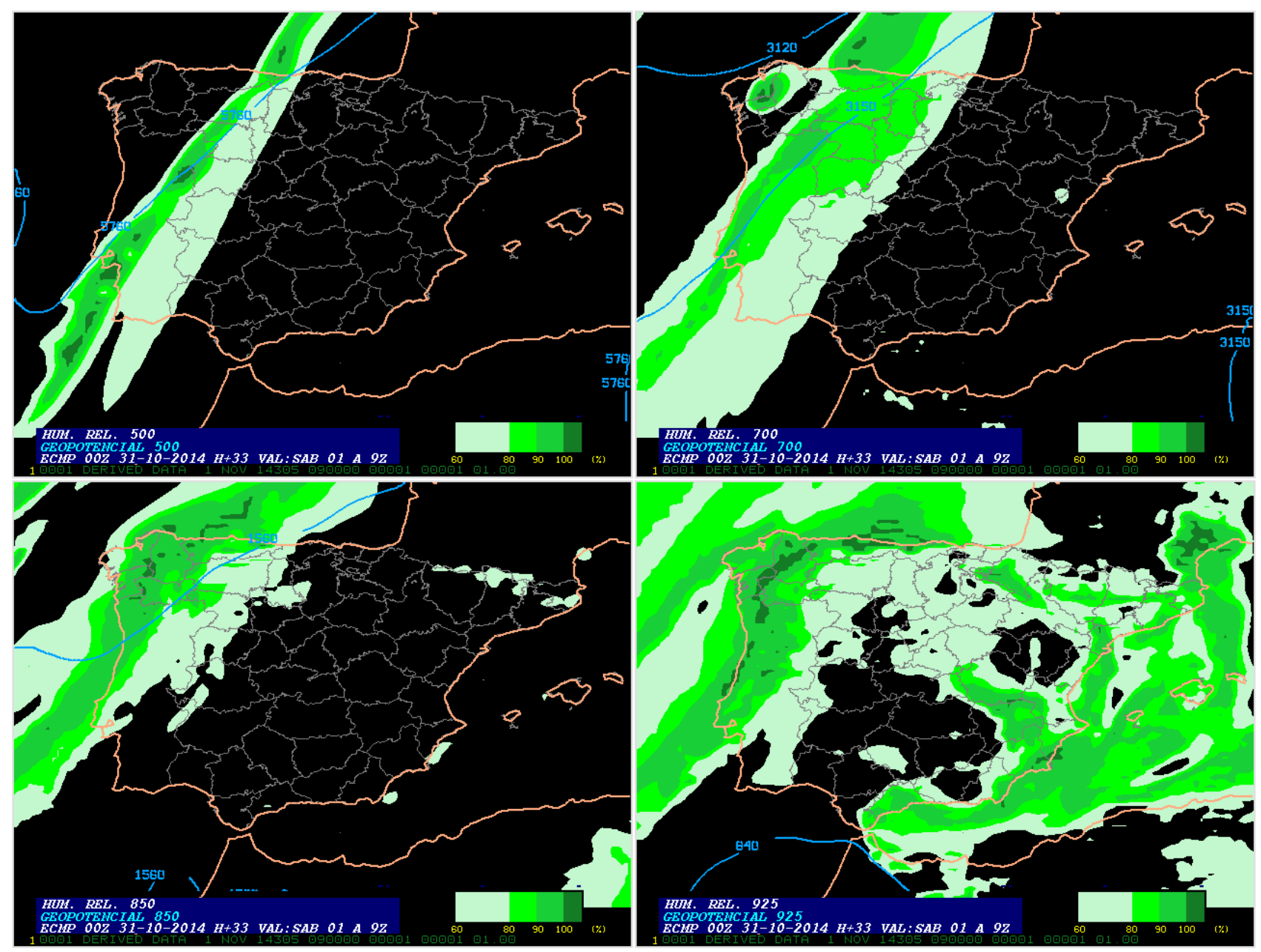

Figura 2.42. Humedad relativa (\%) y geopotencial (m) en distintos niveles (500, 700, 850 y $925 \mathrm{hPa}$ ). 


\section{Precipitaciones fuertes en una hora (PEFMA)}

Justificación básica: Se usan salidas directas del modelo de la variable precipitación acumulada en 3 horas para estimar las localizaciones de precipitaciones fuertes en una hora (más de $15 \mathrm{~mm} / \mathrm{h}$ ). Para ello se han graduado algunos valores umbrales que se consideran orientativos, con dos variantes en función de si el modelo prevé o no precipitación convectiva. Hay que tener en cuenta que estos algoritmos son muy aproximados y la cantidad horaria acumulada dependerá de las características de la situación meteorológica, de la orografía, duración, etc. Además hay que tener presente que los umbrales de aviso del plan Meteoalerta varían de unas zonas a otras. Por ello el objetivo de esta herramienta es tratar de poner de manifiesto las zonas en las que el modelo prevé precipitaciones que podrían ser "potencialmente intensas"... Para ello se tiene en consideración la precipitación (total y convectiva) prevista por el modelo en las tres horas siguientes, tratando a partir de esta variable, de inferir si hay entorno favorable para precipitación fuerte en una hora (figura 2.43). El valor añadido del predictor es fundamental en la predicción operativa.

\section{Regla Precipitaciones intensas en 1 hora}

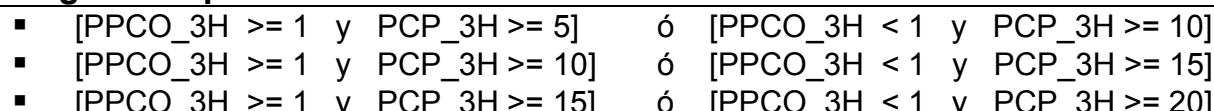

Inconvenientes: Al igual que en otras variables, pero especialmente en las precipitaciones fuertes horarias, el algoritmo es empírico y muy aproximado, dependiendo en gran medida de la habilidad del modelo para representar precipitaciones fuertes. Aparte hay una limitación importante, que es la no disponibilidad del valor de precipitación en una hora por parte de los modelos disponibles, por lo que la estimación empírica se hace a partir de la precipitación en tres horas. Ello puede llevar a sobreestimar el riesgo en situaciones de precipitaciones moderadas persistentes. No obstante este producto trata de fijar la atención en las zonas que potencialmente podrían ser susceptibles de precipitaciones intensas en una hora. Lógicamente también es una tarea complejísima la previsión de la localización e intensidad de las precipitaciones convectivas repentinas.

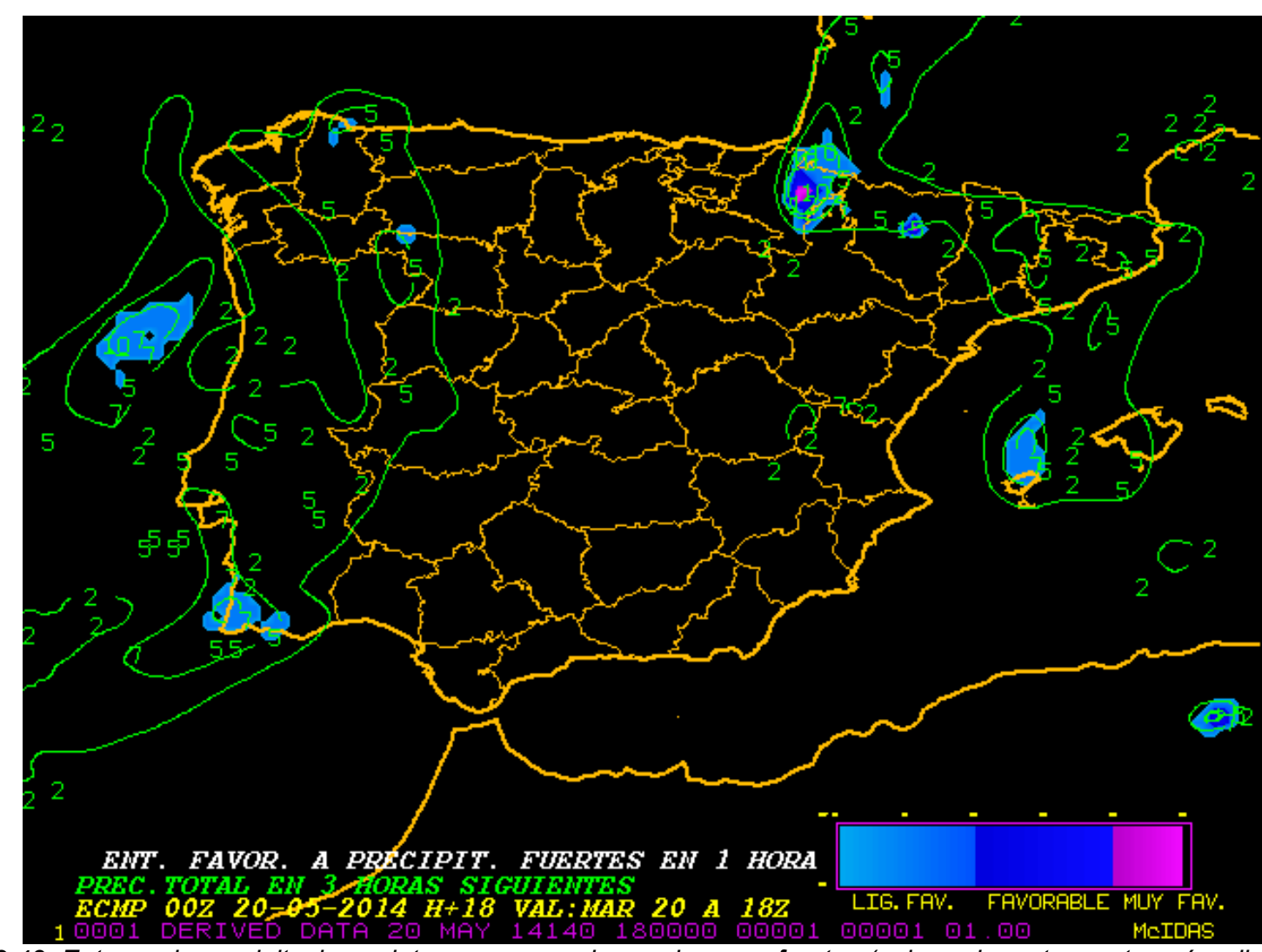

Figura 2.43. Entorno de precipitaciones intensas en una hora, al menos fuertes (coloreado en tres categorías: ligeramente favorable/favorable/muy favorable) entre las 18 y las 21 UTC del día 20 de mayo de 2014. 


\section{Precipitaciones copiosas en 12 horas (PEFMA)}

Justificación básica: Se usan salidas directas del modelo de la variable precipitación acumulada en 12 horas para estimar las localizaciones de precipitaciones de más de $\mathbf{4 0} \mathbf{m m}$ en las siguientes $\mathbf{1 2}$ horas al alcance de predicción (figura 2.44). Para ello se han graduado algunos valores umbrales que se consideran orientativos, con dos variantes en función de si el modelo prevé o no precipitación convectiva. Hay que tener en cuenta que estos algoritmos son muy aproximados y la cantidad horaria acumulada dependerá de las características de la situación meteorológica, de la orografía, persistencia, etc. Además hay que tener presente que los umbrales de aviso del plan Meteoalerta para lluvias acumuladas en 12 horas varían de unas zonas a otras. El valor añadido del predictor es fundamental en la predicción operativa.

\section{Regla Precipitaciones intensas en 12 horas}

- $\left[\mathrm{PPCO} \_12 \mathrm{H}>=1\right.$ y $\left.\mathrm{PCP} \_12 \mathrm{H}>=25\right]$ ó $\left[\mathrm{PPCO} \_12 \mathrm{H}<1\right.$ y $\left.\mathrm{PCP} \_12 \mathrm{H}>=30\right]$

- $\quad\left[P P C O \_12 \mathrm{H}>=1\right.$ y $\left.\mathrm{PCP}_{-} 12 \mathrm{H}>=30\right]$ ó $\left[\mathrm{PPCO}_{-} 12 \mathrm{H}<1\right.$ y $\left.\mathrm{PCP} \_12 \mathrm{H}>=35\right]$

- $\left[\mathrm{PPCO} \_12 \mathrm{H}>=1\right.$ y $\left.\mathrm{PCP} \_12 \mathrm{H}>=35\right]$ ó $\left[\mathrm{PPCO} \_12 \mathrm{H}<1\right.$ y $\left.\mathrm{PCP} \_12 \mathrm{H}>=40\right]$

Inconvenientes: Al igual que en otras variables, el algoritmo es empírico y muy aproximado, dependiendo fuertemente de la habilidad del modelo para representar precipitaciones copiosas acumuladas. Este producto no obstante trata de fijar la atención en las zonas que potencialmente podrían ser susceptibles de precipitaciones cuantiosas acumuladas en 12 horas. Lógicamente será muy difícil la previsión de la localización e intensidad de precipitaciones convectivas de ámbito espacial reducido.

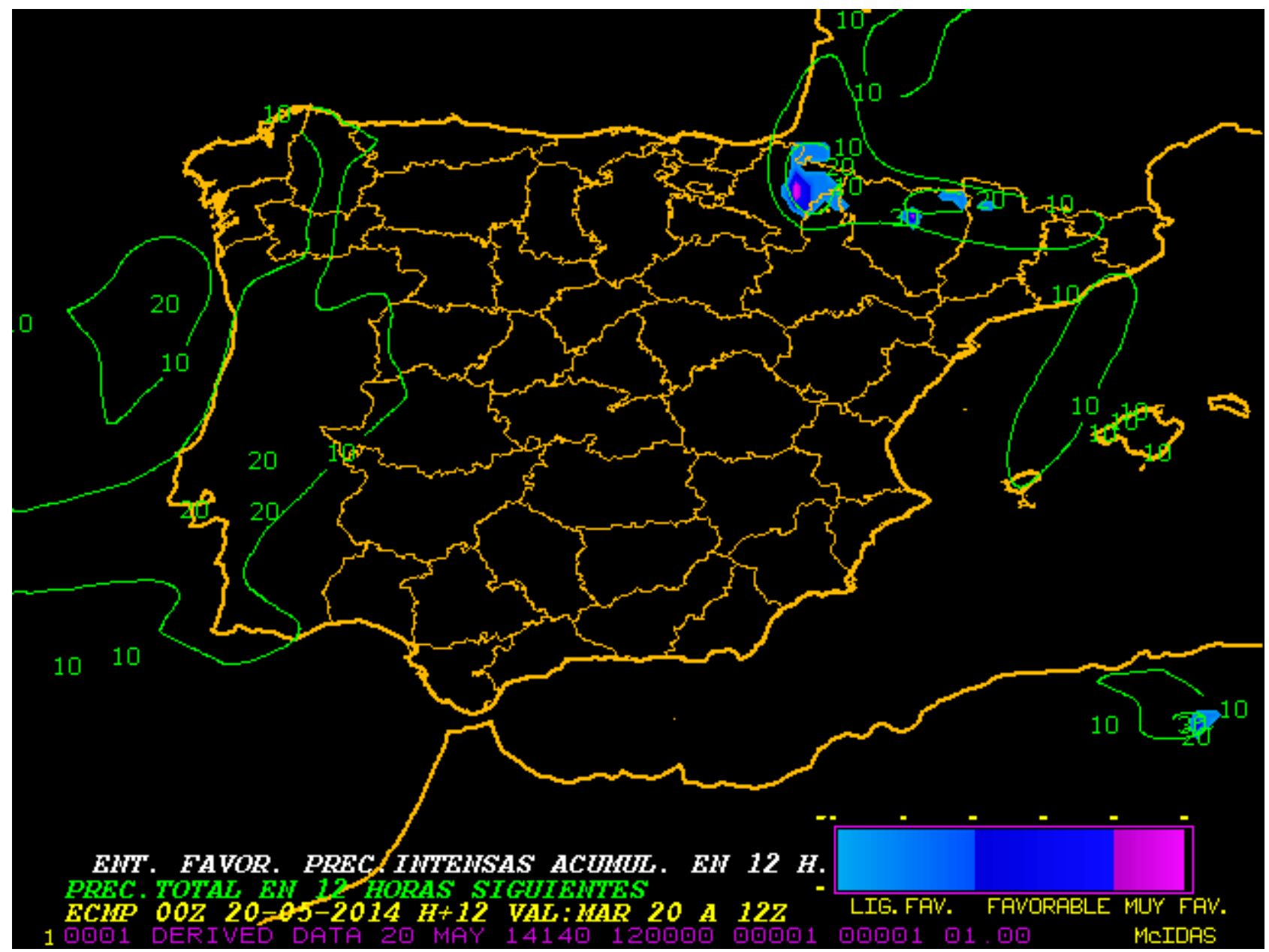

Figura 2.44. Entorno de precipitaciones intensas en 12 horas, al menos de $40 \mathrm{~mm}$ (coloreado en tres categorías: ligeramente favorable/favorable/muy favorable) en el norte peninsular en las 12 horas siguientes a las 12 UTC del 20 de mayo de 2014. 


\section{3.- Casos de estudio}

En este apartado se pondrán de manifiesto casos reales "recientes", presentándose los campos de la aplicación y comentándose de manera esquemática su comportamiento y validez. Se hará de manera independiente, por un lado para el diagnóstico convectivo general y por otro para una serie de fenómenos severos en superficie: precipitaciones intensas, granizo grande, vientos severos no tornádicos, supercélulas y tornados.

\section{1.- Diagnóstico convectivo general}

Se revisa aquí el episodio del día 3 de julio de 2014, en el que una depresión aislada en niveles altos se situó sobre la Península, mientras que la perturbación al nivel del mar tenía su centro sobre el norte de África, generando un flujo en general de componente este. Los rayos afectaron en mayor medida a zonas del centro y norte peninsular, sobre todo durante las horas centrales del día y por la tarde (figura 3.1).
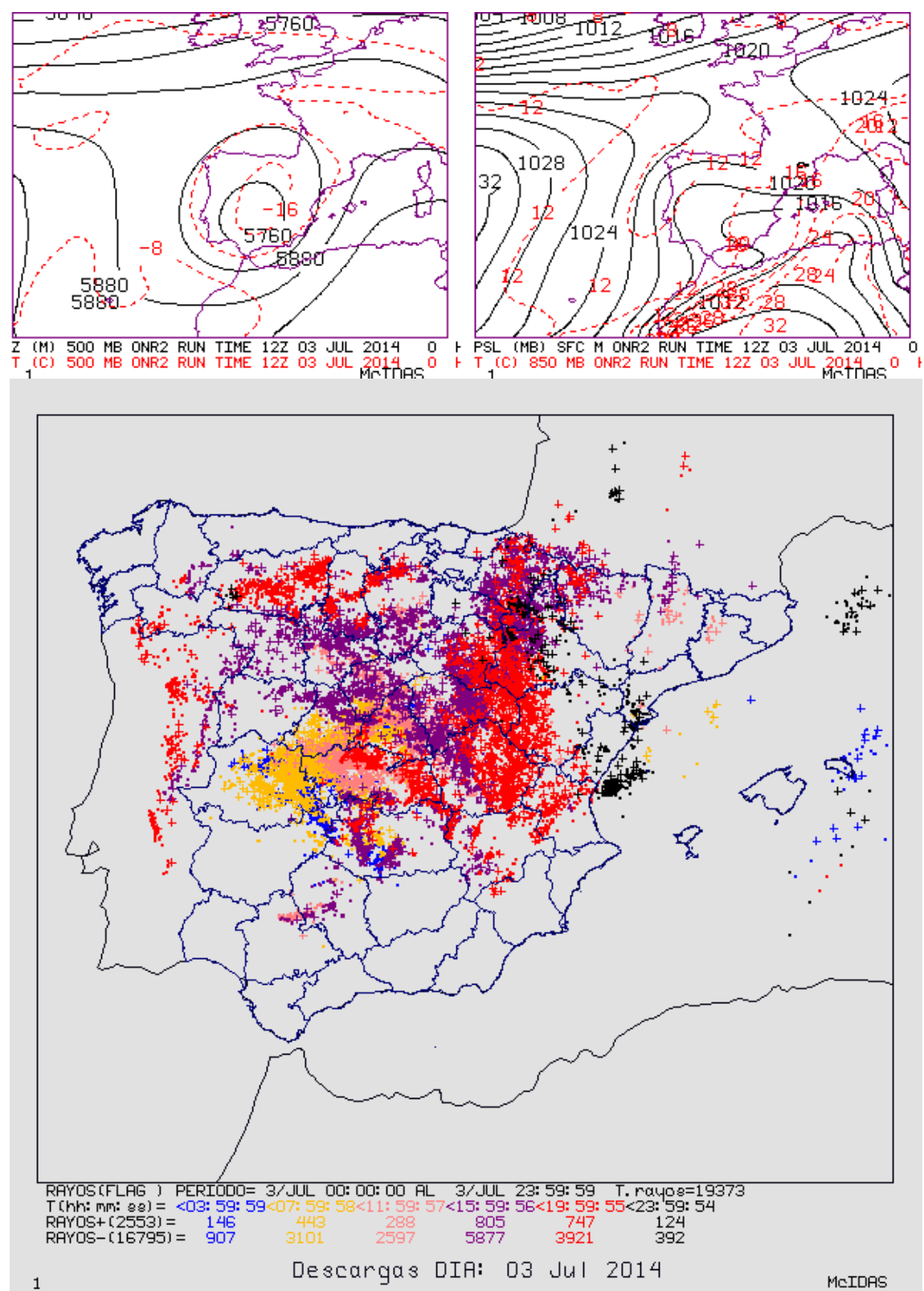

Figura 3.1. Arriba: Situación meteorológica básica a las 12 UTC del 3 de julio de 2014

(izquierda: Z y T en $500 \mathrm{hPa}$, derecha: PSL y $T_{850}$ ). Abajo: rayos registrados.

A continuación se mostrarán y describirán sucintamente los valores de algunos campos fundamentales a la hora de elaborar operativamente un diagnóstico convectivo. Por simplicidad y con fines comparativos se usará una predicción a 12 horas a partir de la pasada operativa de las 0 UTC del modelo IFS del ECMWF. 


\section{a) Convección en general}

\section{Diagnóstico Convectivo}

Integrado por tres productos combinados, a su vez compuestos por cuatro paneles cada uno.

- Diagnóstico Convectivo I: ventana integrada por varios campos fundamentales. Se observa en este caso, cómo una baja está centrada en la Península, con valores de CAPE bastante elevados en zonas interiores y entornos favorables a convección, que podría ser organizada en algunas zonas (figura 3.2.a).

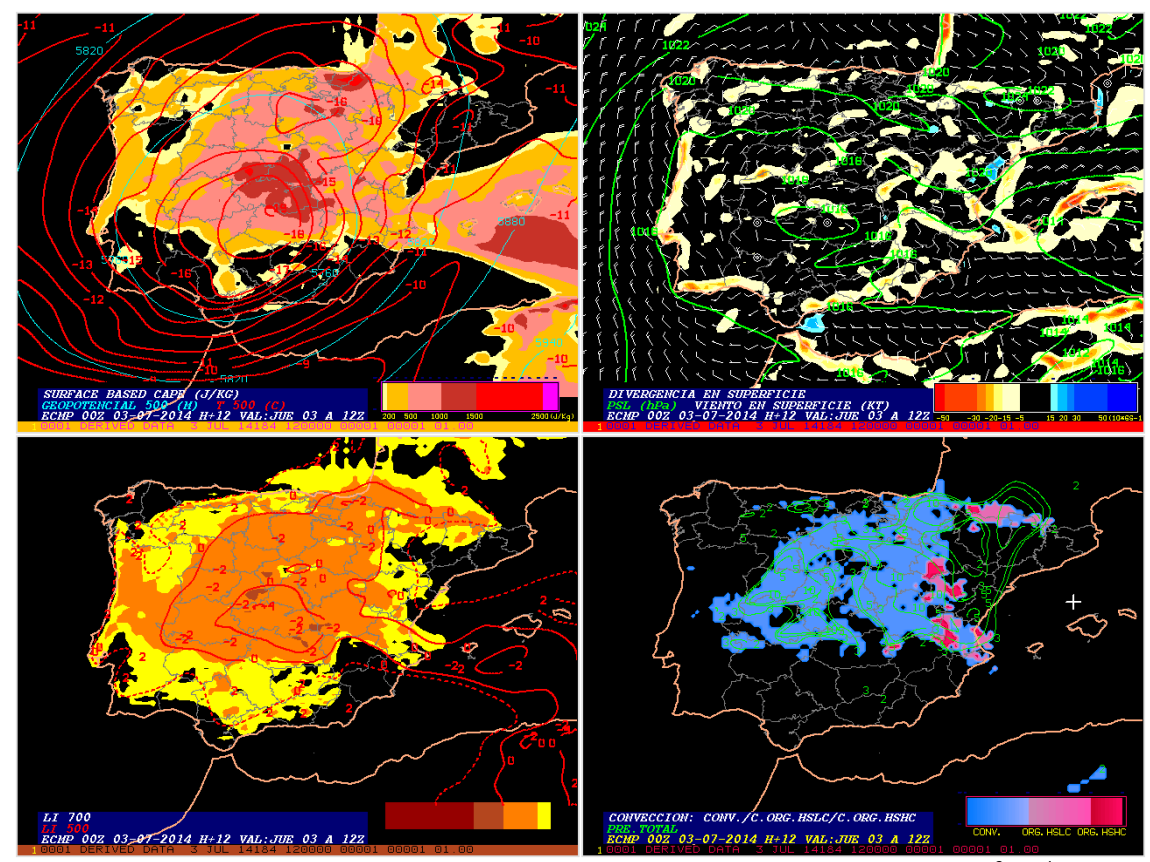

Figura 3.2.a. Arriba izquierda: SBCAPE (J/Kg), Z (m) y T (C) en $500 \mathrm{hPa}$, arriba derecha: Div $\left(10^{6 *} \mathrm{~s}^{1}\right)$, viento en superficie (kts) y PSL (hPa), abajo izquierda: LI 700 (sombreado) y LI 500 (contorneado), abajo derecha: organización de la convección.

- Diagnóstico Convectivo II: se muestran varios paneles con distintos índices y helicidades efectivas relativas a la tormenta para células que se mueven a izquierda y derecha del viento medio (figura 3.2.b). Se resaltan dos zonas en cuanto a la posible intensidad de la convección: interior peninsular y sur de Baleares, aunque esta última con manifiesta inhibición (altos valores de NCL-NCA). La helicidad efectiva proporciona valores altos en el entorno de Ibiza para células que se muevan a la derecha del viento medio.
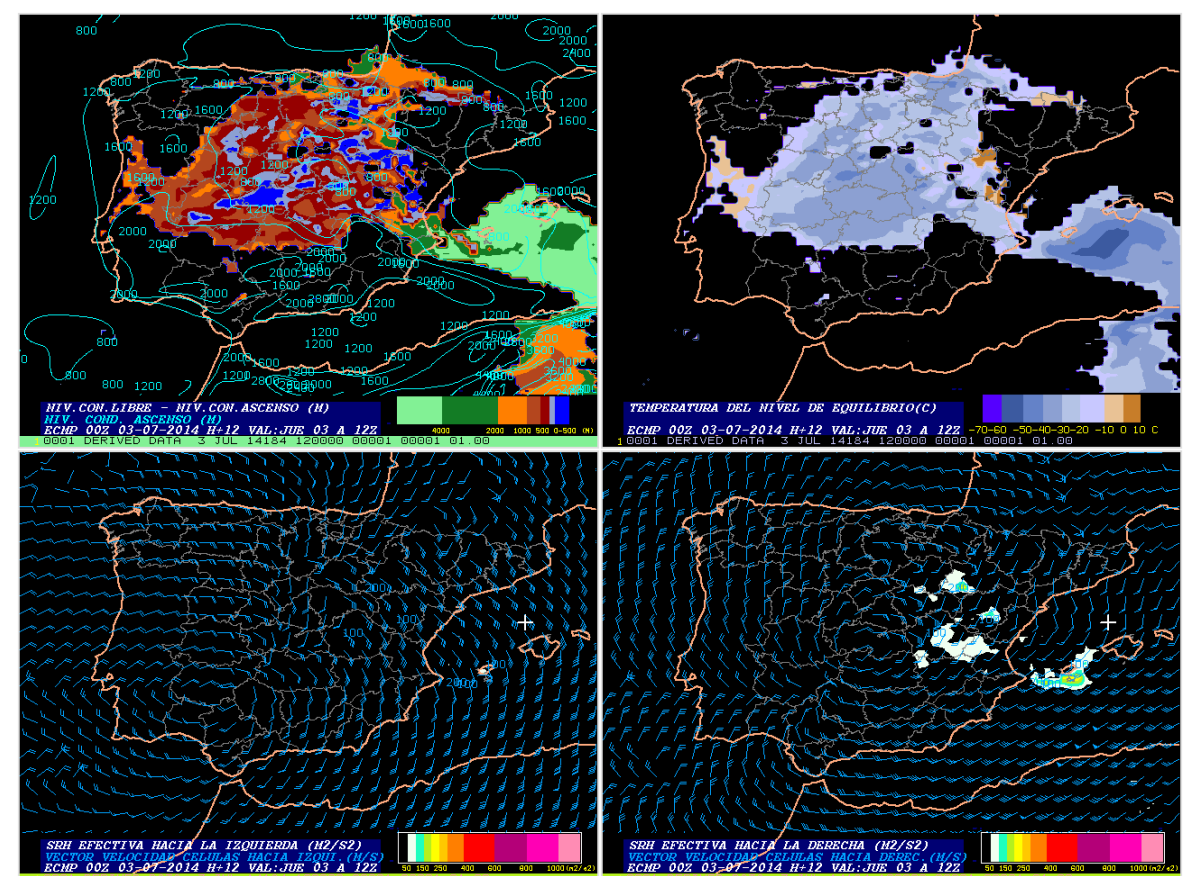

Figura 3.2.b. Arriba izquierda: NCL-NCA $(m)$ y NCA (contorneado), arriba derecha: Temperatura del NE (C), abajo izquierda: SRH para las células hacia la izquierda calculada en la capa Efectiva junto con los vectores velocidad ( $\mathrm{m} / \mathrm{s}$ ), abajo derecha: $\mathrm{SRH}$ para las células hacia la derecha calculada en la capa Efectiva junto con los vectores velocidad $(\mathrm{m} / \mathrm{s})$. 
- Diagnóstico Convectivo III: Aparte de la inestabilidad existente en el interior peninsular, se aprecia la presencia de una importante cizalladura en el entorno de Baleares, así como a su vez en esa área, valores destacables de flujo húmedo y agua precipitable (figura 3.2.c).

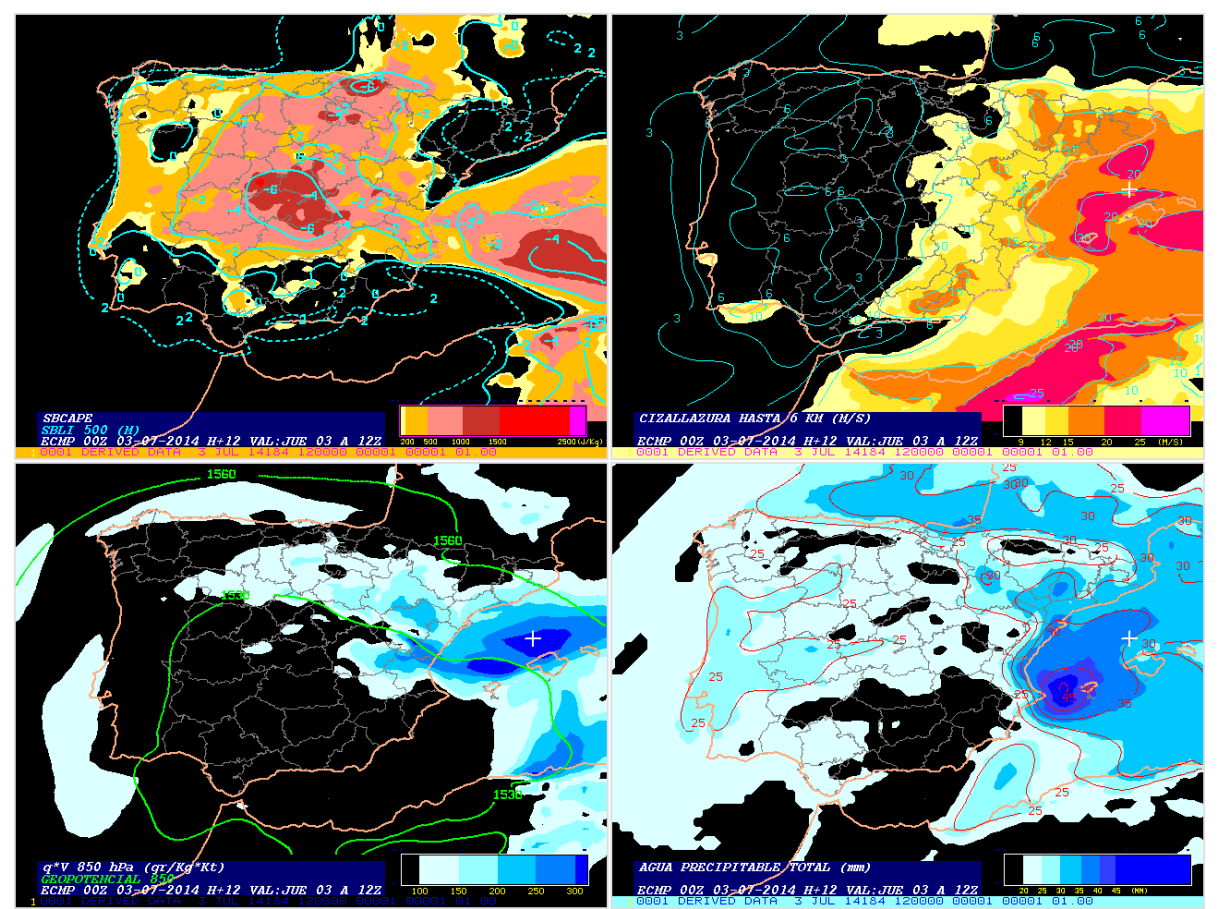

Figura 3.2.c. Arriba izquierda: SBCAPE (J/Kg) (sombreado) y LI 500 con las condiciones en superficie (contorneado), arriba derecha:

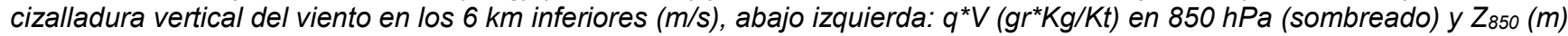
(contorneado), abajo derecha: agua precipitable total en la columna $(\mathrm{mm})$.

\section{CAPE / Cizalladura}

Tiene por objeto mostrar la inestabilidad y la organización existentes a partir de los campos de CAPE (evolución desde las condiciones promedio de los primeros $100 \mathrm{hPa}$ ) y SBCAPE (evolución desde superficie), y las cizalladuras en los 3 y en los 6 primeros kilómetros (figura 3.3). Vemos cómo la inestabilidad es más acusada en la zona interior central peninsular, y en cambio la cizalladura es superior en el área Mediterránea.

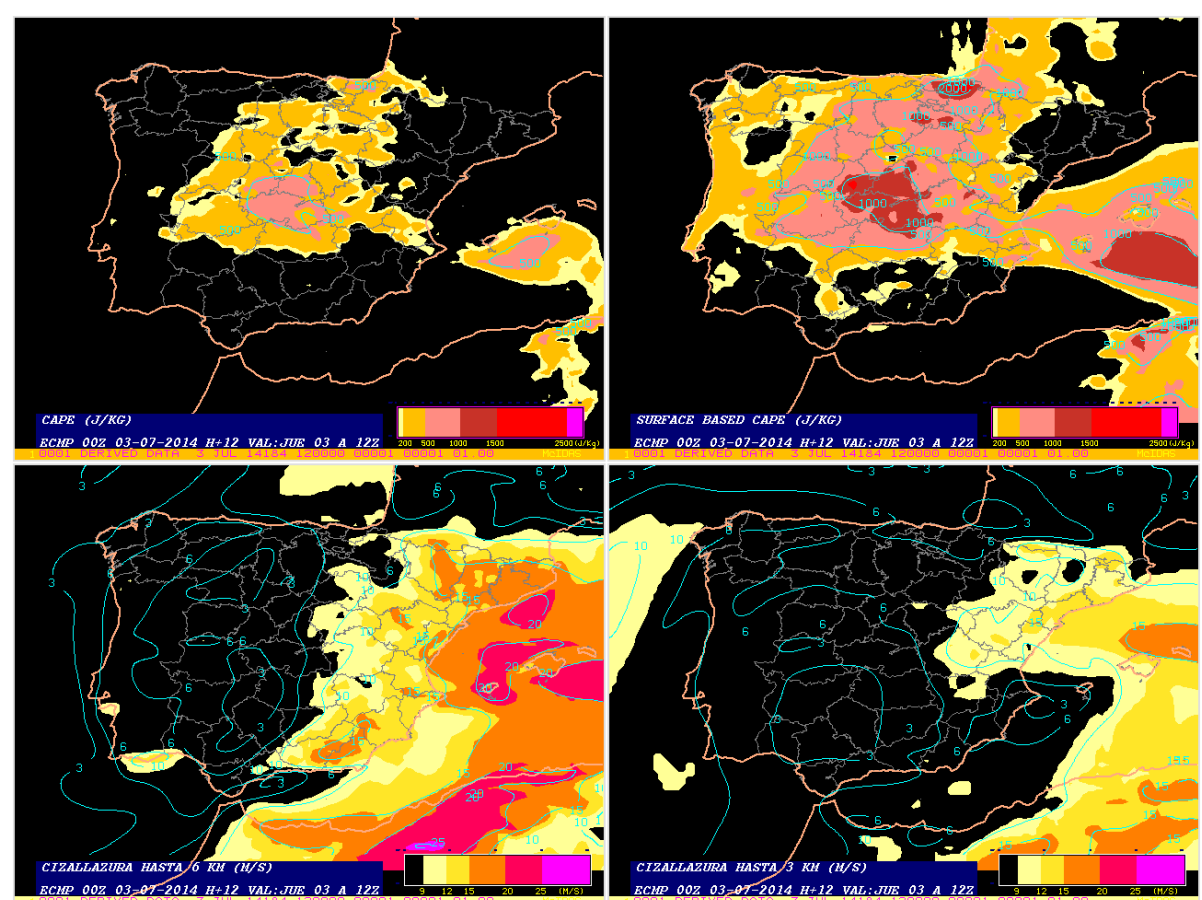

Figura 3.3. Panel de CAPEs y Cizalladuras. Arriba izquierda: CAPE (J/Kg), arriba derecha: SBCAPE (J/Kg), abajo izquierda: cizalladura vertical del viento en los $6 \mathrm{~km}$ inferiores $(\mathrm{m} / \mathrm{s})$, abajo derecha: cizalladura vertical del viento en los $3 \mathrm{~km}$ inferiores ( $\mathrm{m} / \mathrm{s})$. 


\section{SHERB}

Se trata de un índice apropiado para casos de gran cizalladura, pero con CAPE "reducido" (SBCAPE $<500 \mathrm{~J} / \mathrm{kg}$ ), lo cual no ocurre en esta situación sobre la Península (figura 3.4). Su uso suele ser más típico en casos de la temporada fría.

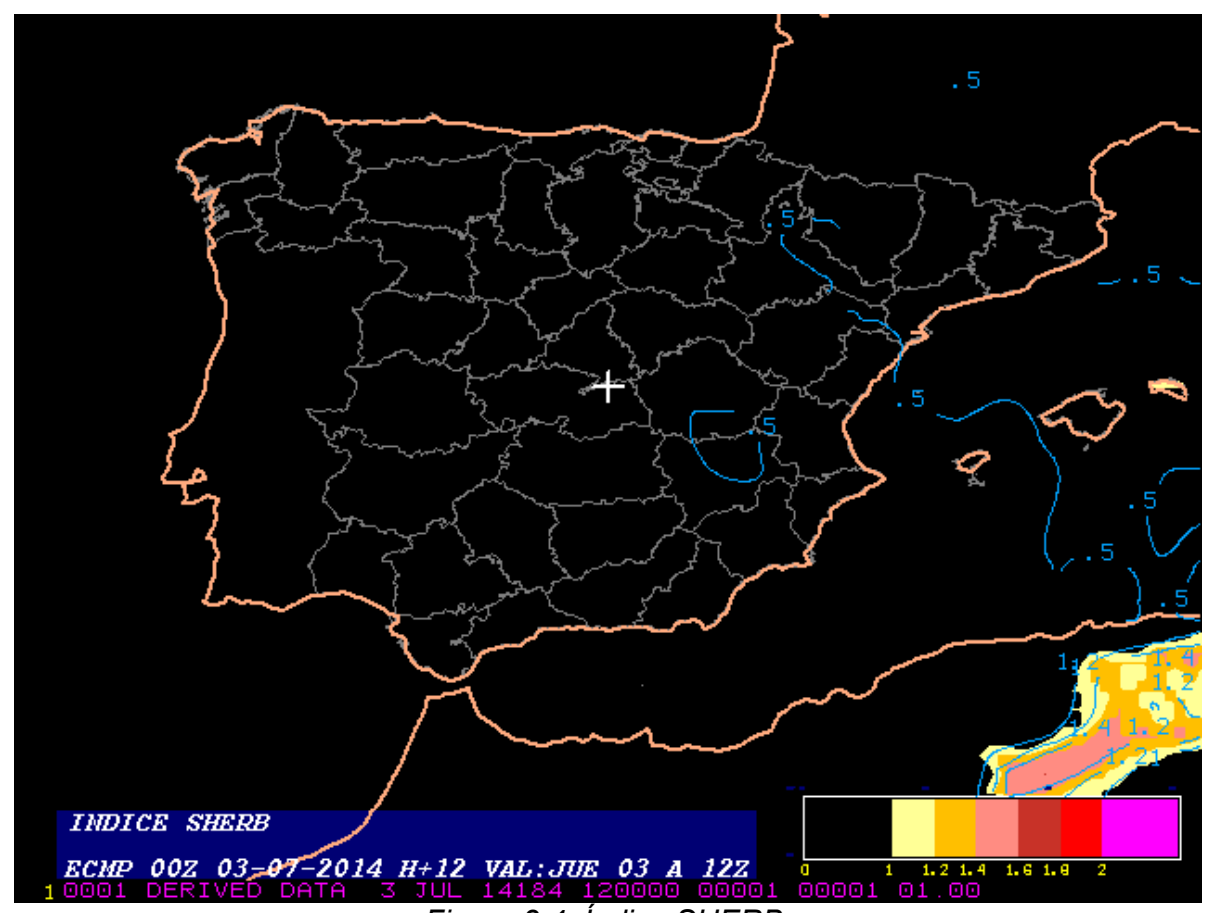

Figura 3.4. Índice SHERB.

\section{LPI}

Trata de mostrar, de una manera aproximada e indirecta, la actividad eléctrica esperada. Es un producto muy derivado, aplicado a un modelo hidrostático con variables no exactamente microfísicas. Debe usarse con mucha precaución. En este caso proporciona señales intensas a 12 UTC localizadas en el centro y norte peninsular (figura 3.5).

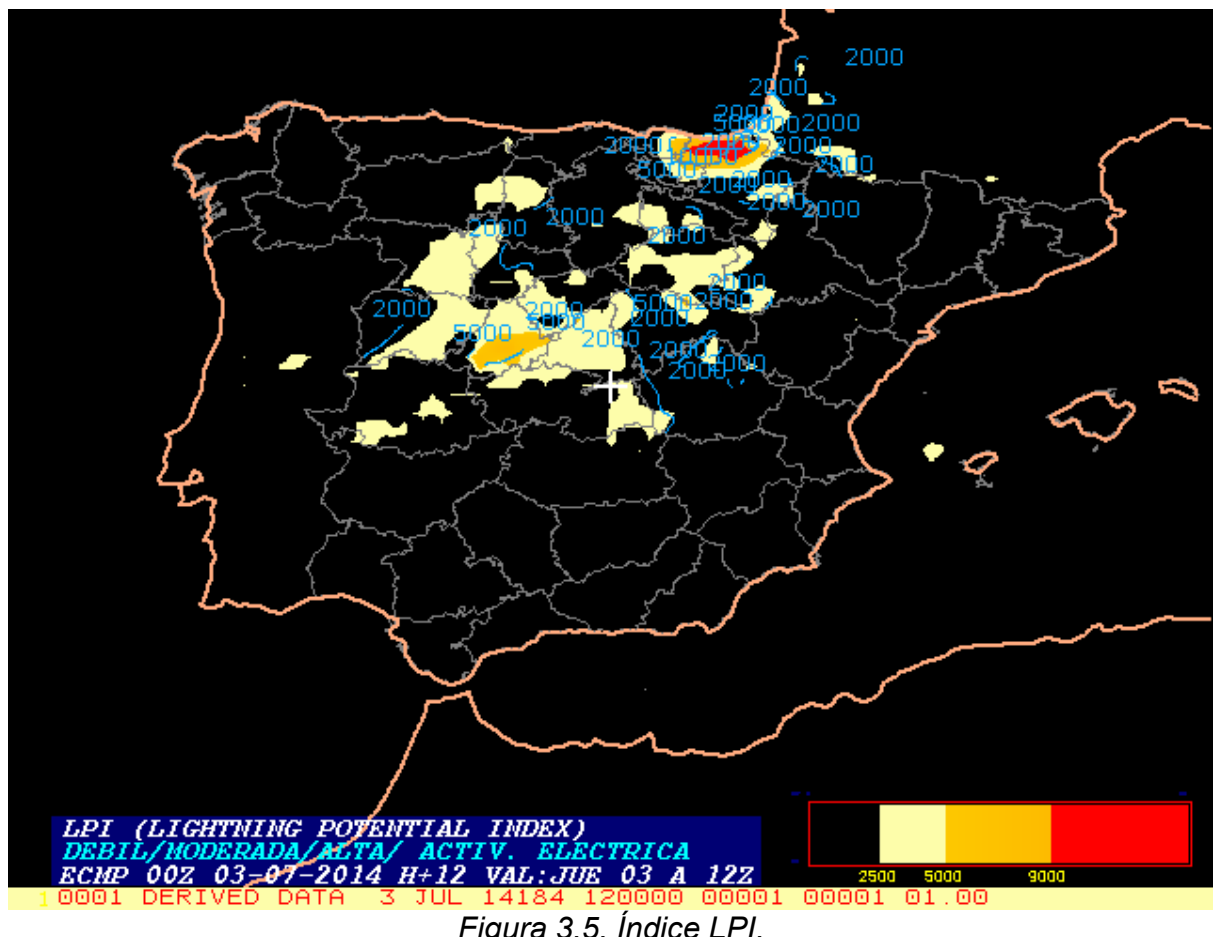

Figura 3.5. Índice LPI. 


\section{Entornos convectivos}

Intenta delimitar cuánto de favorable es el entorno para que se pueda desencadenar convección (sin entenderse como sinónimo de tormentas). Vemos cómo hay amplias zonas con ambiente bastante adecuado (favorable y muy favorable), especialmente en el centro Peninsular (figura 3.6).

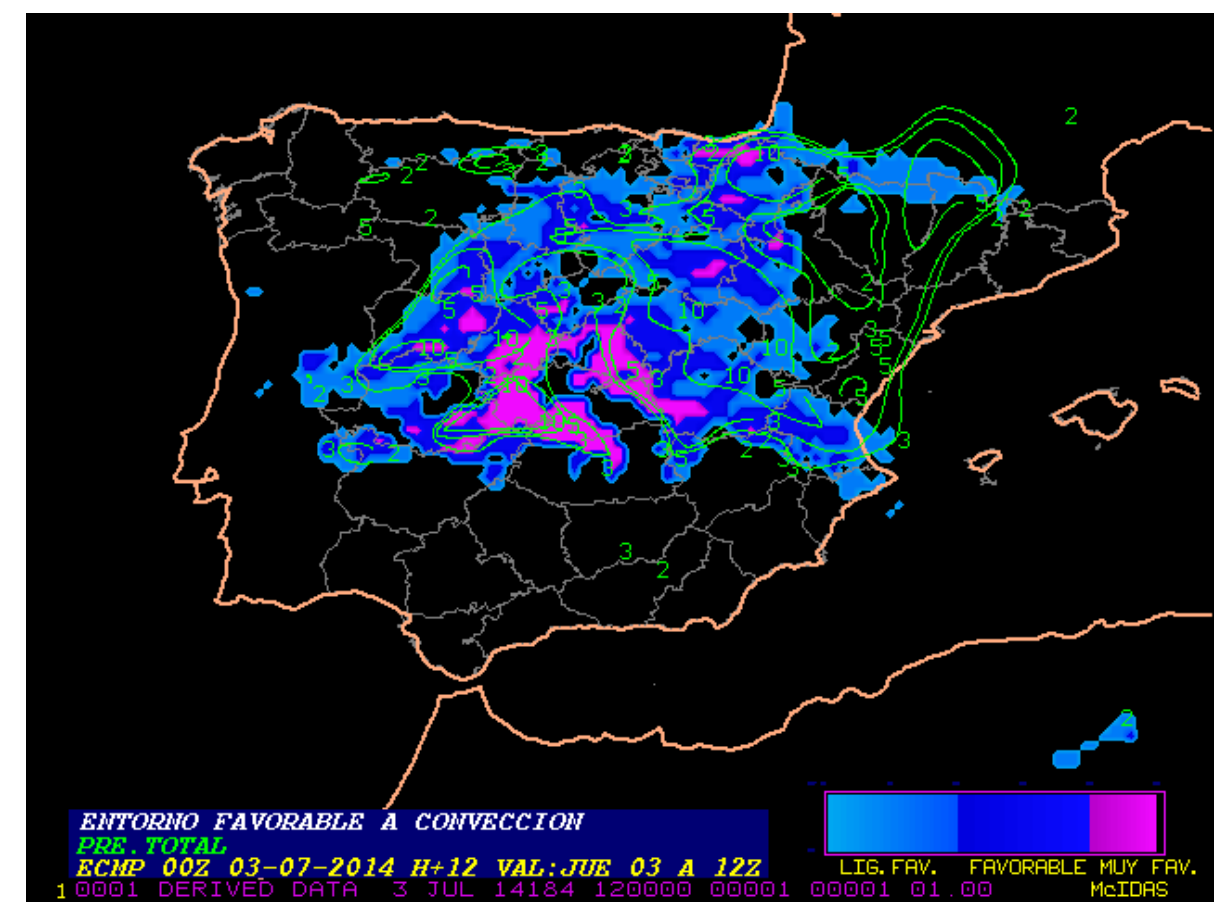

Figura 3.6. Entornos favorables a la convección (ligeramente favorable, favorable y muy favorable).

\section{Convección Organizada}

Ahora se diferencian los tipos de convección en tres categorías: general, de gran cizalladura y bajo CAPE y de gran cizalladura y gran CAPE (figura 3.7). El entorno más peligroso a priori puede ser el que toma tonalidades rojizas. Hay que tener en cuenta que este producto depende totalmente de los umbrales escogidos para delimitar zonas de "pequeño" CAPE y "gran" CAPE (SBCAPE $>=500 \mathrm{~J} / \mathrm{kg}$ ), y de "pequeña" o "gran" cizalladura (ClZ6 >= $9 \mathrm{~m} / \mathrm{s})$. Esto no deja de ser un convencionalismo y puede haber situaciones que estén próximas a los valores umbrales que sean de dudosa catalogación.

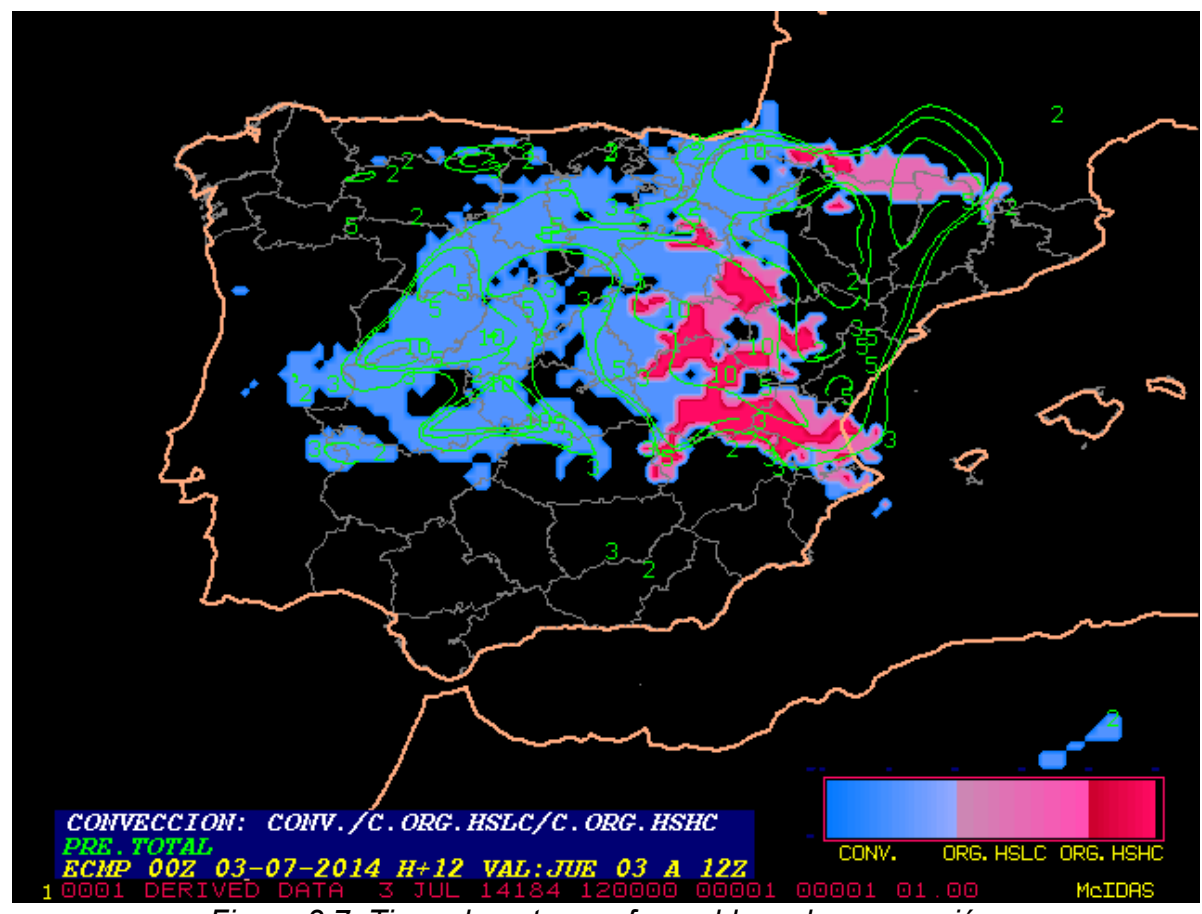

Figura 3.7. Tipos de entornos favorables a la convección. 


\section{Áreas convectivas}

Producto muy similar al anterior (aunque utiliza otro algoritmo) que trata de caracterizar entornos convectivos y de convección organizada (figura 3.8).

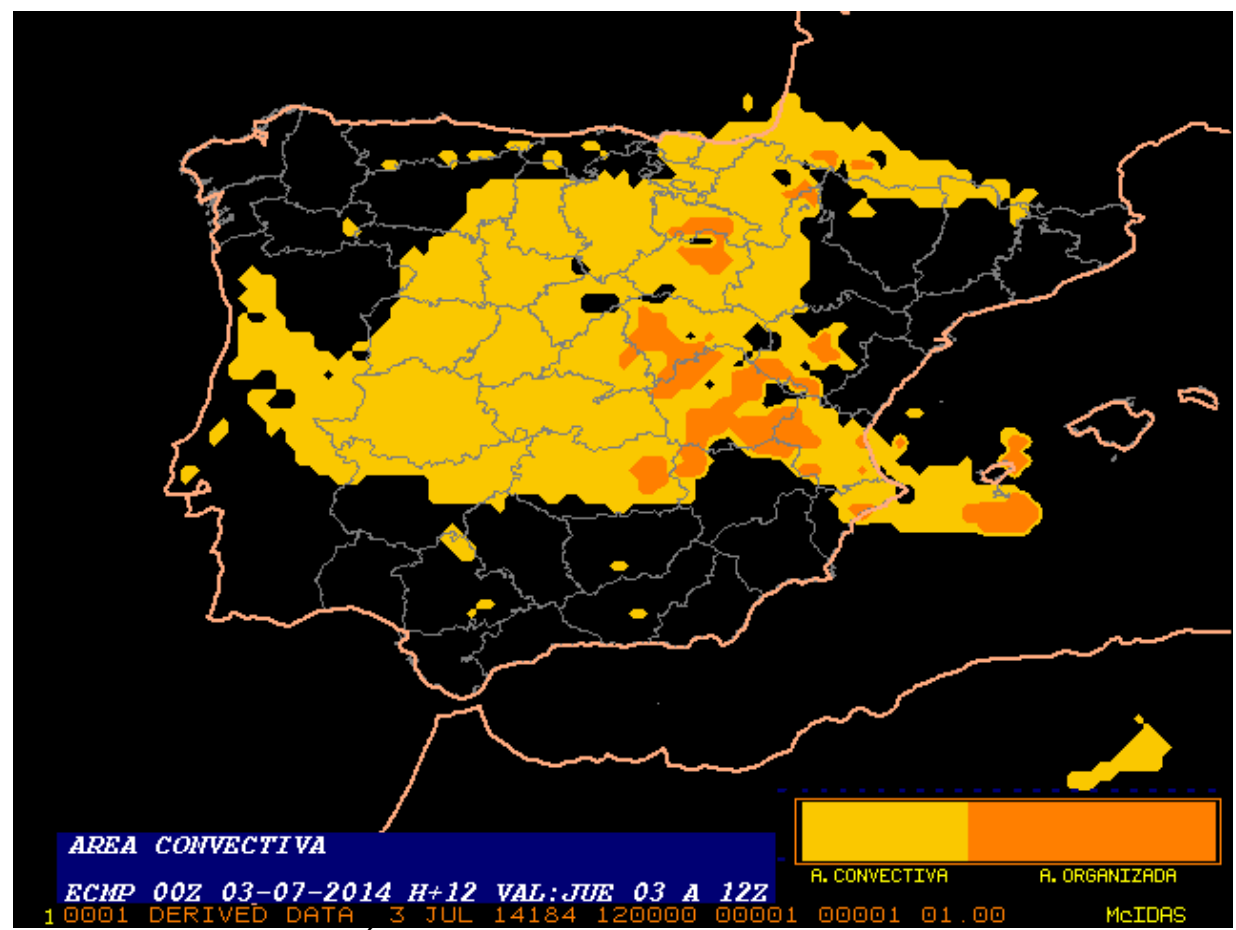

Figura 3.8. Áreas de convección y de convección organizada.

\section{b) Forzamiento dinámico}

\section{$(\mathrm{Z} / \mathrm{T}) \mathbf{5 0 0}$}

Sirve para tener una idea cuantitativa de los valores de geopotencial y temperatura en $500 \mathrm{hPa}$. Se aprecia la presencia de una baja centrada en el interior de la Península con un mínimo térmico de $-19^{\circ} \mathrm{C}$ (figura 3.9).

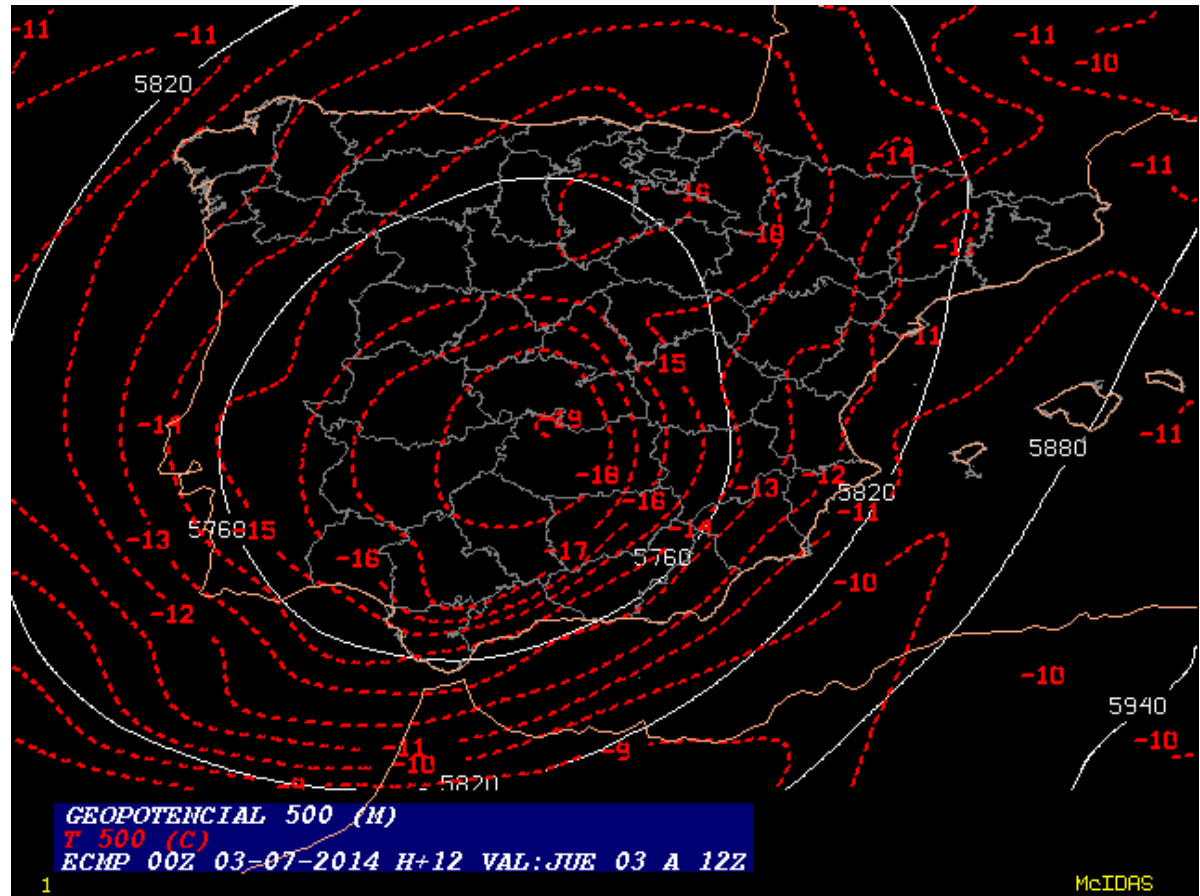

Figura 3.9. Z/T en 500 hPa. 
Es importante disponer también del geopotencial en $300 \mathrm{hPa}$ y el viento (coloreado en intensidad a partir de un valor umbral), de cara a la interpretación de la teoría cuasigeostrófica, y estimar los forzamientos existentes en las salidas y entradas de los máximos de viento (figura 3.10).

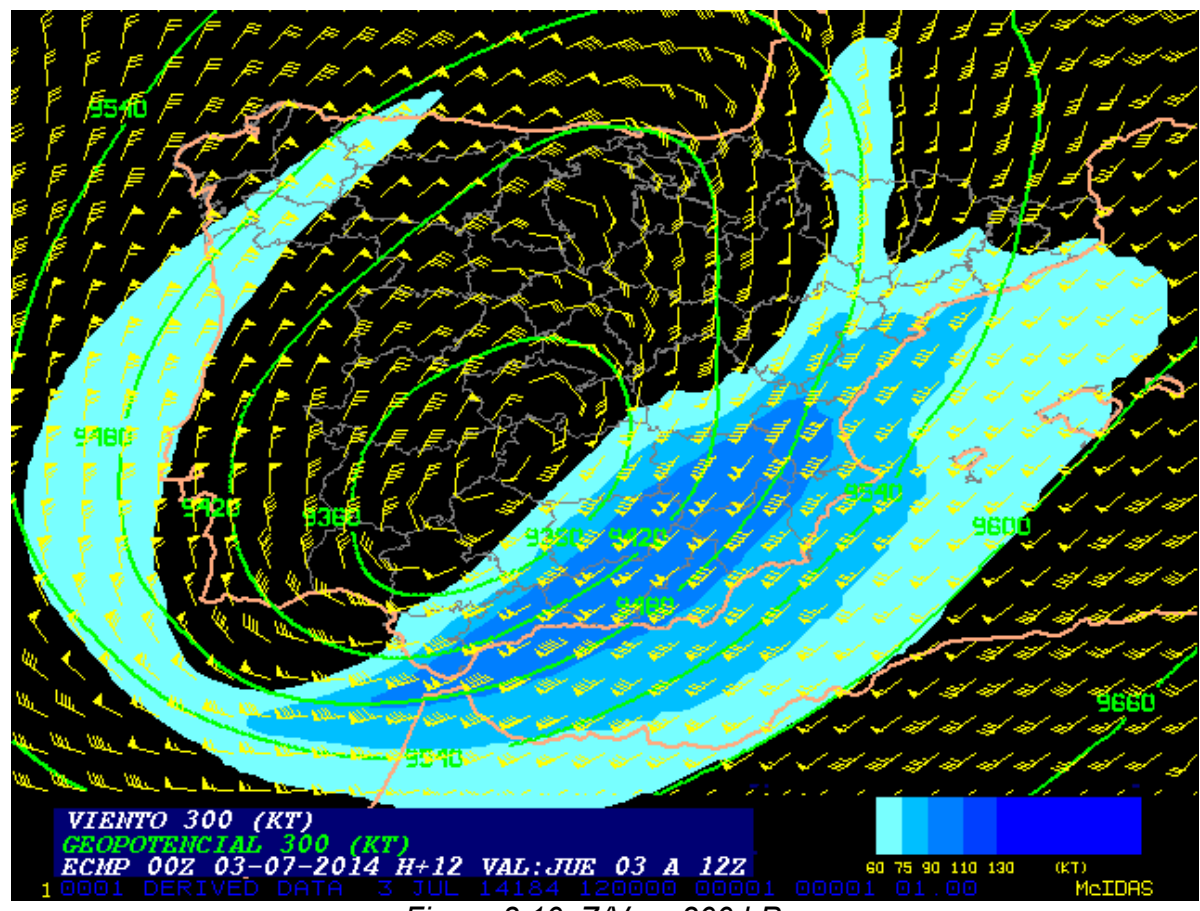

Figura 3.10. ZN en $300 \mathrm{hPa}$.

\section{(V / DVG) sfc}

Por supuesto resultan fundamentales los campos de presión y viento en superficie, así como la existencia de posibles convergencias que puedan provocar ascensos locales desde el suelo (figura 3.11). Se observan en este caso zonas de convergencias dinámicas, en algunos casos motivadas por la orografía.

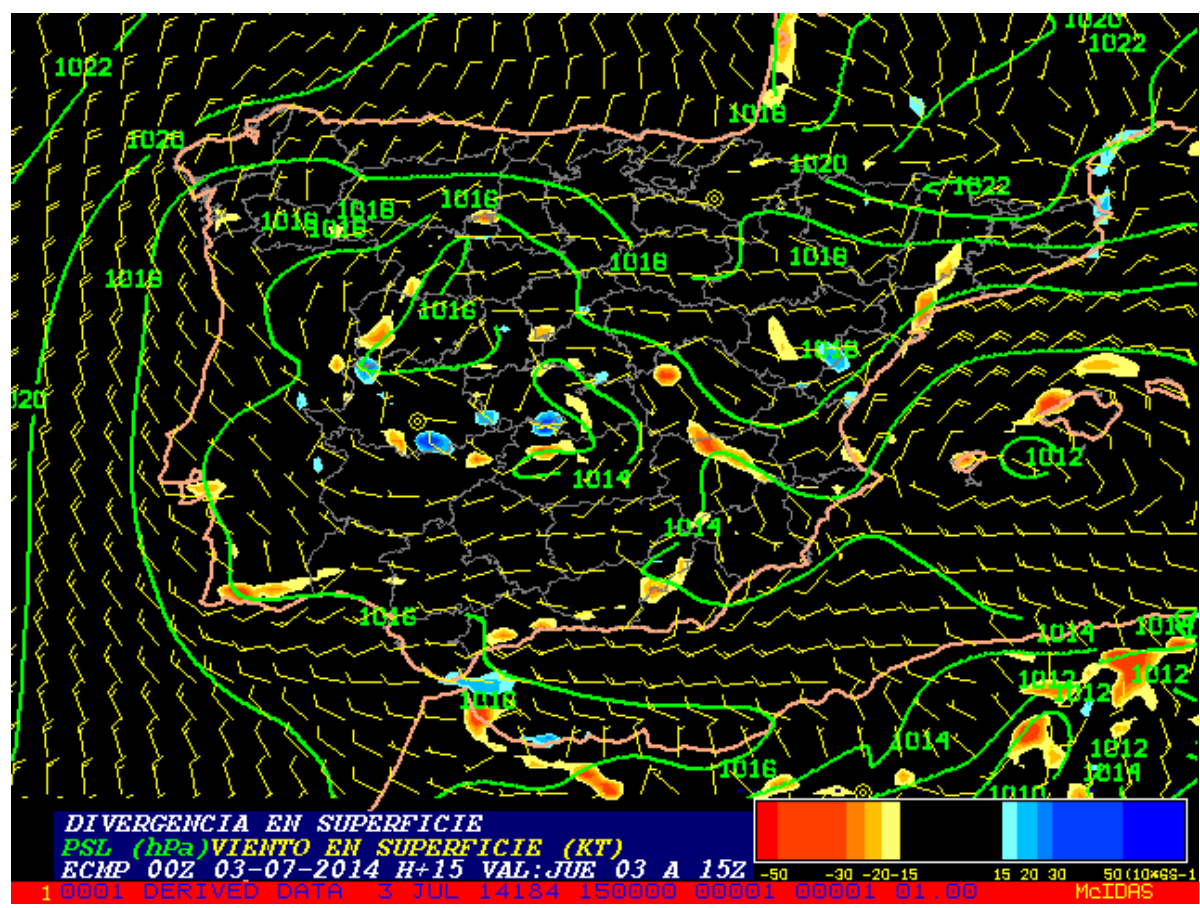

Figura 3.11. PSL, V, DIV al nivel del mar. 
Otro producto a tener en cuenta es el ascenso (descenso), debidamente coloreado, previsto por el modelo, en distintos niveles. En el episodio que nos ocupa se identifican zonas con ascensos en diversas topografías (figura 3.12).
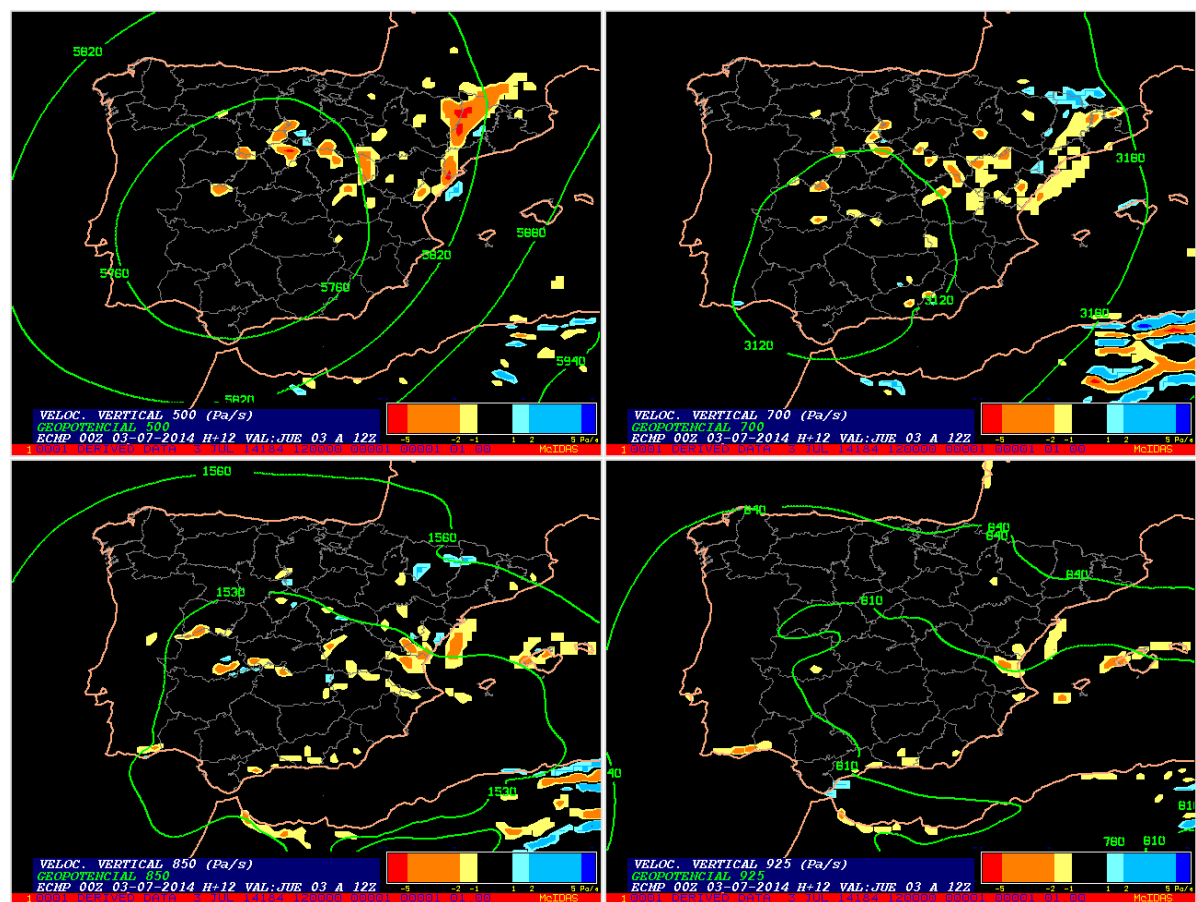

Figura 3.12. Velocidad vertical (w) en Pa/s (colores cálidos: ascensos y colores fríos: descensos) y geopotencial en los niveles de 500, 700, 850 y $925 \mathrm{hPa}$

(PFT / Z) 500, 700, 850, 925

Por último se incluye el parámetro frontal térmico en distintos niveles (figura 3.13). Este campo sirve para diferenciar distintas masas de aire o discontinuidades térmicas y de humedad, que en este ejemplo no son significativas, salvo una señal existente en el entorno de Baleares, especialmente en capas bajas. El Parámetro Frontal Térmico (PFT) es más útil para marcar la posición de sistemas frontales bien marcados.
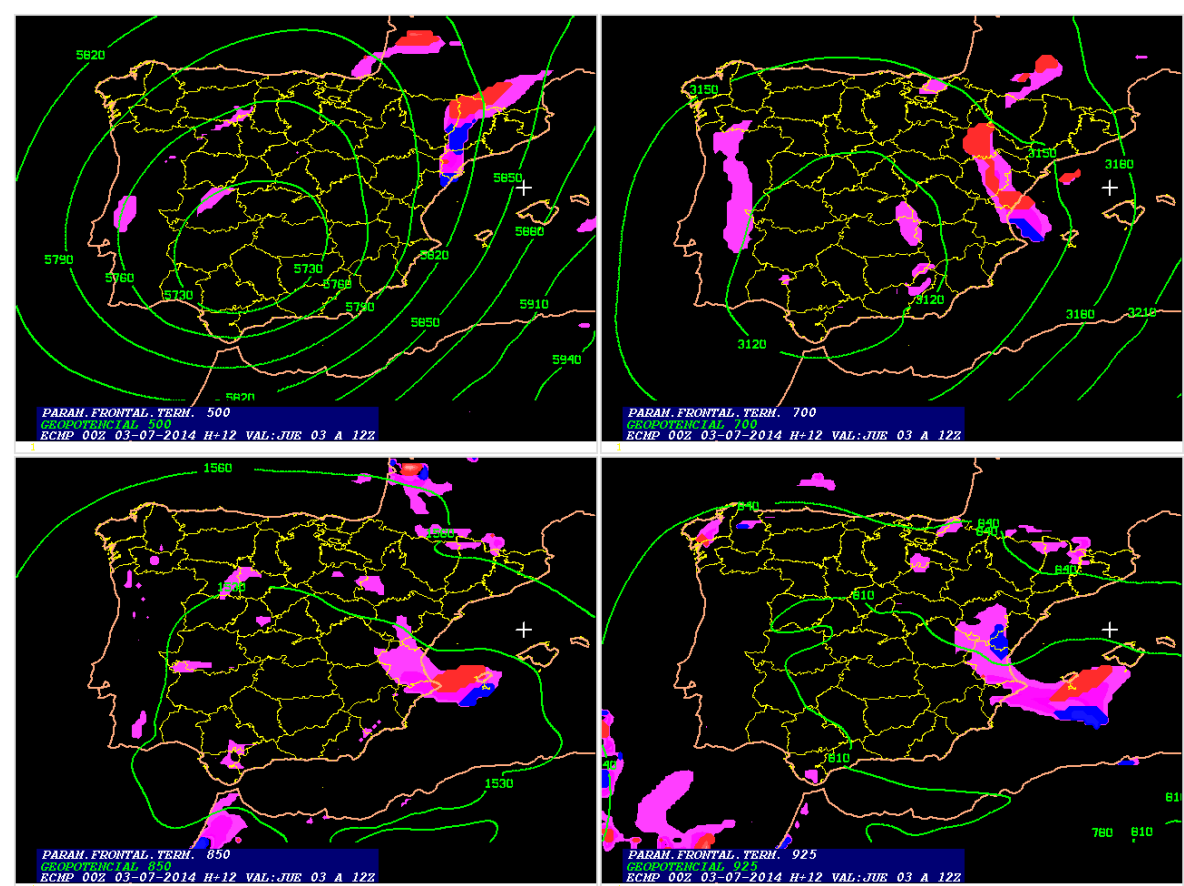

Figura 3.13. PFT y geopotencial en 500, 700, 850 y $925 \mathrm{hPa}$. 


\section{c) Campos Termodinámicos}

\section{LI7 /LI / TT / K}

Los índices LI (hasta 700 y hasta 500), así como el TT y el K, dan valores que denotan inestabilidad en amplias zonas de la Península, extendida en algunos casos hasta gran parte de Baleares (figura 3.14).

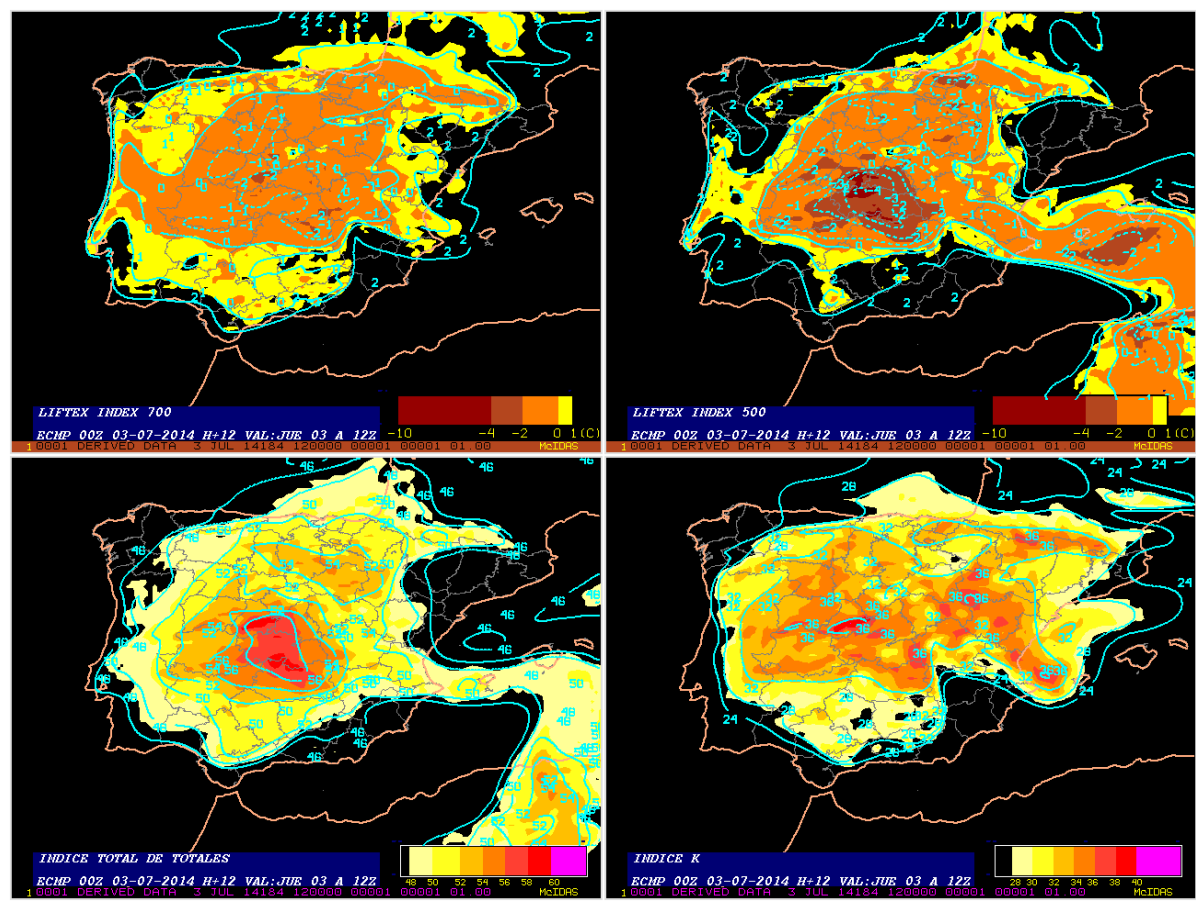

Figura 3.14. Arriba izquierda: LI 700, arriba derecha: LI 500, abajo izquierda: Indice TT, abajo derecha: Indice K.

\section{LI / LI7 / SBLI / SBLI7}

Los índices LI (hasta 700 y hasta 500), tanto evolucionando desde superficie como desde el promedio de la capa de los 100 primeros $\mathrm{hPa}$, muestran los valores más inestables en el centro peninsular (figura 3.15).
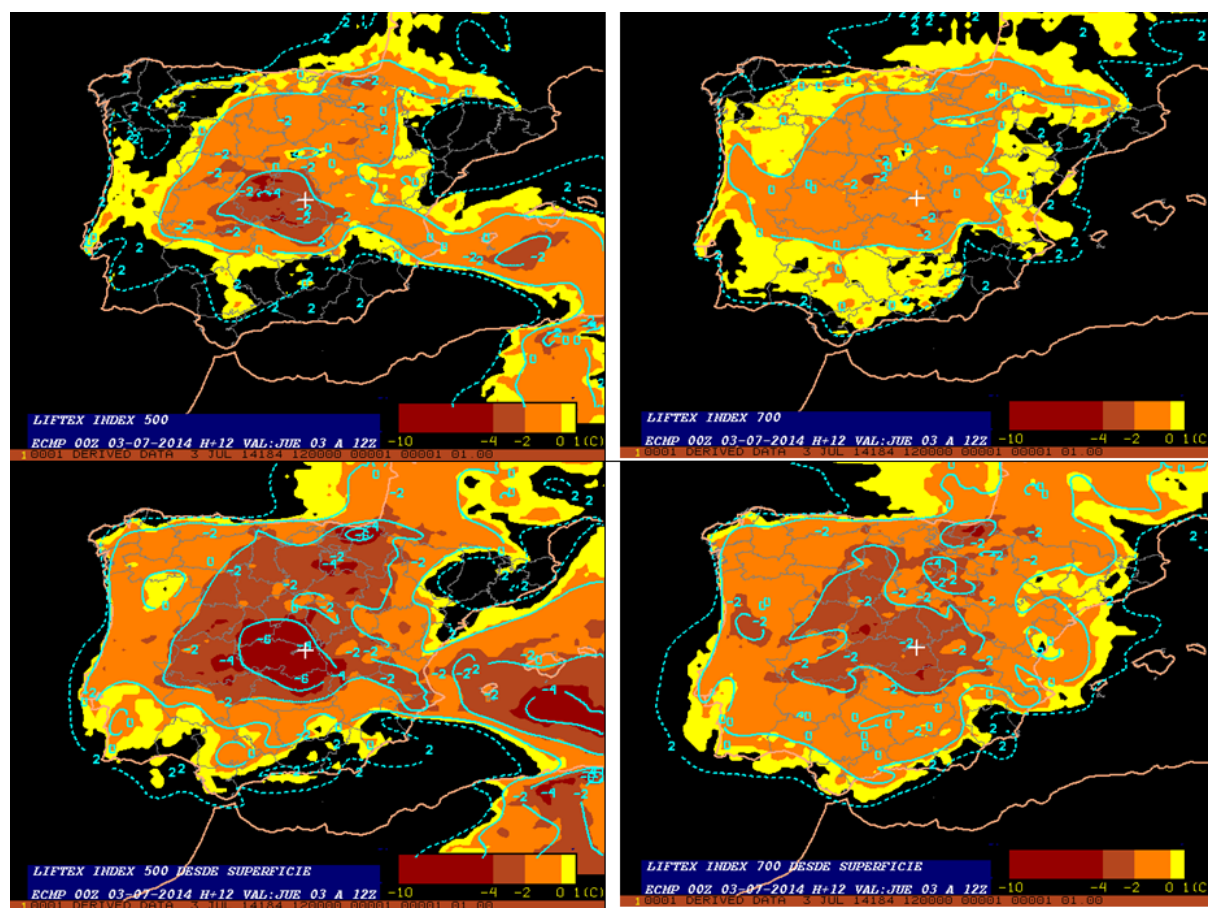

Figura 3.15: Arriba izquierda: LI 500 con las condiciones medias de los 100 primeros hPa, arriba derecha: LI 700 con las condiciones medias de los 100 primeros $h P a$, abajo izquierda: LI 500 con las condiciones en superficie, abajo derecha: LI 700 con las condiciones en superficie 


\section{CAP3 / MUCAPE / SBCAPE / CAPE}

Más o menos las mismas zonas que con los índices anteriores, son resaltadas con los distintos tipos de CAPE (hasta $3 \mathrm{~km}$, el más inestable, el que parte de superficie y el clásico en que la burbuja evoluciona desde la capa promedio de los primeros $100 \mathrm{hPa}$ ), tal y como indica la figura 3.16.
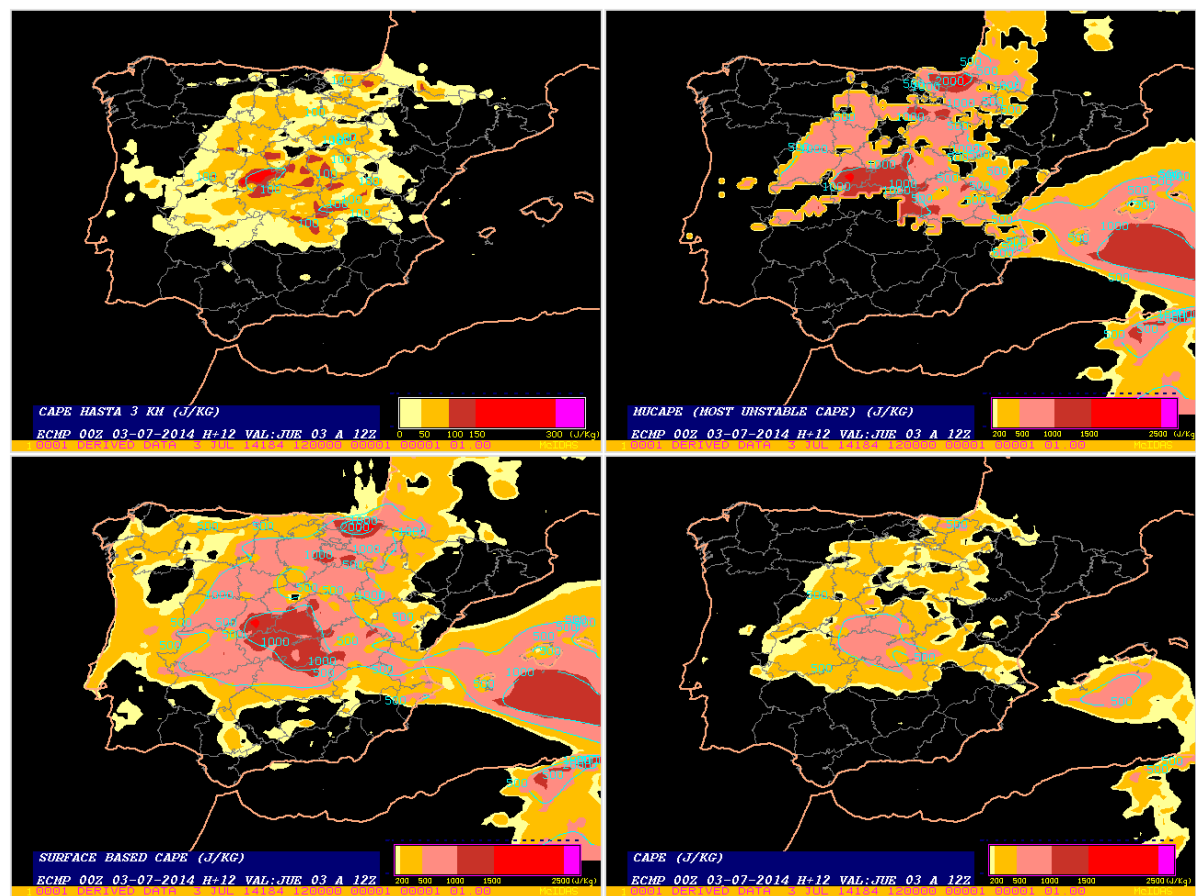

Figura 3.16. Panel de CAPEs (J/Kg). Arriba izquierda: CAPE hasta $3 \mathrm{~km}$, arriba derecha: MUCAPE, abajo izquierda: SBCAPE, abajo derecha: CAPE.

\section{CAPE / CIN / SBCAPE / SBCIN}

En este caso se comparan los CAPE (en sus dos formulaciones según el nivel de partida) y los correspondientes $\mathrm{CIN}$. Se observa cómo sobre el mar hay valores bastante más destacables de CIN, lo que implica inhibición convectiva a priori (figura 3.17).
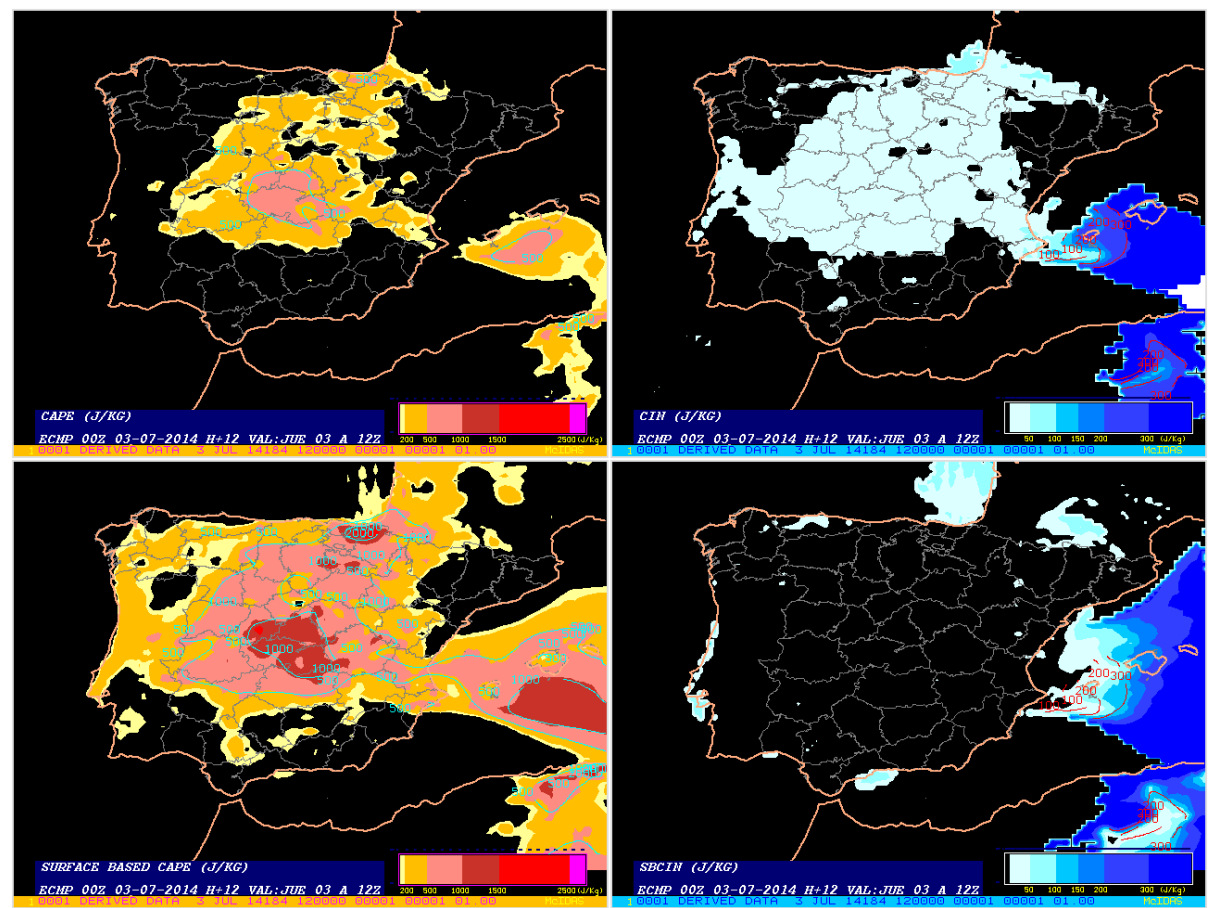

Figura 3.17. Panel de CAPEs y CINs (J/Kg). Arriba izquierda: CAPE, arriba derecha: CIN abajo izquierda: SBCAPE, abajo derecha: SBCIN. 


\section{$(Z / T) 500$ y $(Z / T) 850$}

Estos campos son básicos pero permiten valorar los flujos y temperaturas a esos dos niveles y determinar la inestabilidad desde un punto de vista aproximado en el apartado térmico (figura 3.18).

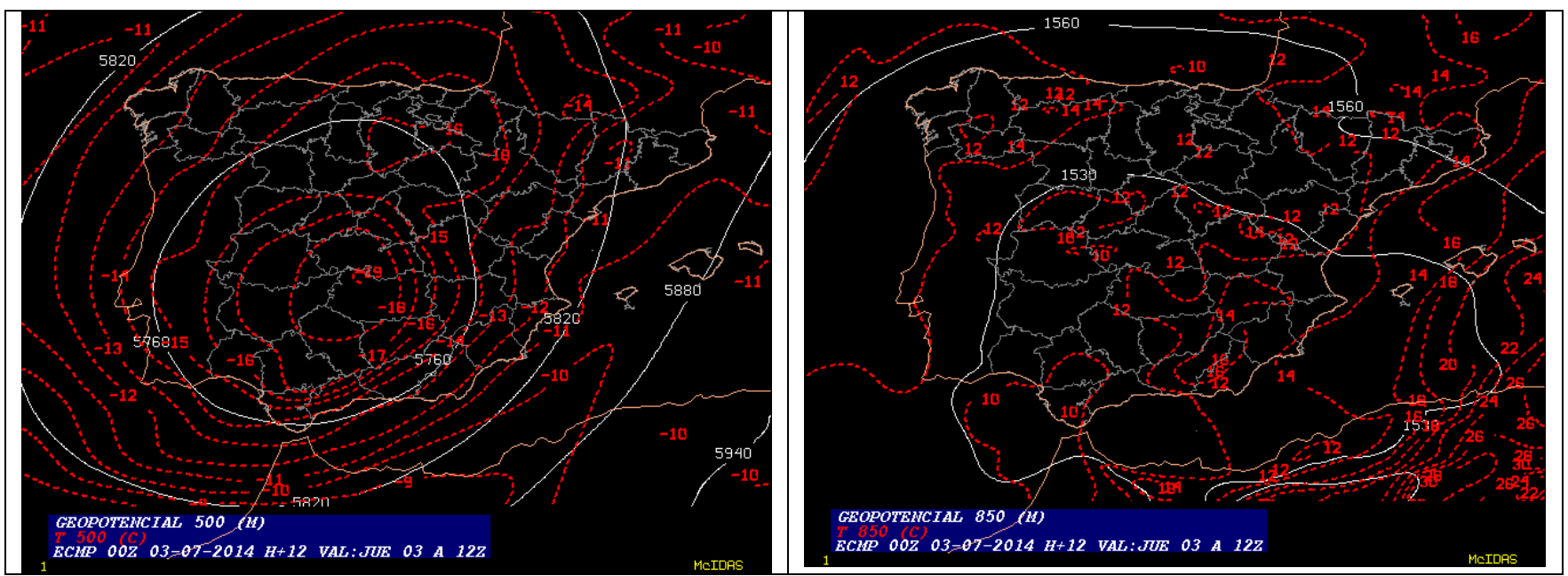

Figura 3.18. Izquierda: Z/T en $500 \mathrm{hPa}$, derecha: Z/T en $850 \mathrm{hPa}$.

(RH / Z) 500, 700, 850 y 925

Es fundamental ver los flujos en capas medias y bajas, e identificar los ambientes saturados y los no saturados en distintos niveles, para tenerlo en cuenta en el diagnóstico de precipitaciones intensas y severidad de las tormentas. En este caso se observa cómo hay saturación hasta al menos $700 \mathrm{hPa}$ en bastantes zonas del interior peninsular, llegando hasta la vertiente Mediterránea (figura 3.19)

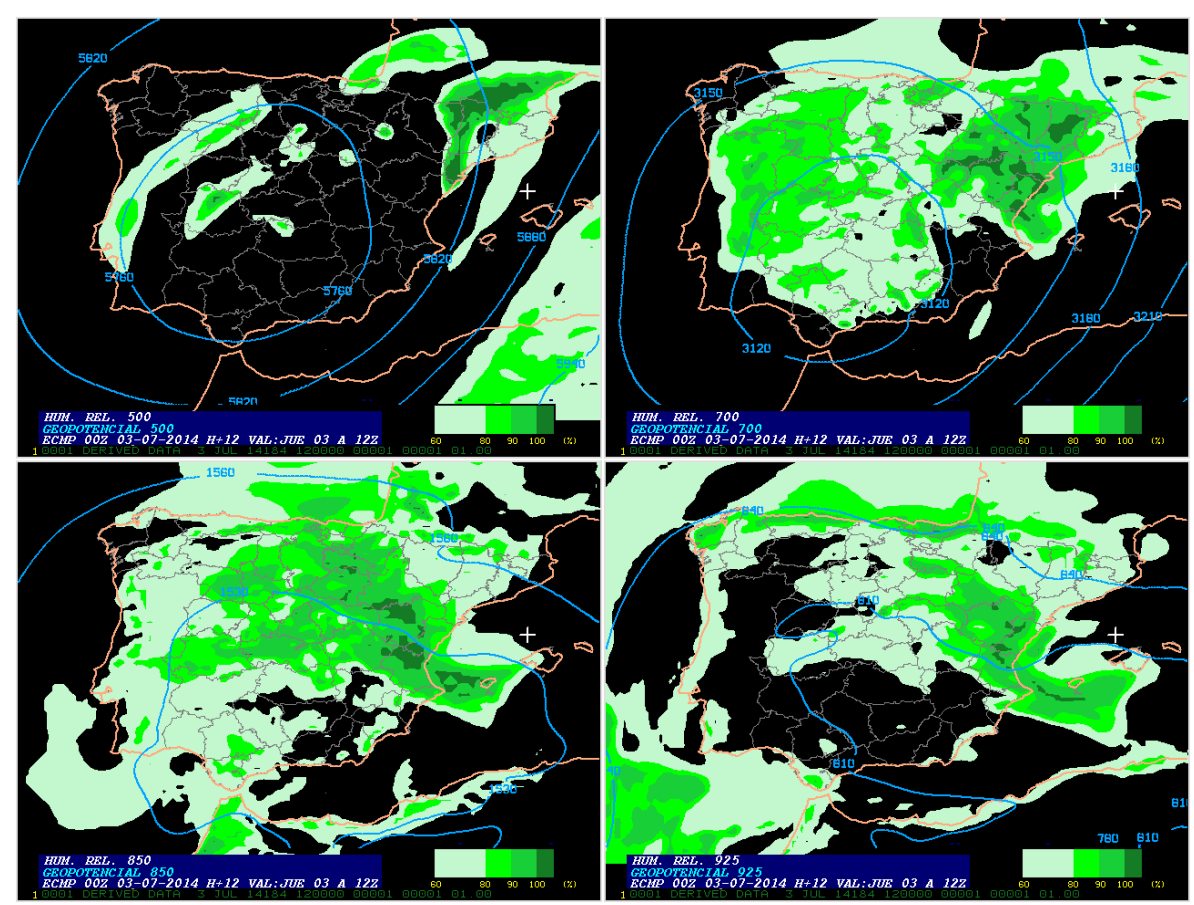

Figura 3.19. Humedad relativa (\%) y geopotencial (m) en distintos niveles (500, 700, 850 y 925 hPa). 


\section{ESTW $(700,850,925)$ y GVT $700-500$}

Puede ser interesante ver el campo estabilidad estático-húmeda en distintos niveles, especialmente mediosbajos. En esta situación existe una marcada inestabilidad en el centro peninsular en 850 y $700 \mathrm{hPa}$. Asimismo el gradiente térmico vertical entre 700 y 500 es bastante acusado en una zona reducida del centro peninsular (superior a 7), y sobre todo en zonas sobre el Mediterráneo (figura 3.20).

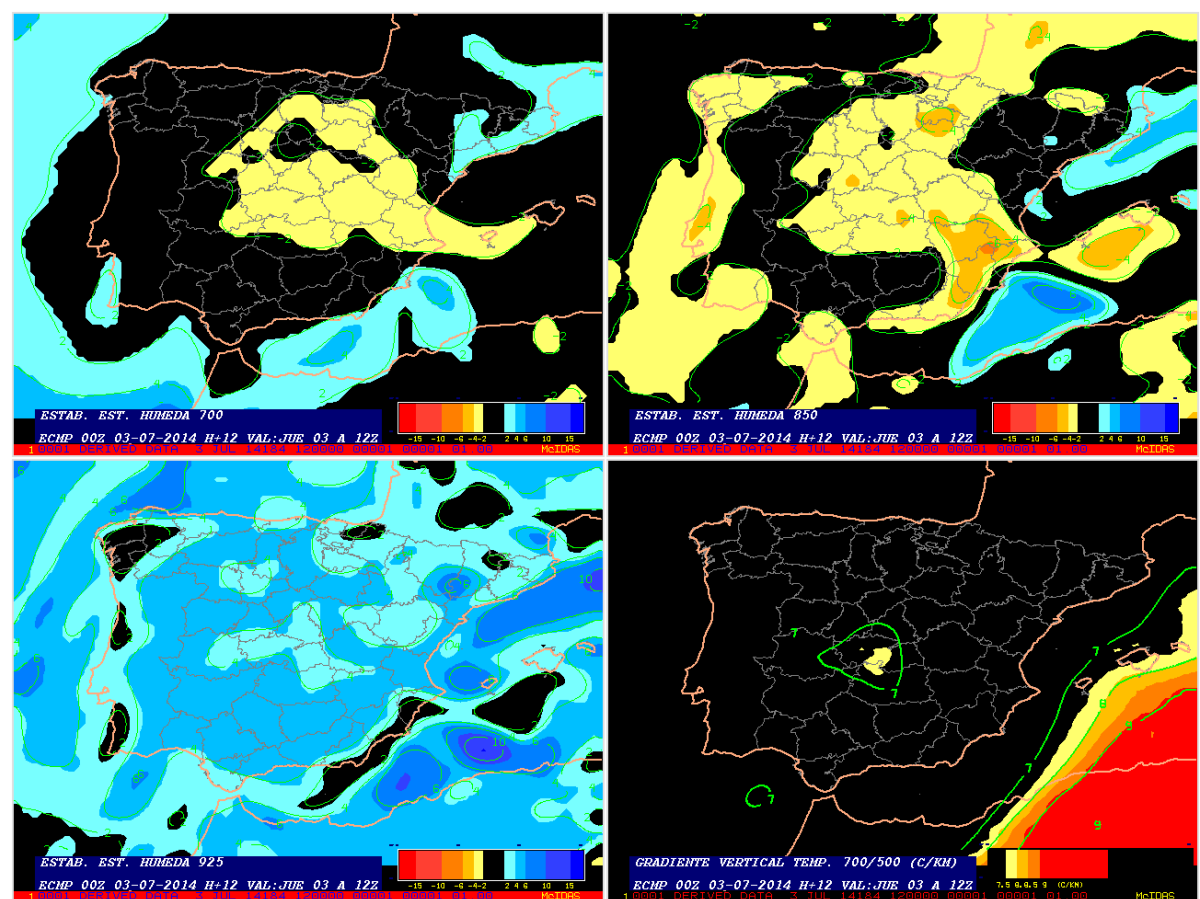

Figura 3.20. Arriba izquierda: ESTW en 700 hPa, arriba derecha: ESTW en 850 hPa, abajo izquierda: ESTW en 925 hPa, abajo derecha: gradiente térmico vertical entre 700 y $500 \mathrm{hPa}$.

\section{THE Y ADVECCIÓN (500, 700, 850 y $925 \mathrm{hPa})$}

La temperatura potencial equivalente sirve como trazador de separación de masas de aire en distintos niveles (figura 3.21).

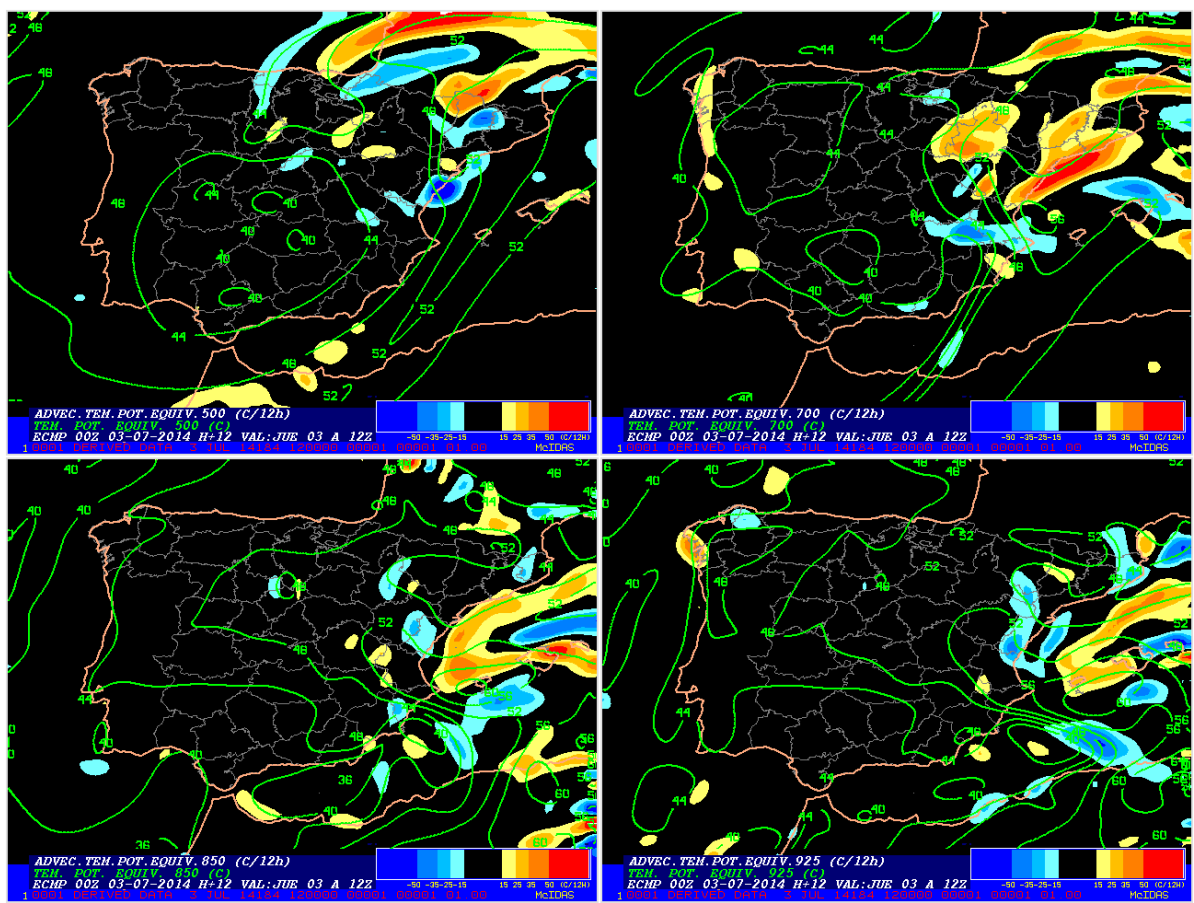

Figura 3.21. THE (C) y su advección ( $\left.{ }^{\circ} \mathrm{C} / 12 \mathrm{~h}\right)$ en varios niveles (500, 700, 850 y $\left.925 \mathrm{hPa}\right)$. 


\section{NCA / NCC / NCL / NE (m)}

Es fundamental conocer los valores de distintos "niveles" importantes en la convección. En este caso los dos niveles de condensación (por ascenso y convectivo) están más bajos en el centro y mitad norte peninsular, y en el mar Balear. El de convección libre es también más bajo en zona centro, mientras que aumenta sobre el mar Balear. El nivel de equilibrio es muy elevado en zonas del centro Peninsular y Baleares (figura 3.22).

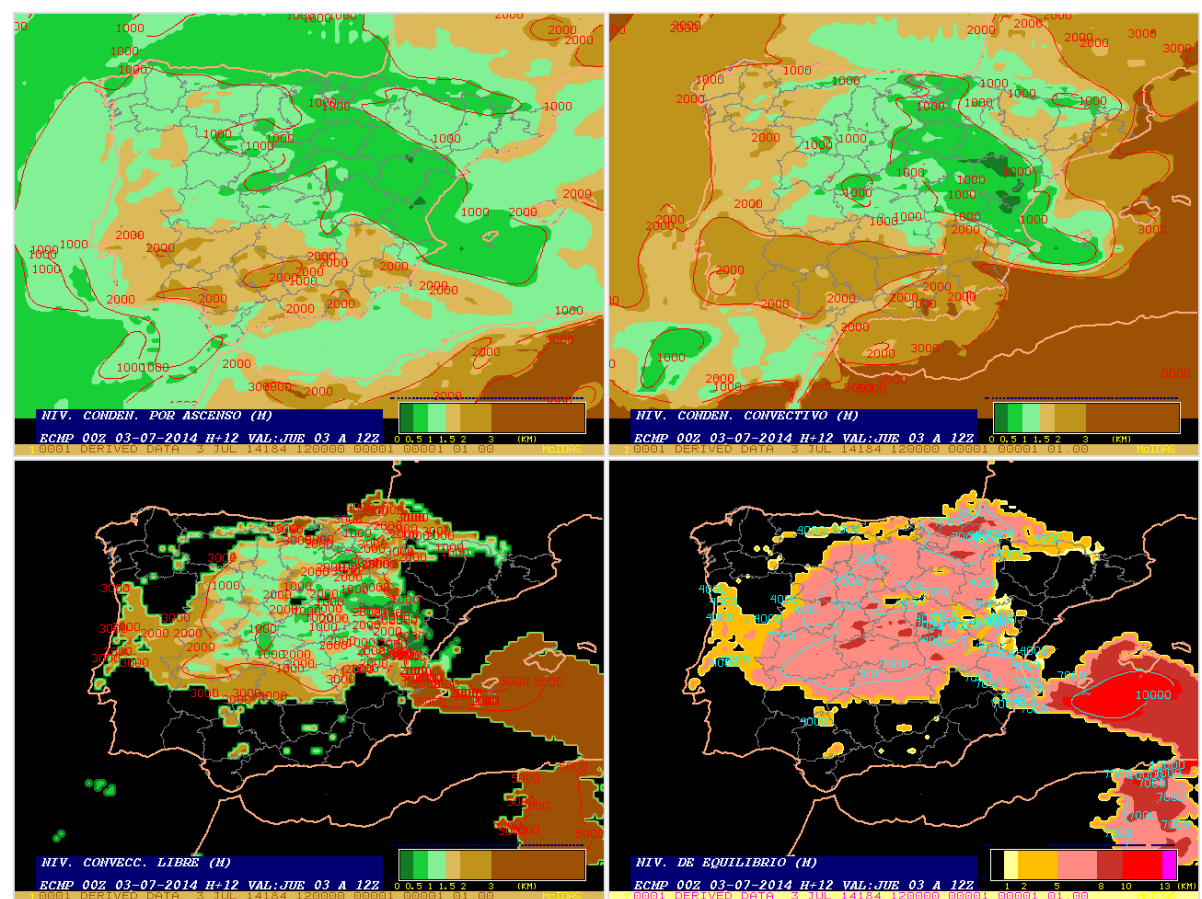

Figura 3.22. Arriba izquierda: $N C A(m)$, arriba derecha: $N C C(m)$, abajo izquierda: $N C L(m)$, abajo derecha: $N E(m)$.

\section{TNE}

Este producto proporciona la temperatura del nivel de equilibrio, que es más baja en este caso sobre el centro Peninsular y al sur de Baleares (figura 3.23).

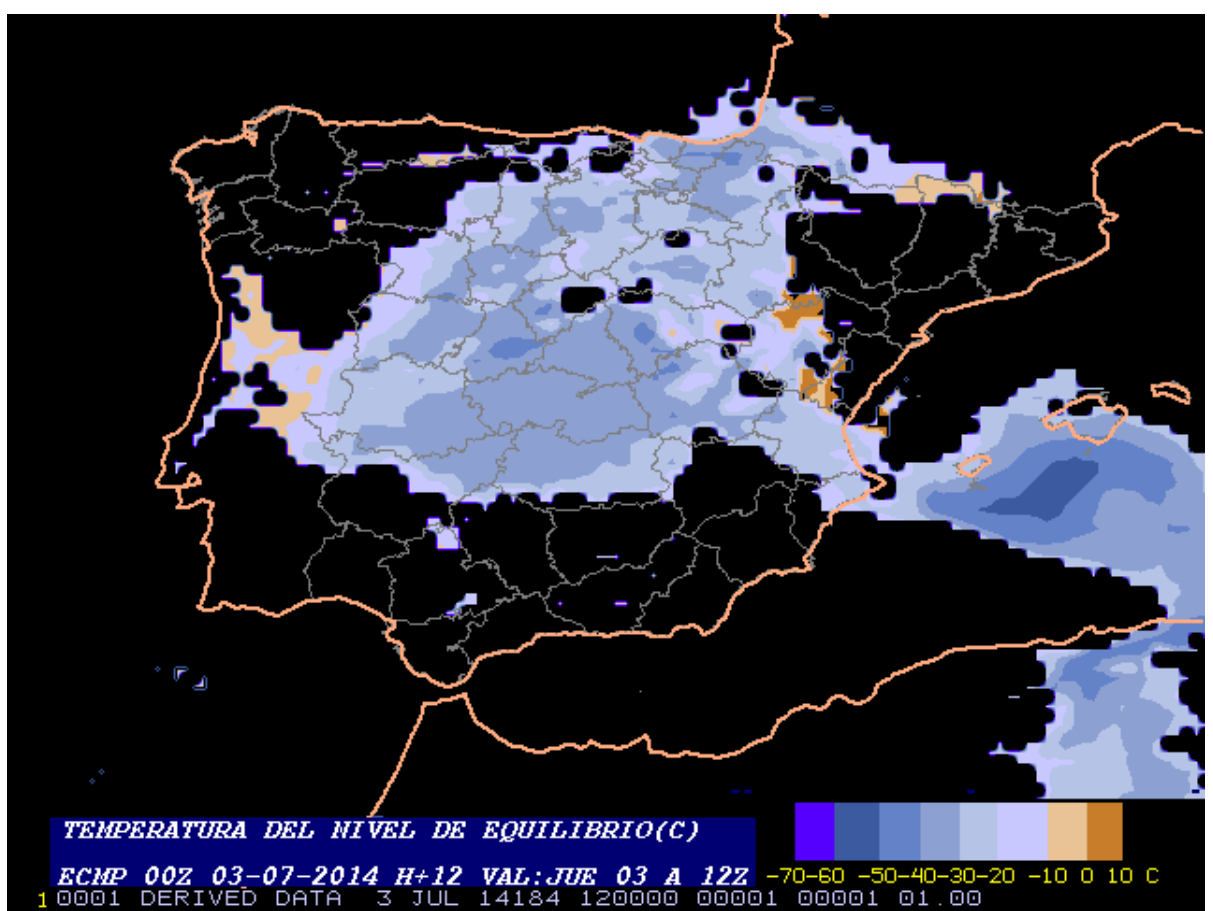

Figura 3.23. Temperatura del Nivel de Equilibrio $\left({ }^{\circ} \mathrm{C}\right)$. 


\section{NCL-NCA / NCA}

Para que se dispare la convección, es importante que la diferencia entre el NCL y NCA sea pequeña. Viene a indicar algo similar al CIN, y en este caso es más baja en zonas del centro peninsular, aumentando bastante en el área Mediterránea. Se superpone además, contorneado, el NCA (figura 3.24).

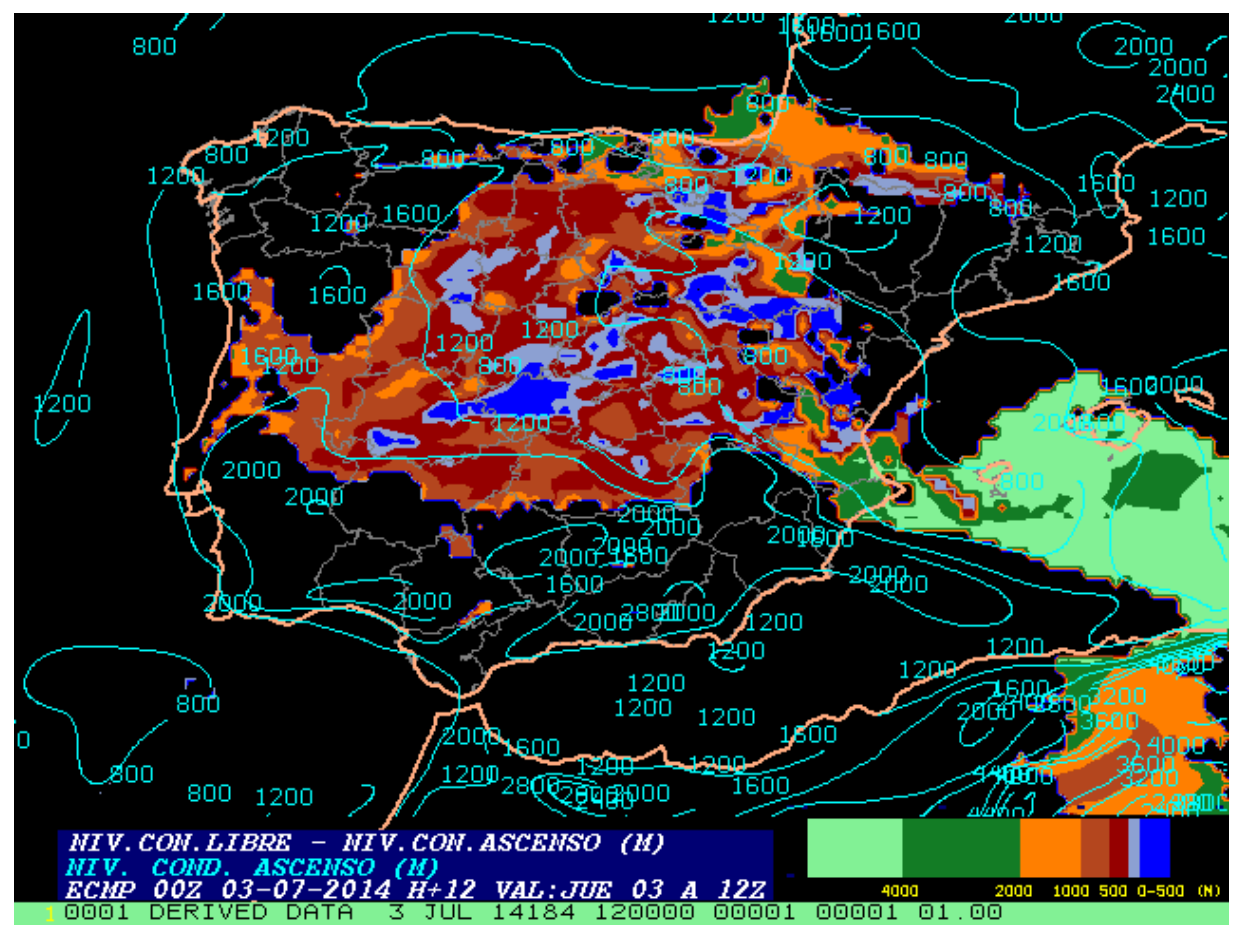

Figura 3.24. Nivel de condensación por ascenso y diferencia entre el nivel de convección libre y el nivel de condensación por ascenso.

\section{T. disparo / NCC}

Para el disparo propiamente convectivo, es fundamental analizar cual es en cada zona la temperatura de disparo desde superficie por si puede saltar la convección desde ese nivel. También lógicamente es importante conocer cual es la altura desde superficie hasta el nivel de condensación convectivo. Las temperaturas de disparo más bajas se observan por el centro y norte peninsular (figura 3.25).

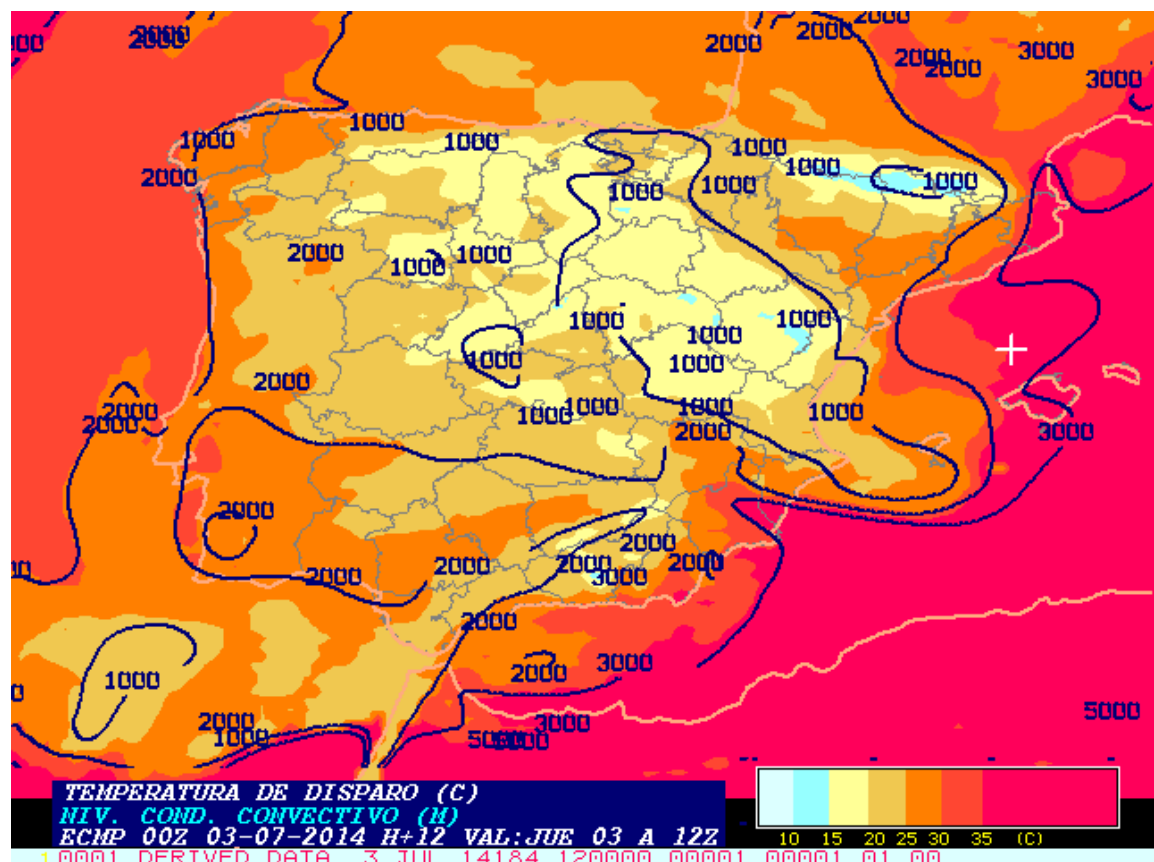

Figura 3.25. Temperatura de disparo y altura del nivel de condensación convectivo. 


\section{Flotabilidad de la Columna}

Se aprecia que para puntos del centro peninsular hay flotabilidad prácticamente en toda la columna en zonas reducidas del centro peninsular (figura 3.26). Si la burbuja parte desde más arriba, el área crece.

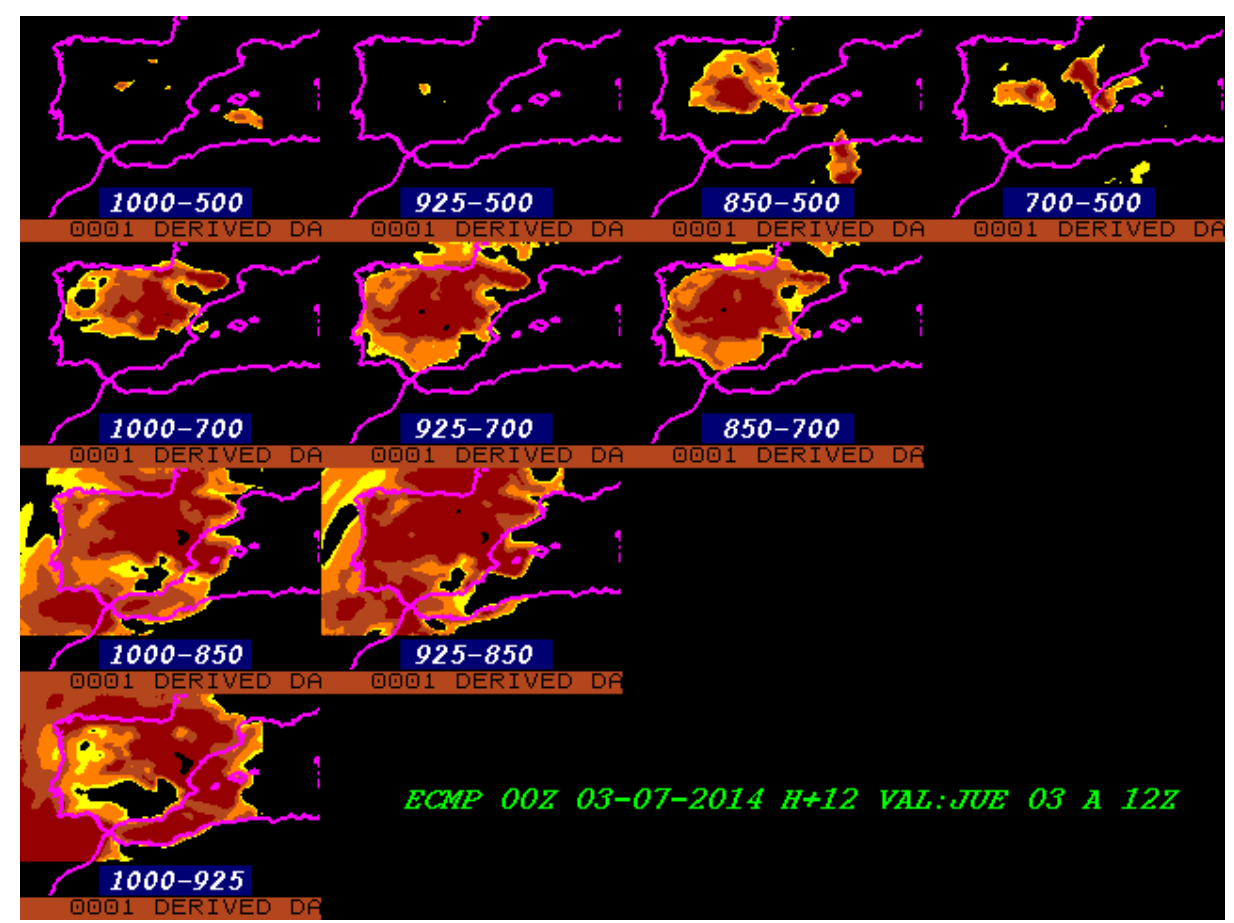

Figura 3.26. Flotabilidad en la columna.

\section{d) Cizalladura / Organización}

\section{$\mathrm{ClZ} 6,3$ y $1 \mathrm{~km}$}

La cizalladura es necesaria en la organización de la convección. En este episodio, los valores son altos en el área Mediterránea, especialmente en el mar Balear, tanto en una capa de $1 \mathrm{~km}$ como en la de 3 y en la de $6 \mathrm{~km}$ (figura 3.27).
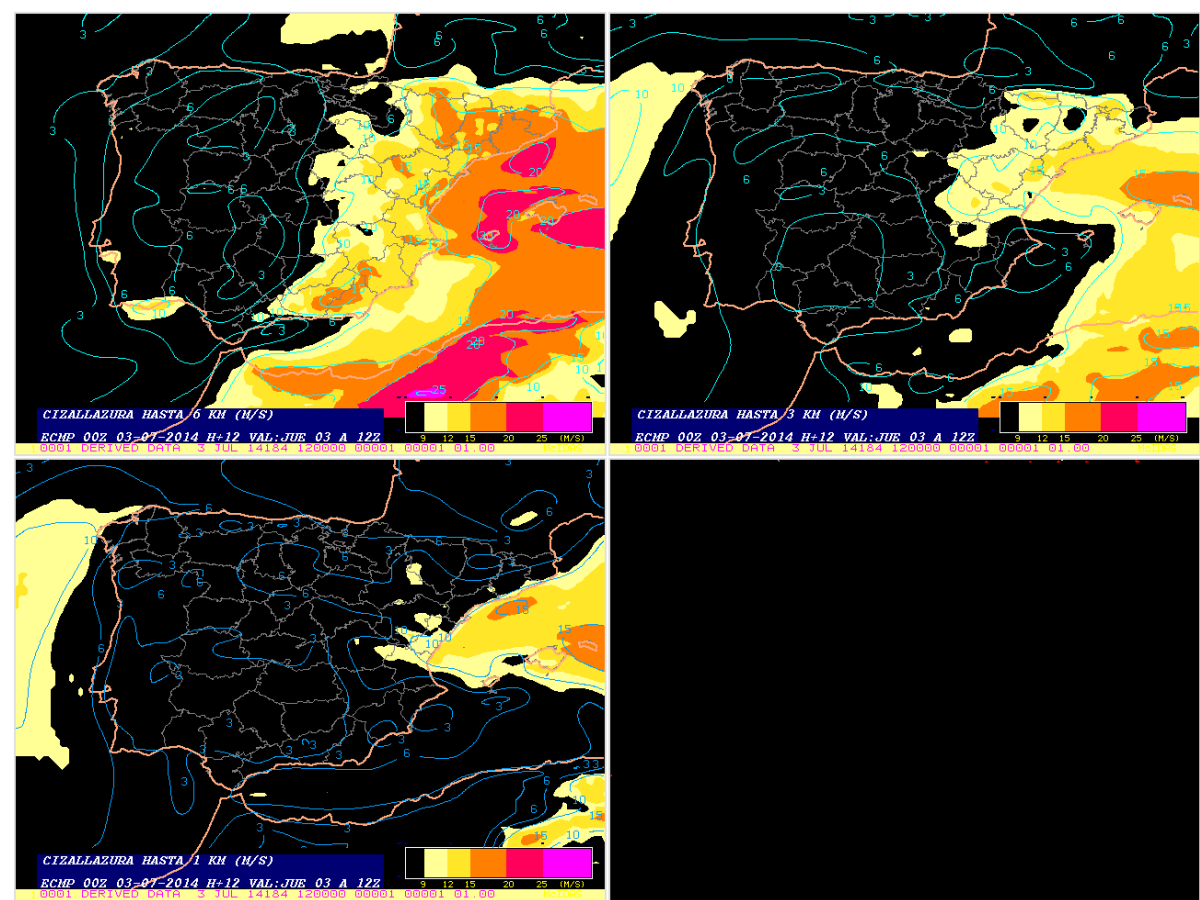

Figura 3.22. Arriba izquierda: cizalladura hasta $6 \mathrm{~km}(\mathrm{~m} / \mathrm{s})$, arriba derecha: cizalladura hasta $3 \mathrm{~km}$ (m/s), abajo izquierda: cizalladura hasta $1 \mathrm{~km}(\mathrm{~m} / \mathrm{s})$. 
La visualización del viento y geopotencial en distintos niveles, aparte de otros productos de diagnóstico, nos permite cuantificar de modo aproximado la cizalladura existente (figura 3.28).

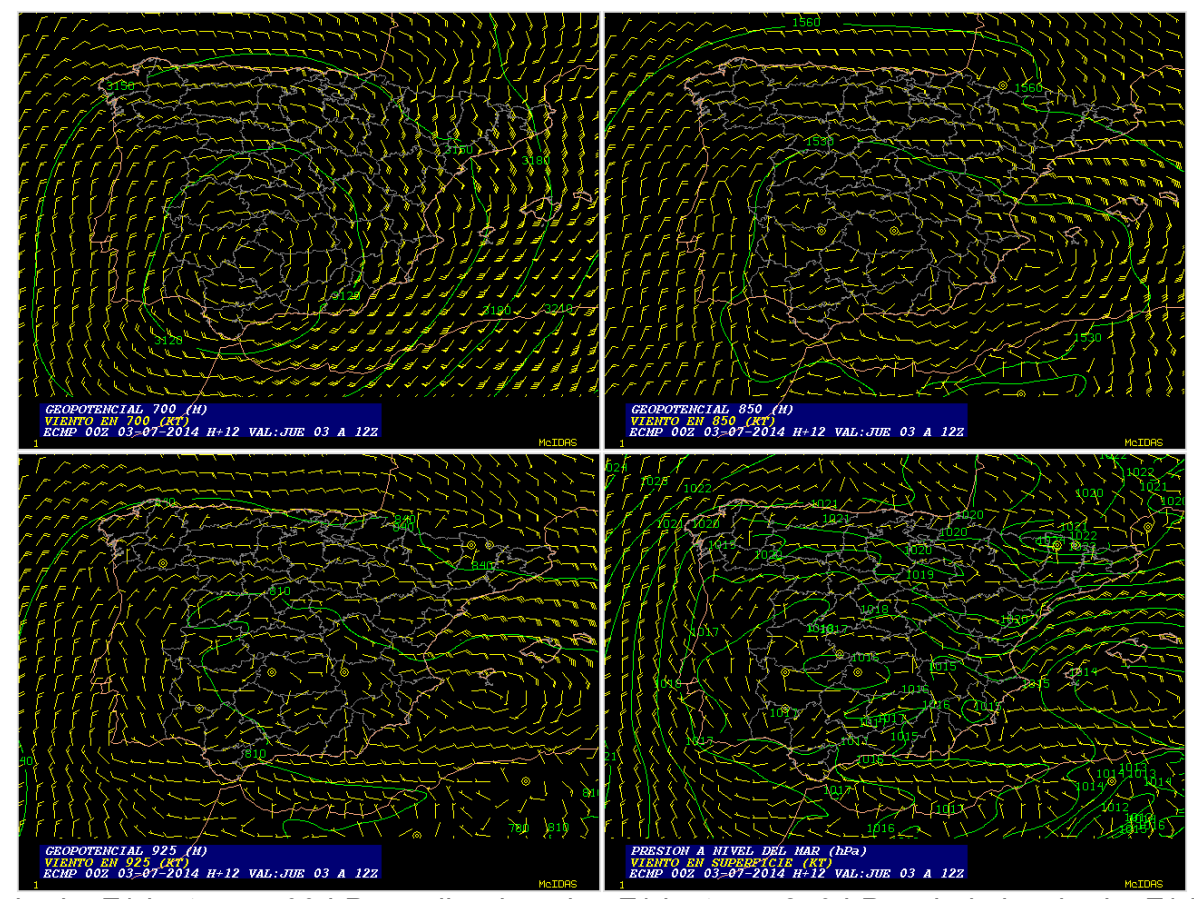

Figura 3.28. Arriba izquierda: Z/viento en 700 hPa, arriba derecha: Z/viento en 850 hPa, abajo izquierda: Z/viento en 925 hPa, abajo derecha: presión a nivel del mar (mb) y viento en superficie (Kt).

\section{SRH 1 y 3 km (Bunkers)}

Los altos valores de helicidad relativa a la tormenta (método de Bunkers) en una capa que se extiende a lo largo del primer kilómetro y de otra de tres kilómetros nos indican en cierto modo la capacidad que posee la atmósfera de organizar la convección para generar tornados y supercélulas. Se observan en esta situación, elevados valores en la zona de Baleares, de la helicidad relativa para células que se movieran a la derecha del viento medio, especialmente en la capa de $3 \mathrm{~km}$ (figura 3.29).

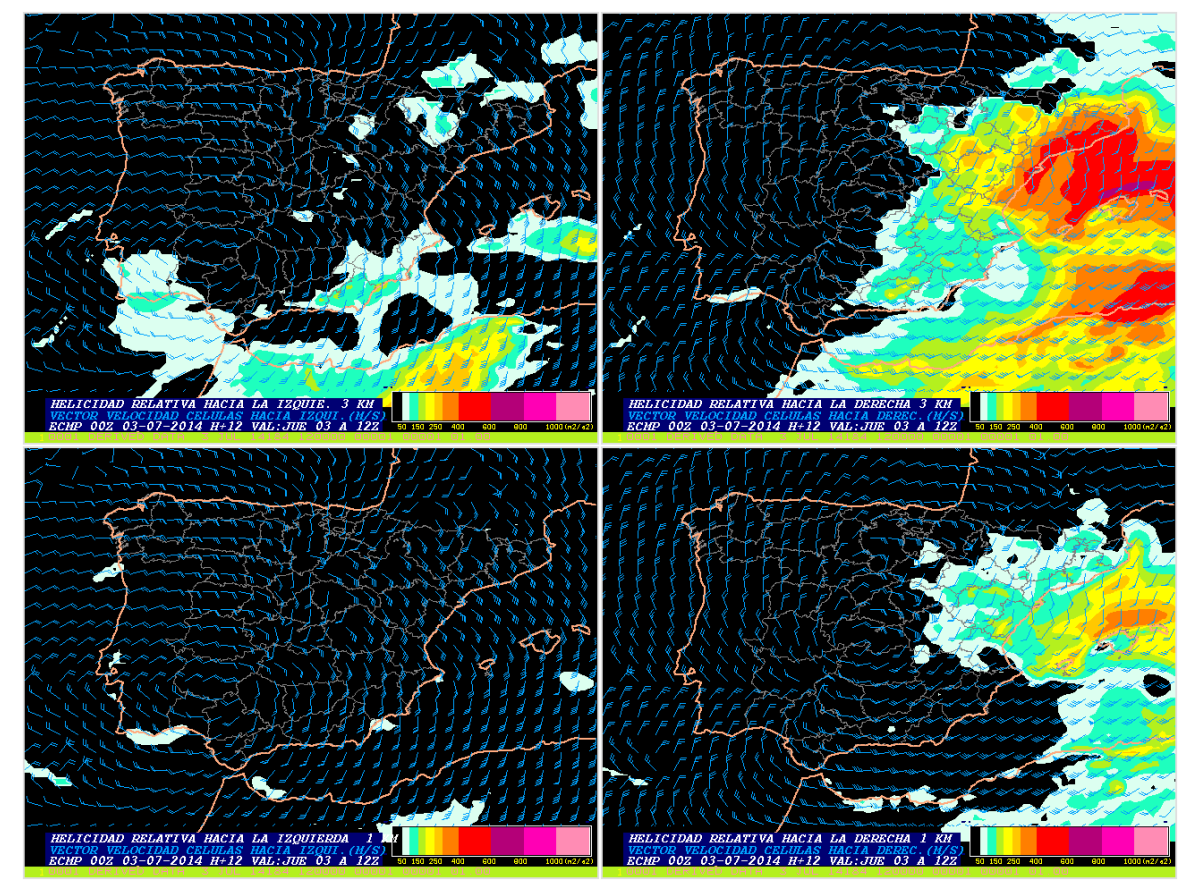

Figura 3.29. SRH $\left(\mathrm{m}^{2} / \mathrm{s}^{2}\right)$ según método Bunkers Arriba izquierda: $\mathrm{SRH}$ en la capa de $3 \mathrm{~km}$ sobre el suelo y vector velocidad (m/s) de las células convectivas que se mueven a la izquierda del viento medio, arriba derecha: SRH en la capa de $3 \mathrm{~km}$ sobre el suelo y vector velocidad $(\mathrm{m} / \mathrm{s})$ de las células convectivas que se mueven a la derecha del viento medio, abajo izquierda: SRH en la capa de $1 \mathrm{~km}$ sobre el suelo y vector velocidad $(\mathrm{m} / \mathrm{s})$ de las células convectivas que se mueven a la izquierda del viento medio, abajo derecha: $S R H$ en la capa de $1 \mathrm{~km}$ sobre el suelo y vector velocidad $(\mathrm{m} / \mathrm{s})$ de las células convectivas que se mueven a la derecha del viento medio. 


\section{SRH efectiva}

En este caso se presenta la helicidad efectiva, que da señal para células que se mueven a derecha del viento medio (sobre todo en Ibiza). También se aprecia en la misma zona, que la base de la capa efectiva está por encima de $1000 \mathrm{~m}$, y el espesor es también superior al km. (figura 3.30).
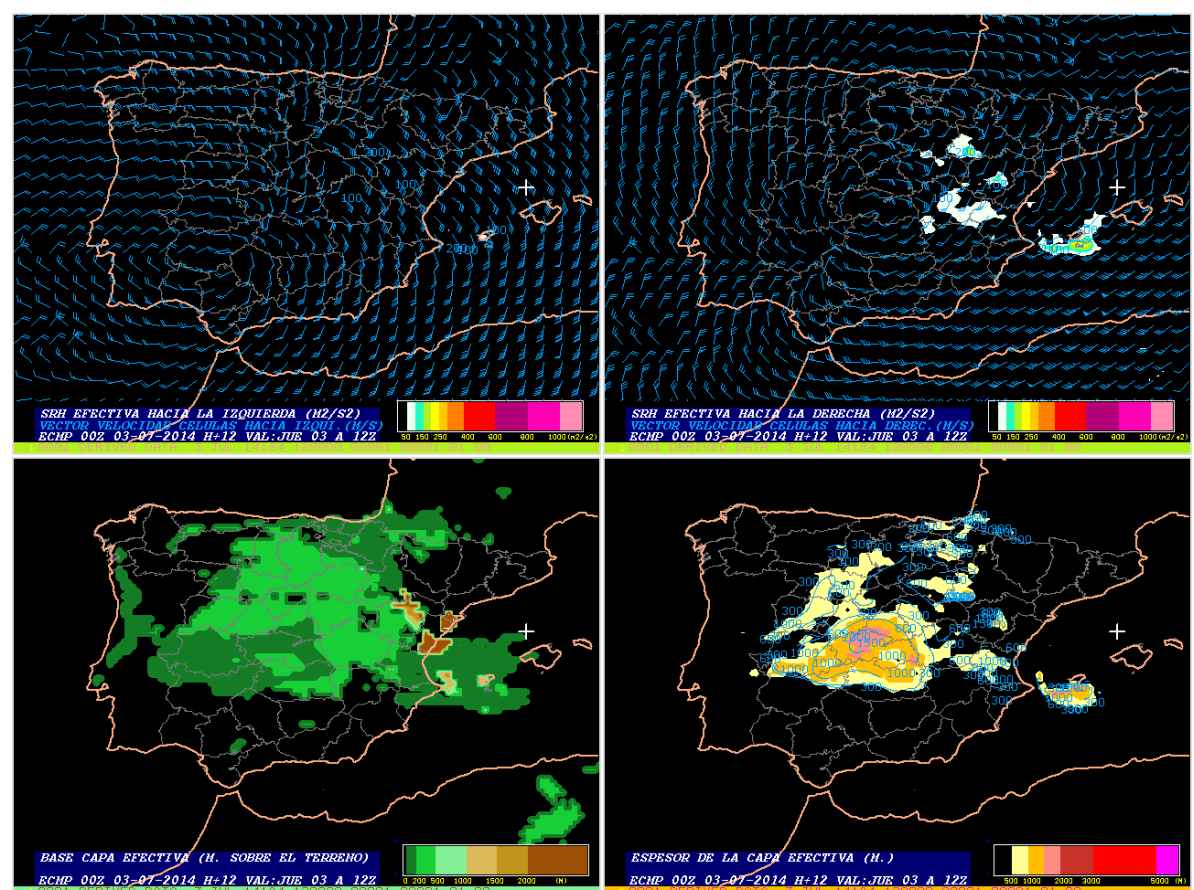

Figura 3.30. Helicidad relativa a la tormenta calculada en la capa efectiva $\left(\mathrm{m}^{2} / \mathrm{s}^{2}\right)$. Arriba izquierda: helicidad relativa a la tormenta junto con el vector velocidad $(\mathrm{m} / \mathrm{s})$ de las células convectivas que se mueven a la izquierda, arriba derecha: helicidad relativa a la tormenta junto con el vector velocidad $(\mathrm{m} / \mathrm{s})$ de las células convectivas que se mueven a la derecha, abajo izquierda: base en metros sobre el terreno de la capa efectiva, abajo derecha: espesor de la capa efectiva (m).

\section{EHI y NRG}

En el episodio que nos ocupa hay valores significativos de ambos índices en el Centro Peninsular y Baleares, pero sin solaparse (figura 3.31). Ello denota posibles entornos ligeramente favorables a severidad.

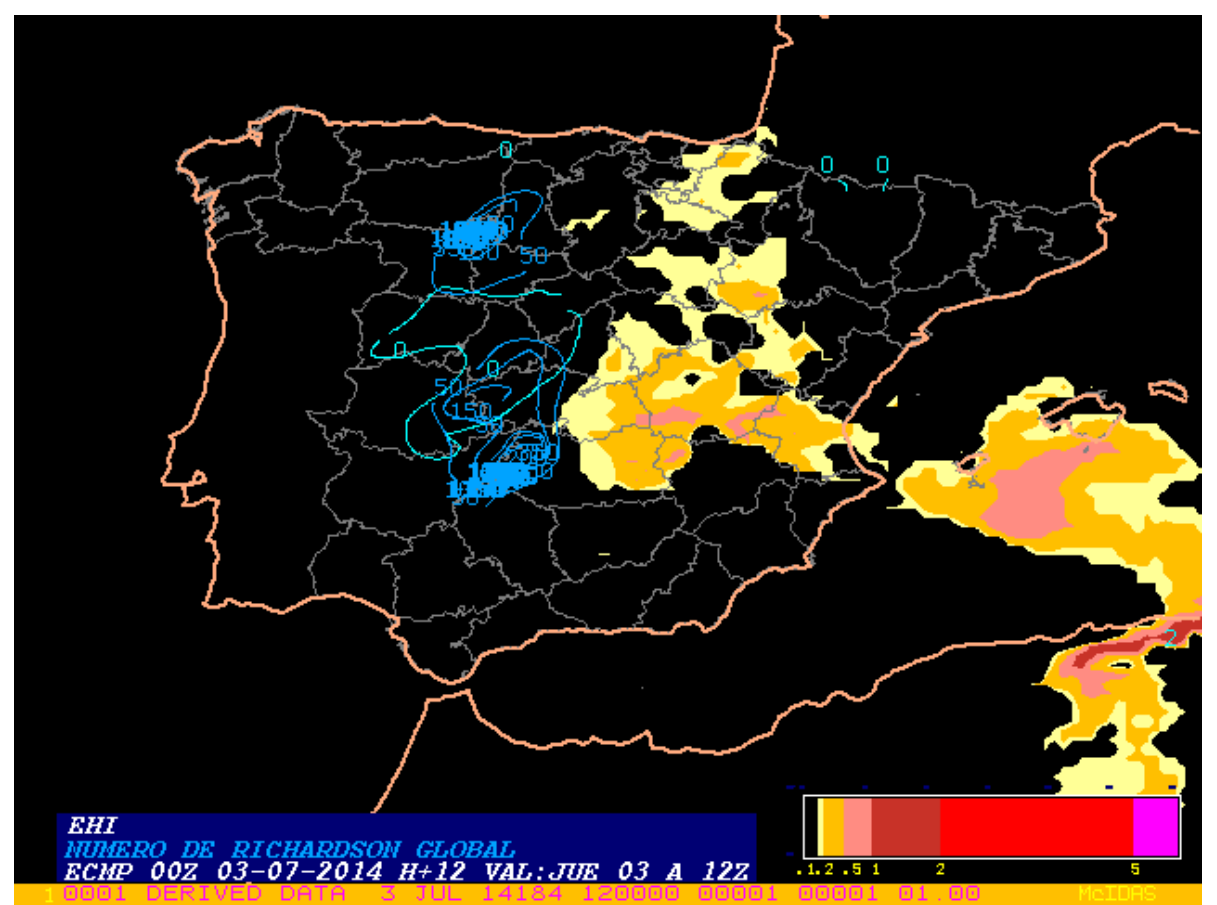

Figura 3.31. EHI y NRG. 


\section{2.- Precipitaciones intensas (1 hora)}

Se repasa el episodio del 28 de septiembre de 2014, donde de madrugada se registraron precipitaciones torrenciales en Marbella (Málaga) y por la tarde en Cataluña.

El producto hay que tomarlo con mucha precaución pues intenta de manera aproximada marcar las áreas favorables para la precipitación intensa en una hora, a partir de la salida de modelos de los que se dispone la precipitación en intervalos de tres horas. Se trata de reflejar la existencia de un ambiente que según el modelo pueda provocar "al menos" precipitaciones fuertes en una hora (figura 3.32).

Obviamente este campo depende fundamentalmente de la habilidad del modelo. Ello junto con el algoritmo usado hace que puedan existir sub y sobrepredicciones, pero de manera aproximada puede indicar las zonas de riesgo potencial. En este caso delimita aproximadamente bien el desplazamiento de las zonas de precipitaciones fuertes.

Lógicamente deben utilizarse otras herramientas de diagnóstico como la inestabilidad, la intensidad y persistencia del flujo húmedo, el agua precipitable, etc., para valorar la gravedad pluviométrica de la situación en cada zona. Aparte en las situaciones más críticas la vigilancia intensiva puede conducir a enmendar la predicción inicialmente realizada a partir de las salidas de los modelos numéricos.

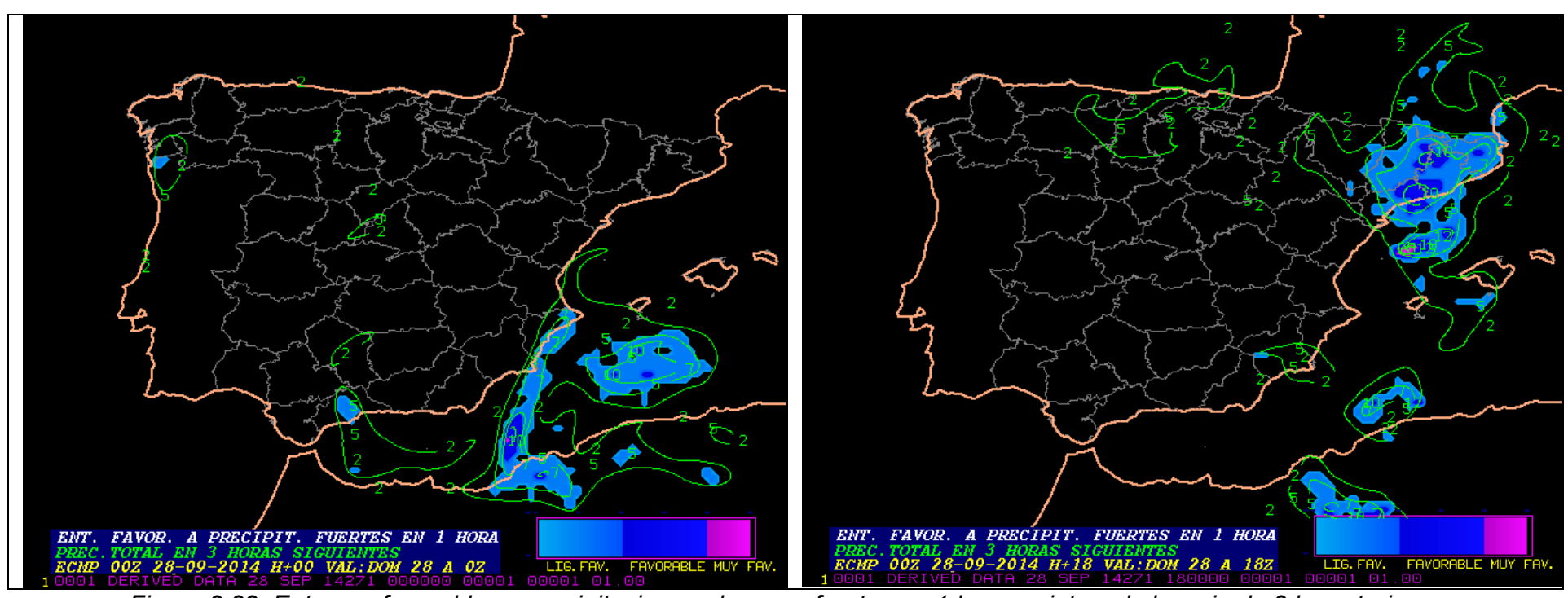

Figura 3.32. Entornos favorables a precipitaciones al menos fuertes en $1 \mathrm{~h}$ en un intervalo horario de $3 \mathrm{~h}$ posteriores. Izquierda: 0 UTC, derecha: 18 UTC. 


\section{3.- Granizo de tamaño grande}

Se diagnostica la existencia de entorno favorable a granizo de tamaño grande, en la situación del 4 de septiembre de 2014, en la finalmente se recogió en Morella (Castellón), pedrisco de hasta $5 \mathrm{~cm}$ de diámetro.

En este caso parece delimitarse bien la zona del interior de la provincia de Castellón y áreas de Pirineos. La herramienta, que suele comportarse aceptablemente bien, sólo sirve para estimar zonas donde puede producirse granizo de tamaño grande, de más de $2 \mathrm{~cm}$ de diámetro (figura 3.33).

Al mismo tiempo deben estimarse la inestabilidad y organización de la convección y la elevación desde superficie de la isocero del termómetro húmedo.

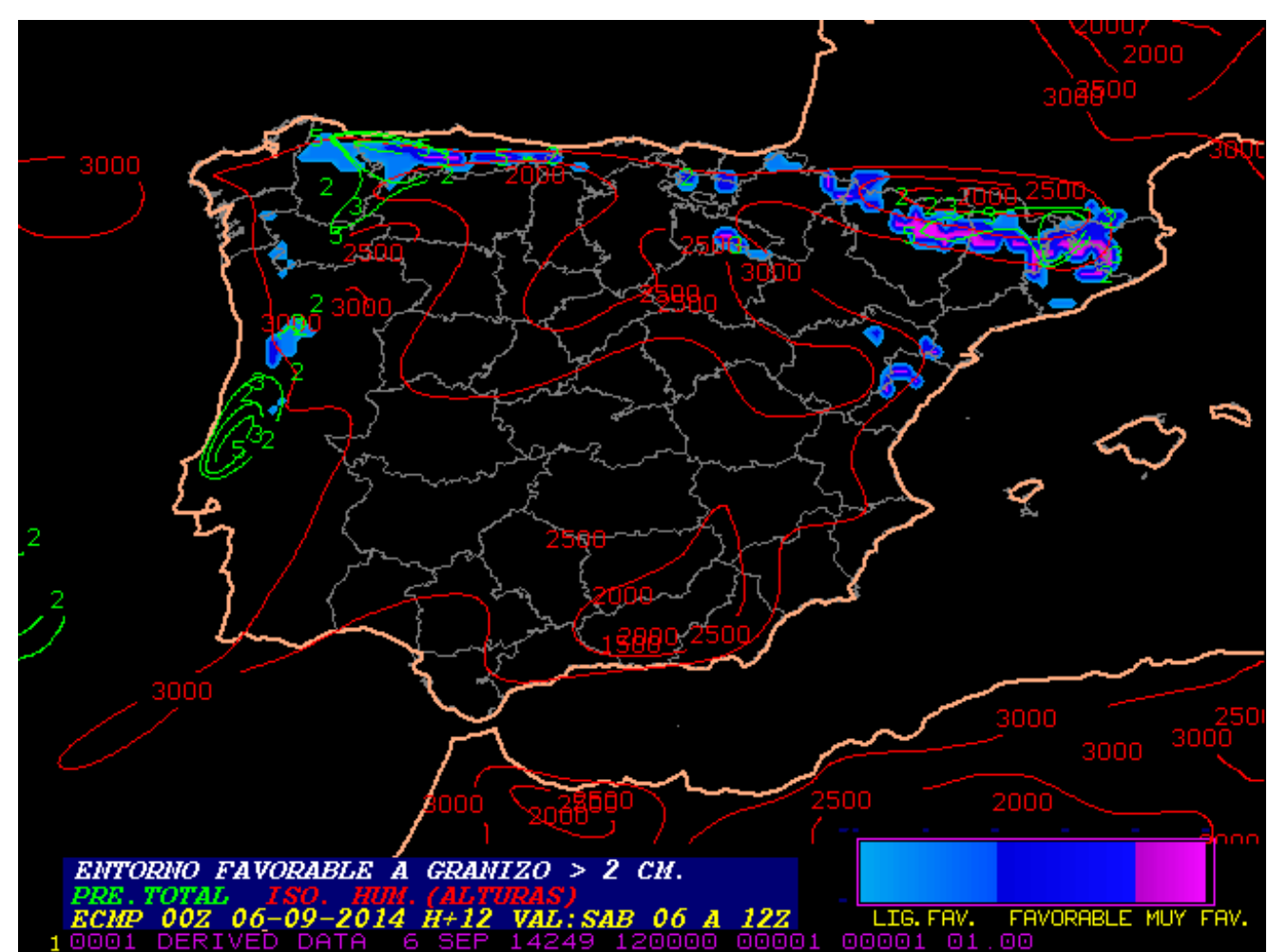

Figura 3.33. Entornos favorables a granizo de tamaño grande y valor de la isocero del termómetro húmedo. 


\section{4.- Vientos convectivos severos no tornádicos}

Se revisa el evento que tuvo lugar el 2 de septiembre de 2014, día en el que datos de varios emplazamientos con rachas muy intensas (asociadas a posibles microbursts) en zonas de Castilla la Mancha y Extremadura. Este campo puede valer para situaciones convectivas de tipo húmedo o de tipo seco.

Uno de los productos interesantes a utilizar es el DCAPE. Valores superiores a $1000 \mathrm{~J} / \mathrm{kg}$ suelen indicar entornos potencialmente favorables para alcanzar rachas de viento convectivo muy fuerte en superficie. En este episodio esa característica se produce en zonas de Extremadura, norte de Andalucía, áreas de Castilla la Mancha y localmente en la Región de Murcia (figura 3.34).

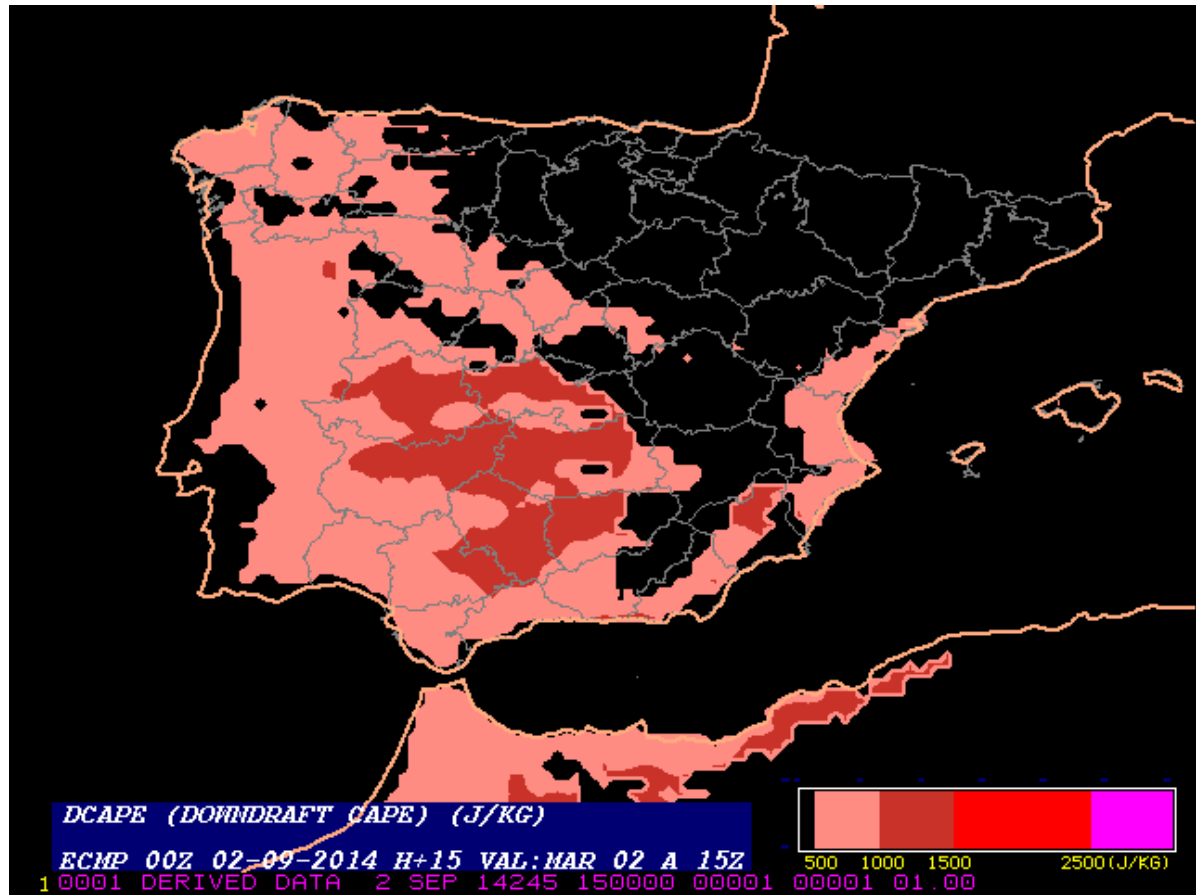

Figura 3.34. Valor del DCAPE en $\mathrm{J} / \mathrm{kg}$.

Se dispone también de un producto derivado de carácter empírico (figura 3.35) que tiene en cuenta fundamentalmente el DCAPE y el índice GUSTEX, que marcaba ese día como favorables, unas zonas análogas a las reseñadas por el DCAPE.
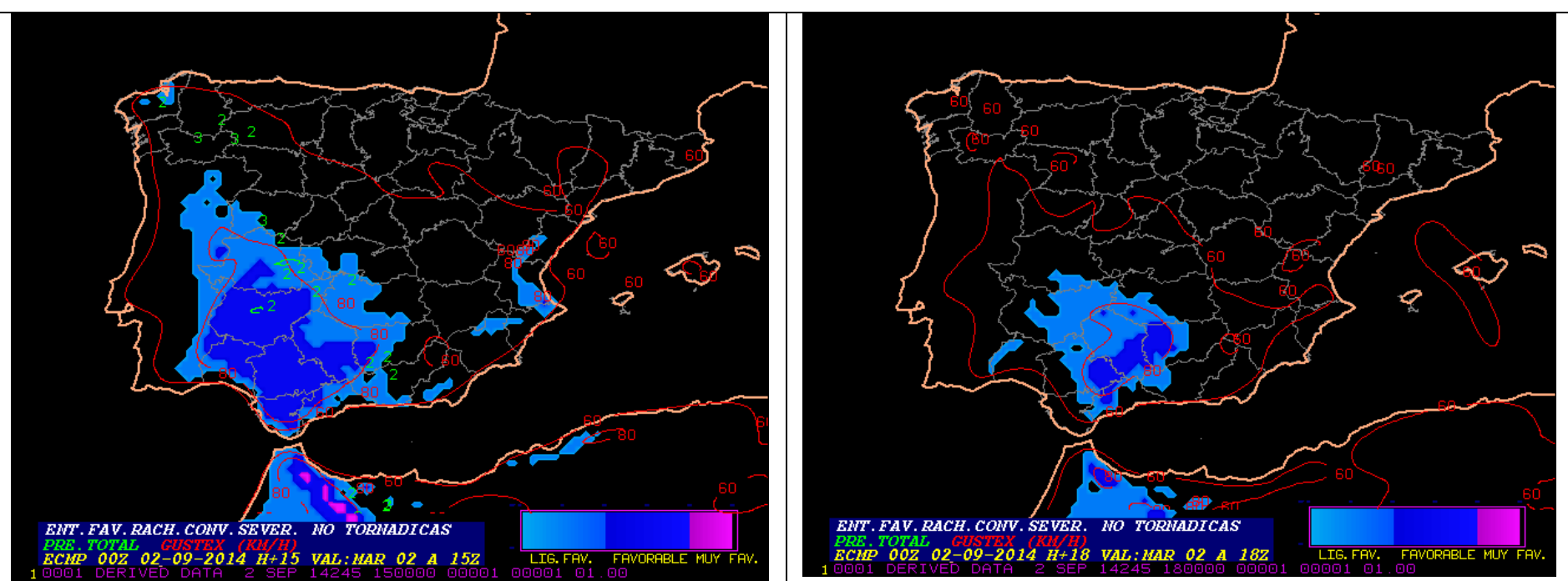

Figura 3.35. Entornos favorables a rachas convectivas al menos muy fuertes y valor del WINDEX.

Izquierda: 15 UTC, derecha: 18 UTC.

Por supuesto hay que realizar un análisis de ingredientes para cuantificar el grado de inestabilidad, determinar el perfil vertical térmico y estimar la racha convectiva que podría darse en superficie. Los índices WINDEX y GUSTEX pueden ser de utilidad incluso con sus limitaciones. Lógicamente también ha de tenerse en cuenta la velocidad de desplazamiento de los sistemas convectivos para estimar adecuadamente la máxima racha esperada. 


\section{5.- Supercélulas}

Se repasa el episodio del 14 de septiembre de 2014, en el que grupos de aficionados a la caza de tormentas observaron varias supercélulas en la zona norte peninsular.

El índice Supercell Composite Parameter insinúa algo, al presentar valores de 0.5 en la zona de Cataluña y Aragón, principalmente. El producto empírico de entorno favorable para supercélulas sí daba emplazamientos favorables y muy favorables, aunque bastante localizados (figura 3.36).

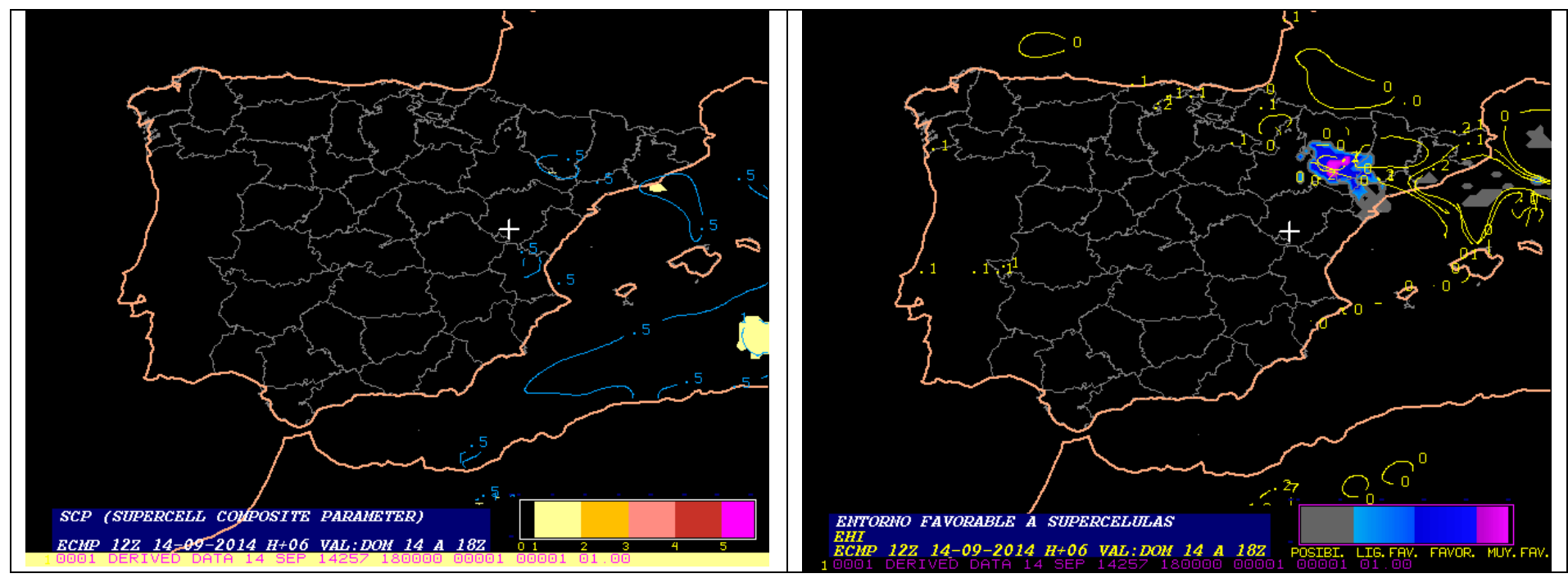

Figura 3.36. Izquierda: índice SCP, derecha: producto de entornos favorables a supercélulas.

Ese día había valores de SBCAPE superiores a $500 \mathrm{~J} / \mathrm{kg}$ en extensas áreas del nordeste peninsular (localmente por encima de $1000 \mathrm{~J} / \mathrm{kg}$ ) y aparte una cizalladura y helicidad relativa a la tormenta, considerables (figura 3.37).
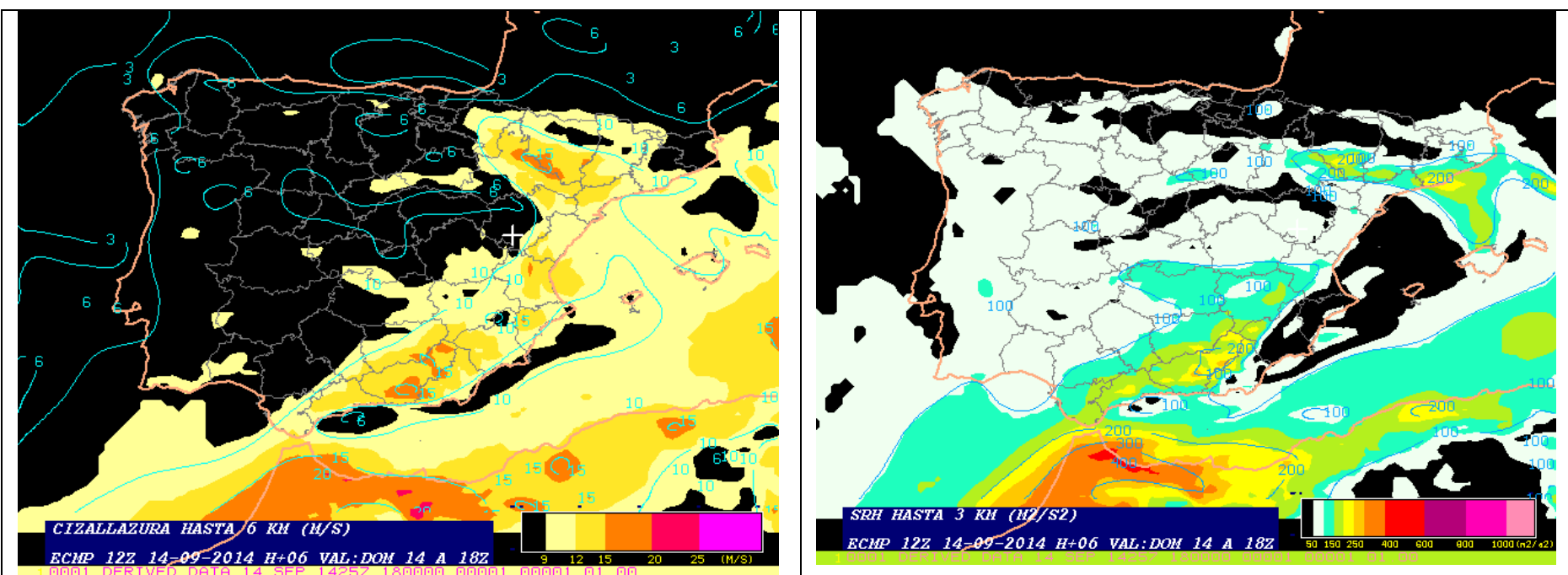

Figura 3.37. Izquierda: cizalladura en los 6 primeros $\mathrm{km}$, derecha: $\mathrm{SRH}$ hasta $3 \mathrm{~km}$. 


\section{6.- Tornados}

Se estudia el comportamiento de algunos campos durante el tornado de Valdelamusa (pedanía del municipio de Cortegana en la comarca onubense del Andévalo), el 16 de septiembre de 2014.

Tanto el Universal Tornado Index como el Significant Tornado Parameter (figura 3.38), dan una señal nítida en la zona de Valdemusa.

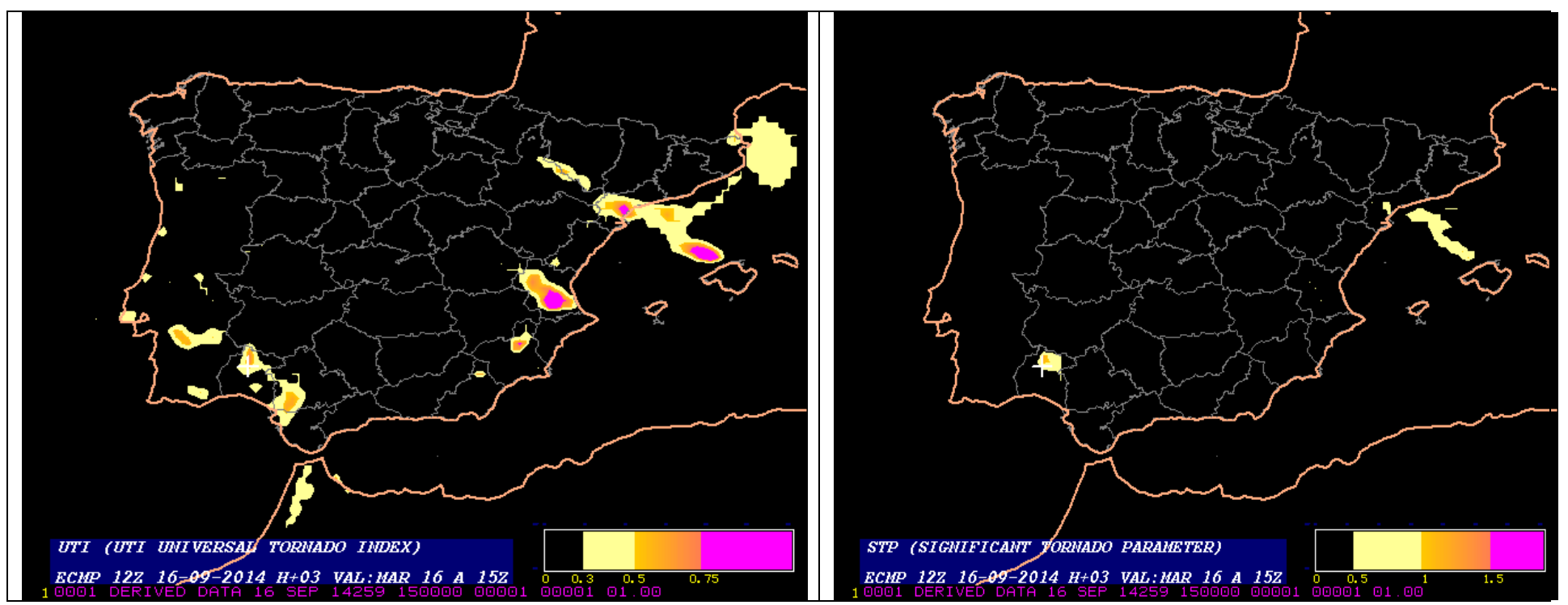

Figura 3.38. Izquierda: índice UTI, derecha: STP.

También en el índice empírico de entorno favorable para tornados (figura 3.39), aparece una señal (favorable) en la zona de interés.

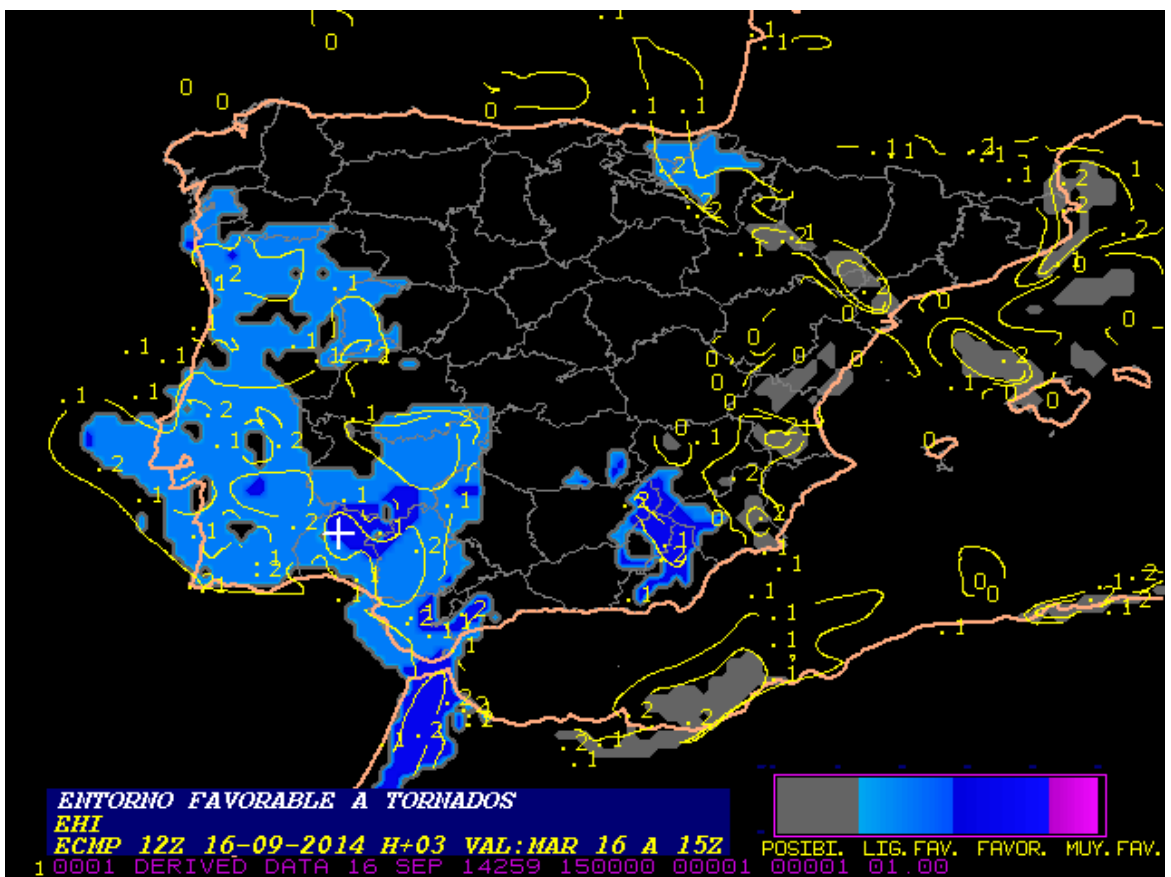

Figura 3.39. Índice empírico de entorno favorable a tornados. 
- Brady, R. H., \& Szoke, E. J., 1989. A case study of nonmesocyclone tornado development in northeast Colorado: Similarities to waterspout formation.Monthly weather review, 117(4), 843-856

- Bunkers, M. J., B. A. Klimowski, J. W. Zeitler, R. L. Thompson, and M. L. Weisman, 2000: Predicting supercell motion using a new hodograph technique. Wea. Forecasting, 15, 61-79.

- Burgess, D.W., R.R. Lee, S.S. Parker, and D.L. Floyd, 1995: A study of mini supercells observed by WSR-88D radars. Preprints, 27th Conference on Radar Meteorology, Vail, CO, Amer. Meteor. Soc., 4-6.

- Caracena, F., and J.A. Flueck, 1988: Classifying and predicting microburst activity in the Denver, Colorado, Area. J. of Aircraft, 25, 525-530.

- Carlson, T. N., S. G. Benjamin, G. S. Forbes and Y. F. Li, 1983: Elevated mixed layers in the regional severe storm environment: Conceptual model and case studies. Mon. Wea. Rev., 111, 1453-1473.

- Conesa, A., 2004: Triggering of convection and evolution to supercell with an F3 tornado in Bajo Aragon, northeast of Teruel province. 3rd European Conference on Severe Storms, Leon

- Crook, N. A., and J. B. Klemp, 2000: Lifting by convergence lines. J. Atmos. Sci., 57, 873-890.

- Craven, J. P., and H. E. Brooks, 2004: Baseline climatology of sounding derived parameters associated with deep moist convection. Nat. Wea. Digest, 28, 13-24.

- Davies, J. M., 2006. Tornadoes in environments with small helicity and/or high LCL heights. Weather \& Forecasting, 21(4).

- Davies, J. M., 2006. Tornadoes with Cold Core 500-mb Lows. Weather \& Forecasting, 21(6)

- Davies, J. M., and R. H. Johns, 1993: Some wind and instability parameters associated with strong and violent tornadoes. 1: Wind shear and helicity. The Tornado: Its Structure, Dynamics, Prediction, and Hazards, Geophys. Monogr., No. 79, Amer. Geophys.Union, 573-582.

- Davies-Jones, R., 1984: Streamwise vorticity: The origin of updraft rotation in supercell storms. J. Atmos. Sci., 41, 2991-3006.

- Doswell, C. A., III, and D. W. Burgess, 1993: Tornadoes and tornadic storms: a review of conceptual models. The Tornado: its Structure, Dynamics, Prediction, and Hazards, Geophys. Monogr., No. 79, Amer. Geophys. Union, 161172.

- Doswell, C.A., Brooks, H.A., Maddox, R.A., 1996. Flash flood forecasting: an ingredients-based methodology. Weather Forecast. 11, 560-581.

- Droegemeir, K., M. Lazarus, R. Davies-Jones, 1993: The Influence of Helicity on Numerically Simaulated Convective Storms. Monthly Weather REview: Vol 121, No. 7, pp 2005-2029

- Edwards, R., and R. L. Thompson, 2000: RUC-2 supercell proximity soundings, Part II: An independent assessmentof supercell forecast parameters. Preprints, 20th Conf. on Severe Local Storms, Orlando, FL, Amer. Meteor. Soc., 435-438.

- EUMETRAIN. Warning Decision Training Branch. Distance Learning Operation course. "IC 5.7: Convective Storm Structure and Evolution":

http://www.eumetrain.org/data/1/12/Content/images/ic57 Convective\%20Storm\%20Structure\%20and\%20Evolution pschlatter-Version0308.2.pdf

- $\quad$ Frisbie, P.R., J.D. Colton, J.R. Pringle, J.A. Daniels, J.D. Ramey Jr., and M.P. Meyers, 2009: Lightning Prediction by WFO Grand Junction using Model Data and Graphical Forecast Editor Smart Tools. National Weather Service, Paul.Frisbie(at)noaa.gov

- Fujita, T. T., 1985: "The Downburst- Microburst and Macroburst," Sattellite and Mesometeorology Research Project (SMRP) Research Paper 210, Dept. of Geophysical Sciences, Univ. of Chicago, (NTIS PB-148880) Feb. 1985.

- Galway, J.G., 1956:The lifted index as a predictor of latent instability. Bull. Amer. Meteor. Soc., 43 , 528-529

- Gaya M., 2011. Tornadoes and severe storms in Spain. Atmospheric Research 100. pp 334-343.

- Griesen, J: Convection Parameters. http://www.juergen-grieser.de/CovectionParameters/ConvectionParameters.pdf

- Houze, R. A., Jr., 2004: Mesoscale convective systems. Rev.Geophys., 42, RG4003.

- Jansa, A., Genoves, A., Picornell, M.A., Campins, J., Riosalido, R., Carretero, O., 2001. Western Mediterranean cyclones and heavy rain. Part II: statistical approach. Meteorol. Appl. 8, 43-56.

- Johns, R. H., and J. A. Hart, 1993: Some wind and instability parameters associated with strong and violent tornadoes. Part II: Variations in the combinations of wind and instability parameters. The Tornado: Its Structure, Dynamics, Prediction, and Hazards, Geophys. Monogr., No. 79, Amer. Geophys. Union, 583-590

- Knight, C. A., and N. C. Knight, 2001: Hailstorms. Severe Local Storms, Meteor. Monogr., No. 50, 223-254.

- Maddox, R. A., Chappell, C. F., and Hoxit, L. R., 1979: Synoptic and meso-scale aspects of flash flood events, Bull Amer Meteor Soc, 60, 115-123

- Markowski P. and Richardson Y., 2010: Mesoscale Meteorology in Midlatitudes. Wiley-Blackwell. ISBN: 978$0470742136.430 \mathrm{pp}$.

- Martín León, F., Elizaga Rodríguez F., Carretero Porris, O. y San Ambrosio Beirán, I., 1999. Curso de Diagnóstico y Predicción de la Convección Profunda, Área de Técnicas de Análisis y Predicción (ATAP). Nota Técnica del ATAP $N^{\circ}$ 35. AEMET

- Martín León, F. y Riosalido Alonso,R. Modelos Conceptuales de Tormentas: Radar y Rayos. Módulos TempoWeb del ATAP. 1999. AEMET. 
- Martinez, C., Campins, J., Jansà, A., and Genovés, A., 2008: Heavy rain events in the Mediterranean: an atmospheric pattern classification, Adv Sci Res, 2, 61-64

- Marwitz, J.D., 1972: The structure and motion of severe hailstorms. Part I: Supercell storms. J. Appl. Meteor., 11, 166-179.

- Marwitz, J.D., 1972: The structure and motion of severe hailstorms. Part II: Multi-cell storms. J. Appl. Meteor., 11, 180-188.

- McCann, D. W., 1994: WINDEX-A new index for forecasting microburst potential. Wea.Forecasting, 9, 532-541.

- Quirantes, J. A., Riesco, J., Núñez, J.A., 2014: Características básicas de las supercélulas en España. AEMET. NIPO: $281-14-008-X$

- Rasmussen, E.N., D.O. Blanchard, 1998: A baseline climatology of soundingderived supercell and tornado forecast parameters. Wea. Forecasting, 13, 1148-1164

- Rasmussen, E. N., 2003: Refined supercell and tornado forecast parameters.Wea Forecasting, 18, 530-535.

- Richard L. Thompson, Corey M. Mead, and Roger Edwards, 2007: Effective Storm-Relative Helicity and Bulk Shear in Supercell Thunderstorm Environments. Wea. Forecasting, 22, 102-115.

- Riesco J., Polvorinos F., Núñez J. A., Soriano J. D., Jiménez C., 2015: Climatología de tornados en España Peninsular y Bares. AEMET. NIPO: 281-15-005-8.

- Schumacher, R. S., and R.H. Johnson, 2006: Characteristics of U.S. extreme rain events during 1999-2003. Wea. Forecasting, 21, 69-85.

- Sherburn, K. D., and M. D. Parker, 2012: Identifying discriminating environmental features between high shear/low CAPE severe convection and null events. 26th Conference on Severe Local Storms, AMS, 5-8 November 2012, Nashville, TN.

- Taszarek M. Kolendowicz L., 2013. Sounding-derived parameters associated with tornado occurrence in Poland and Universal Tornadic Index. Atmospheric Research 134, 186-197.

- The COMET ${ }^{\circledR}$ Program. "Principios de conveccion I. Empuje Hidrostático y CAPE", "Principios de conveccion II. Uso de la hodógrafa", "Principios de Convección III: cizalladura y tormentas convectivas".

- Thompson, R.L., R. Edwards, J.A. Hart, K.L. Elmore, and P. Markowski, 2003: Close procimity soundings within supercell envrinments obtained from the Rapid Update Cycle. Wea. Forecasting, 18, 1243-1261.

- Wakimoto, R. M., and J. W. Wilson, 1989: Non-supercell tornadoes. Mon. Wea. Rev., 117, 1113-1140.

- Wilson, J. W., and R. M. Wakimoto, 2001: The discovery of the downburst: T. T. Fujita's contribution. Bull. Amer.Meteor. Soc., 82, 49-62.

\section{Agradecimientos}

Se quiere manifestar un agradecimiento especial al personal del ATAP por su herramienta originaria de diagnóstico convectivo, así como a los compañeros del Centro Meteorológico de Málaga por sus sugerencias e igualmente en general al personal del Sistema Nacional de Predicción por la información de retorno y recomendaciones aportadas. Asimismo ha sido importante la ayuda facilitada por el ATAP y la UAM en el desarrollo de macros en Mcidas. 